Florida International University

FIU Digital Commons

FIU Electronic Theses and Dissertations

University Graduate School

$3-9-2020$

\title{
Emoji Marketing: Strengthening the Consumer Brand Relationship and Its Downstream Effects
}

Tessa Marcela Garcia-Collart

Florida International University, tgarc090@fiu.edu

Follow this and additional works at: https://digitalcommons.fiu.edu/etd

Part of the Marketing Commons

\section{Recommended Citation}

Garcia-Collart, Tessa Marcela, "Emoji Marketing: Strengthening the Consumer Brand Relationship and Its Downstream Effects" (2020). FIU Electronic Theses and Dissertations. 4441.

https://digitalcommons.fiu.edu/etd/4441

This work is brought to you for free and open access by the University Graduate School at FIU Digital Commons. It has been accepted for inclusion in FIU Electronic Theses and Dissertations by an authorized administrator of FIU Digital Commons. For more information, please contact dcc@fiu.edu. 


\title{
FLORIDA INTERNATIONAL UNIVERSITY \\ Miami, Florida
}

\section{EMOJI MARKETING: \\ STRENGTHENING THE CONSUMER BRAND RELATIONSHIP AND \\ ITS DOWNSTREAM EFFECTS}

\author{
A dissertation submitted in partial fulfillment of the \\ requirements for the degree of \\ DOCTOR OF PHILOSOPHY \\ in \\ BUSINESS ADMINISTRATION
}

by

Tessa Garcia-Collart 


\section{To: $\quad$ Dean Joanne Li}

College of Business

This dissertation, written by Tessa Garcia-Collart, and entitled Emoji Marketing:

Strengthening the Consumer Brand Relationship and its Downstream Effects, having been approved in respect to style and intellectual content, is referred to you for judgment.

We have read this dissertation and recommend that it be approved.

Kimberly Taylor

Ronald Mesia

Valentina Bruk-Lee

Maura L. Scott

Jayati Sinha, Major Professor

Date of Defense: March 9, 2020

The dissertation of Tessa Garcia-Collart is approved.

Dean Joanne Li

College of Business

Andrés G. Gil

Vice President for Research and Economic Development and Dean of the University Graduate School

Florida International University, 2020 
(C) Copyright 2020 by Tessa Garcia-Collart

All rights reserved. 


\section{DEDICATION}

I dedicate this dissertation to my husband, Daniel. His love, support, patience and incredible sense of humor are the constant force that has brought me here and lifted me up even in the toughest of challenges. I am forever grateful.

I also dedicate this work to my little women, Tessa Isabella and Victoria. They are both the greatest miracle of my life and my inspiration to always move forward with strength and resolve.

Daniel, Tessa Isabella and Victoria: Thank you for sharing this adventure with me. I love you deeply and absolutely. This is for you... for us. 


\section{ACKNOWLEDGMENTS}

I would like to thank my dissertation committee members for their insightful suggestions, which have greatly contributed to enhance the quality of this work. I am especially grateful for my advisor, Dr. Jayati Sinha for her remarkable training to produce rigorous and meaningful research. I am thankful for her confidence in me and her constant dedication so that I could reach my greatest professional achievement yet. It has been a great privilege to have her continuous guidance, support and care.

I would like to thank my parents, Rogelio and Tessa Garcia. Their love and legacy of education, perseverance and courage I honor today. To my brothers, Rogelio, Mauricio and especially to my sister, Grace, who has always made life so much fun and brought much needed laughter and calm throughout this process. Thank you to my in-laws, Sergio and Isabel Collart, who are the best second set of parents I could have ever wished for.

Thank you to my friends, Eileen Busato, Claudia Galeano, Valentina Bruk-Lee, Marisabel Romero, Karen Cerrato, Sarah Thompson, Hanzi Friedli, Maria Claudia Rivera, and my academic sister, Michelle van Solt, whose friendship was fundamental in completing this journey. I am forever thankful for Elsa Luzuriaga, whose incredible love and care for my daughters allowed me to focus on my doctoral studies. To the McKnight Fellowship and The PhD Project for their generous support. I am grateful for the constant support and encouragement of Dr. Maura Scott, Dr. Gail Ayala Taylor, Dr. Samantha Cross, Dr. Rebeca Perren and Dr. Merlyn Griffiths; I consider them mentors and friends.

Finally, but most importantly, I want to thank God Almighty, in whom my faith stands firm. The achievements, moments and people I value most are all significant evidence of the power of His grace in my life. I am blessed and eternally grateful. 


\author{
ABSTRACT OF THE DISSERTATION \\ EMOJI MARKETING: \\ STRENGTHENING THE CONSUMER BRAND RELATIONSHIP AND \\ ITS DOWNSTREAM EFFECTS \\ by \\ Tessa Garcia-Collart \\ Florida International University, 2020 \\ Miami, Florida \\ Professor Jayati Sinha, Major Professor
}

Brands communicate and engage directly with their consumers using online communications that often contain emojis. Recently, empirical studies have begun to examine the influence of emojis within marketing contexts. However, less is known about the role of emojis in helping brands foster stronger connections with their consumers.

In this dissertation, I argue that emojis improve online brand communications by strengthening the consumer-brand relationship with favorable downstream consumption consequences. Across eight studies, including behavioral and field studies involving monetary tradeoffs, I show that brands that use emojis in digital communications are perceived as more human, thereby facilitating greater consumer-brand connections. Importantly, results from this work show that stronger consumer-brand connections help brands attain positive consumption consequences such as increased word of mouth, willingness to pay, purchase behaviors, click through rates and brand attitudes. 
Furthermore, I explore the effects of both facial and artifact emojis, thus contributing to prior related research which was limited to studying the effects of facial emojis.

Findings from this research contribute to marketing theory by providing an understanding of the influence of emoji marketing on the consumer-brand relationship. Additionally, results derived from this dissertation will allow marketing managers to strategically plan online brand communications that help cultivate the consumer asset by driving connections and nurturing a positive relationship between consumer and brand.

Finally, this dissertation advances our current knowledge of the influence of emojis as a relatively new digital language that transcends cultural and geographical borders to help us connect with other humans, while providing an equally valuable opportunity for brands to connect with their consumers and establish stronger consumerbrand relationships. Furthermore, findings from this dissertation contribute to build a theoretical foundation that advances the study of marketing and consumer behavior in digital contexts by understanding how these subtle, nonverbal cues significantly enhance and clarify the emotional content of computer mediated communications. 


\section{TABLE OF CONTENTS}

CHAPTER

PAGE

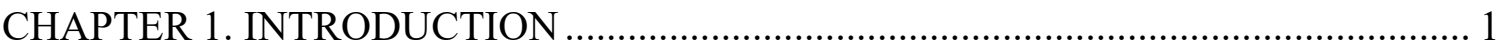

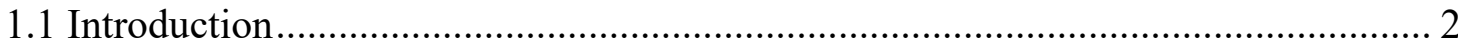

1.2 Dissertation Purpose and Objectives ................................................................. 5

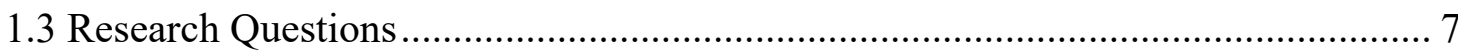

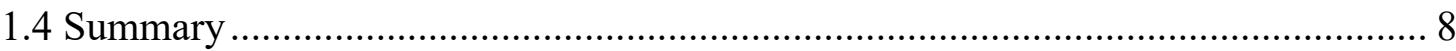

CHAPTER 2. THEORETICAL FRAMEWORK ..................................................... 11

2.1 Emojis: Background and Conceptualization..................................................... 12

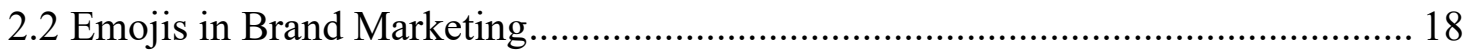

2.3 Consumer-Brand Relationships: Building Self-Brand Connections...................... 25

2.4 Carryover Effects of Self-Brand Connections ................................................ 27

2.5 The Role of Brand Anthropomorphism and SBC on Consumption ...................... 30

2.6 The Moderating Role of Brand as Partners versus Brand as Servants .................. 35

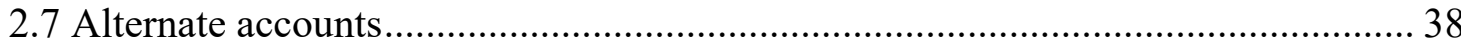

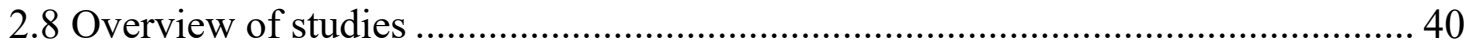

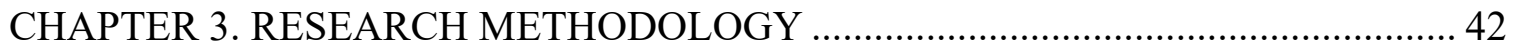

Study 1a: Influence of (Facial) Emojis on Attitude toward a Product........................ 44

Study 1b: Effects of (Artifact) Emojis on Purchase Intentions................................... 47

Study 1c: Effects of (Facial + Artifact) Emojis on Click Through Rates .................... 55

Study 1d. Field Study - Carryover Effects of (Facial + Artifact) Emojis on Actual

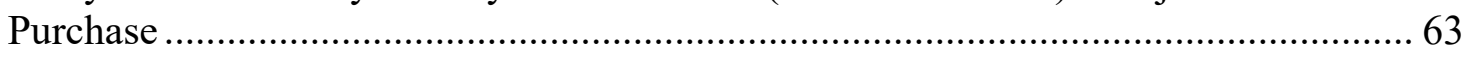

Study 2a: (Facial + Artifact) Emojis on Self-Brand Connections .............................. 73

Study 2b: (Facial + Artifact) Emojis on Anthropomorphism and Self-Brand

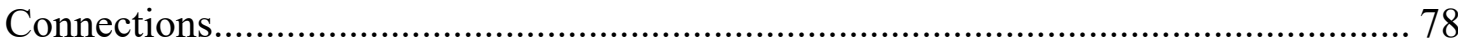

Study 2c: Serial Mediation by Anthropomorphism and Self-Brand Connections........ 88

Study 3: Predicted Boundary Condition - Brand Role .......................................... 102

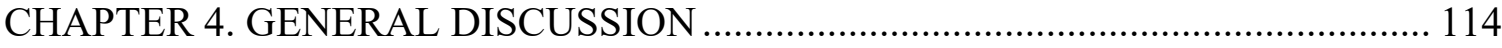

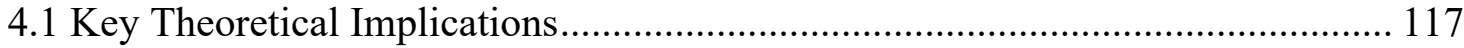

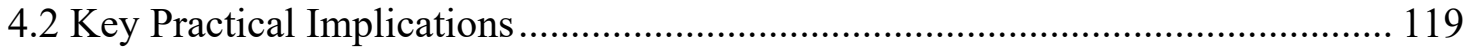

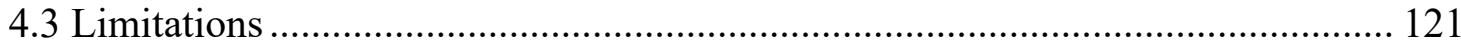




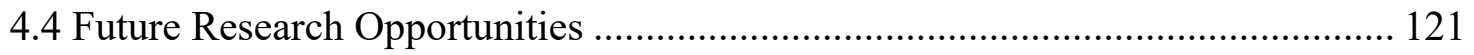

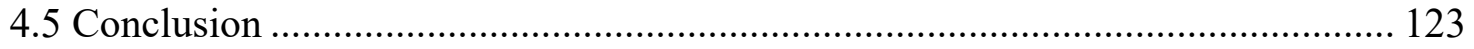

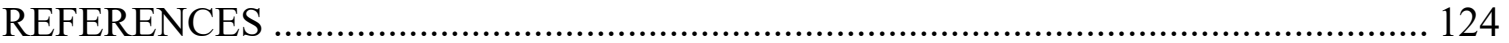

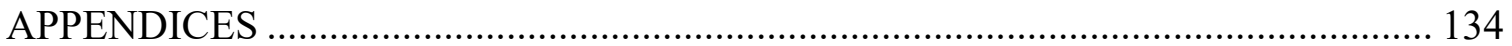

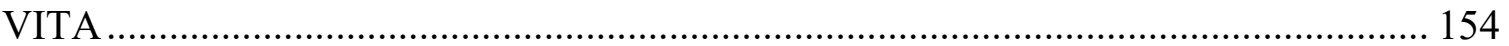




\section{LIST OF TABLES}

TABLE

PAGE

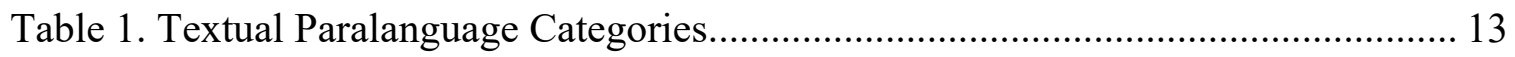

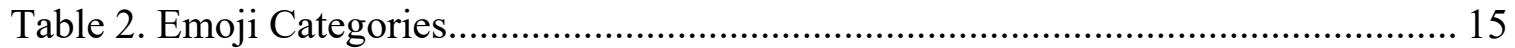

Table 3. Overview of existing emoji studies in marketing contexts.............................. 24

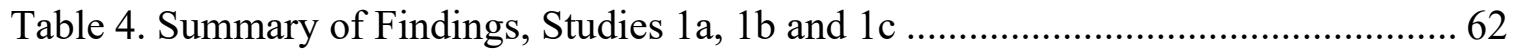

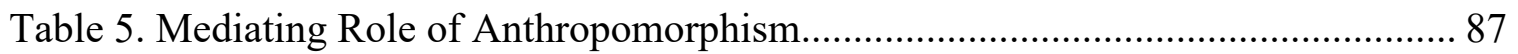

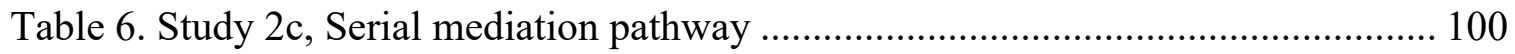




\section{LIST OF FIGURES}

FIGURE

PAGE

Figure 1. Conceptual model and operationalization of key constructs............... 38

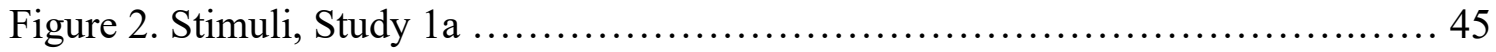

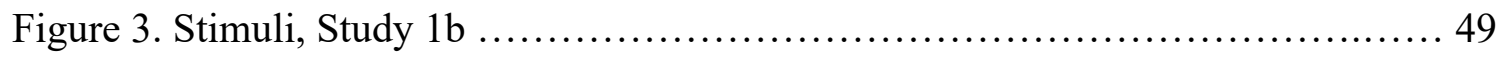

Figure 4. Stimuli, Study 1c .................................................. 56

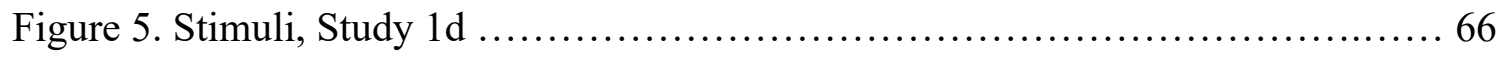

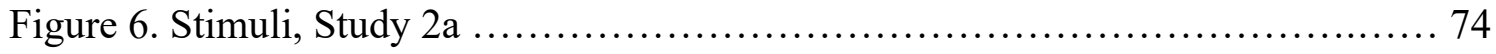

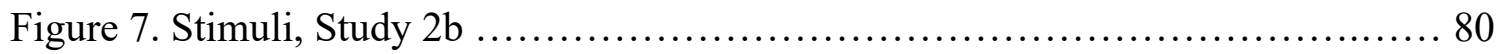

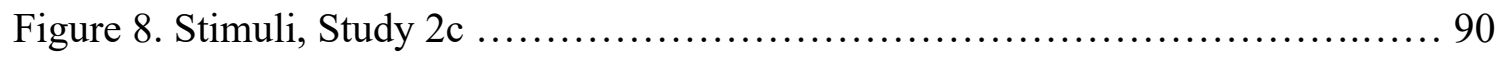

Figure 9. Study 2c, Results of the effects of emoji on consumption consequences...... 98

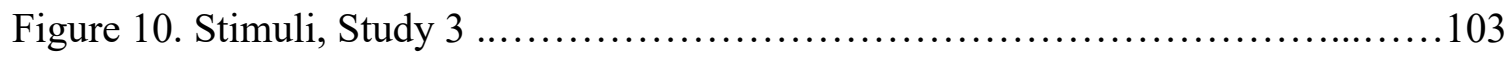




\section{ABBREVIATIONS AND ACRONYMS}

CTR

$\mathrm{CMC}$

MTV

SBC

SMS

TPL

VMA

WOM

WTP
Click Through Rates

Computer Mediated Communications

Music Television

Self-Brand Connections

Short Message Service

Textual Paralanguage

Video Music Awards

Word of Mouth

Willingness to Pay 
CHAPTER 1. INTRODUCTION 
"We live in a digital society that provides a range of opportunities for virtual interaction. Consequently, emojis have become popular for clarifying online communication. This presents an exciting opportunity for psychologists, as these prolific online behaviors can be used to help reveal something unique about contemporary human behavior" Kaye, Malone and Wall (2017)

\subsection{Introduction}

The widespread mainstream use of emojis has reached significant heights that include a full-length feature film ("The Emoji Movie," released in 2017), a televised family game ("Emogenius," now airing in Netflix), and a dedicated World Emoji Day (July $17^{\text {th }}$ ). Additionally, the inclusion of emojis in Dictionary.com (Steinmetz 2018) and the smiley with tears emoji ( ) being recognized as "Word of the Year" by the Oxford Dictionary in 2015 indicate their growing popularity among consumers. In fact, according to Facebook data, more than five billion emojis are shared daily through Facebook Messenger alone (Burge 2017), with brands using emojis additionally through mobile apps and other social media platforms. In addition to the everyday consumer-toconsumer use of emojis, emojis in brand marketing contexts have experienced significant growth in the last few years.

For example, in 2018, Music Television (MTV) launched a successful emoji campaign to promote its annual Video Music Awards (VMA's) and increase consumer excitement online. The campaign included tweets and teasers that used more emojis than text, and consumers were encouraged to decipher and share these messages across multiple social media platforms. According to MTV, this campaign generated significant 
audience participation and organic social media buzz that resulted in an increased television and online audience for the VMA's. In fact, MTV's emoji campaign was so successful that it won a Shorty Social Media Award (Shorty Awards 2019) for best social media campaign in the Emoji category.

Another example of successful emoji use in marketing campaigns was Domino Pizza's Tweet-to-Eat campaign, which allowed Twitter users to order pizza by simply tweeting their order along with the pizza emoji ( $)$. This marketing campaign was so effective that the corporation expanded its digital ordering strategy to include an "AnyWare Ordering" system that enabled easier, faster ordering from multiple devices and platforms, such as Facebook Messenger, Short Message Service (SMS), and Twitter (Beer 2015). Domino's headquarters has disclosed that as much as $55 \%$ of their incoming orders are through digital and mobile channels, allowing them to retain important customer data analytics (Marr 2016). Like Domino's Pizza and MTV (Appendix A), other brands and corporations are using emojis increasingly in their web and mobile communications to connect and engage with consumers in a more casual, relatable manner (Wade 2017).

For perspective, from 2017 to 2018, online posts containing emojis increased by 13\% (Caramela 2018) and are expected to continue to rise each year (Leanplum 2018). To compare, in 2017, brands sent 814 million messages containing emojis (this figure includes online posts, SMS, e-mails, tweets, other messages), compared to 145 million in 2016 - an increase of 461\% (Phipps 2017). This rapid proliferation of emojis in branding contexts and their prevalence in marketing communications have prompted empirical research to conceptualize and examine the use of emojis in mobile and online 
communications (Luangrath, Peck, and Barger 2017). From a psychological perspective, emojis have been found to help convey emotions and clarify information that otherwise textual communications would lack (Riordan 2017). On this basis, emoji research in marketing contexts has begun to emerge in an effort to understand its influence on brands' performance and consumption behavior.

For example, emojis in brand communications have been found to increase brand engagement (Pancer, McShane, and Poole 2017), purchase intentions for hedonic products (Das, Wiener, and Kareklas 2019), and consumers' recall of positive product reviews (Yu-Buck, Mishra, and Mishra, working paper). Similarly, Li, Chan, and Kim (2018) found that emojis can help improve consumer attitudes toward service encounter employees due to increased perceptions of warmth. While these findings demonstrate the influence of emojis in consumer behavior, limited knowledge still exists about the effects of emojis on consumer-brand connections as an indicator of consumer-brand relationship strength. Thus, the focus of this dissertation is to explore how and in which instances will emojis help brands connect and strengthen relationships with their consumers to stimulate favorable consumption consequences. This information will allow firms and marketing managers to devise strategies that include textual paralanguage, such as emojis, in their brand communications. While emojis can be used in different marketing media (i.e. product packaging, print advertising), of particular interest in this dissertation is the influence of emojis in digital communications, which serve as an ideal medium for brands to actively interact and engage with their consumers.

Luangrath, Peck, and Barger (2017) indicate that the use of textual paralanguage (i.e. emoticons, emojis) in digital settings is expected to yield positive consequences, 
such as increased relationship closeness, connections, and loyalty, because they act as non-verbal cues that help convey emotions and clarify communications. However, this prospect has not been examined through an empirical lens. Thus, the aim of this dissertation is to evaluate emojis as facilitators of consumer-brand connections. Most importantly, I plan to investigate the downstream consumption consequences that result from increased consumer-brand connections to help understand and explain the impact of emojis in brand-related communications.

Related research in computer mediated communications (henceforth $\mathrm{CMC}$ ) has found that interactions between consumers and organizations in online settings are more successful when the consumer perceives the organization as having a "human voice" (Kelleher 2009), which can be created when brands employ techniques that increase dynamic interactions with consumers. Therefore, I anticipate that compared to text only, the presence of emojis in addition to text will help bring this "human voice" in digital brand communications and increase consumer-brand connections with favorable downstream consumption consequences.

\subsection{Dissertation Purpose and Objectives}

The purpose of this dissertation is to extend the study of emoji marketing by examining the connections brands can build with consumers when using emojis in digital communications as well as the consumption outcomes of these connections. Fournier (1998) establishes that in addition to brand loyalty, consumer-brand connections are an important facet of the consumer-brand relationship and is defined as " $a$ critical aspect of attachment that involves cognitive and emotional connection between the brand and the 
self' (Park et al. 2010, pp. 2). Therefore, I seek to emphasize that beyond a simple digital illustration, emojis can help brands build valuable consumer-brand connections that help indicate the emotional attachment of the consumer to the brand, thereby leading to stronger consumer-brand relationships (Aaker, Fournier, and Brasel 2004; Fournier 1998). This attachment is of particular interest to marketing because strong consumerbrand connections lead to favorable consumption outcomes, such as brand love, loyalty, attitudes, and purchase behaviors. Rauschnabel and Ahuvia (2014) have found that brand love can predict consumer brand loyalty, which in practice is observed through increased purchase behaviors and greater resistance to replacing brand choice despite negative brand information. Furthermore, strong consumer-brand connections lead to positive word of mouth and referral behaviors (Batra, Ahuvia, and Bagozzi 2012). Therefore, the main objective of this dissertation is to provide both theoretical and managerial contributions to the field of marketing by advancing the current knowledge on emojis in consumer-brand contexts.

First, findings derived from this dissertation will provide theoretical insight of the influence of emojis in brand communications, which, based on recent publications, is a growing topic in the marketing domain. Research on emoji marketing has provided valuable information on the influence of emoji use on engagement, attitudes and purchase intentions. However, to my knowledge, none have evaluated the effect of emojis on consumer-brand connections and related consumption behaviors. While attitudinal measures provide insight of possible consumption choice and purchase intent, consumerbrand connections more accurately capture the commitment a consumer has to the brand (Park, MacInnis, and Priester 2006). 
Second, findings from this dissertation will clarify the role of textual paralanguage in computer-mediated communications by highlighting marketing implications such as willingness to pay, click through rates and word of mouth behaviors. Third, these findings will contribute to the extant work on anthropomorphism by demonstrating that brands can use textual paralanguage, such as emojis to be perceived as more human. This is of special importance given that marketing research has emphasized the benefits of brand anthropomorphism, including increased perceptions of warmth, loyalty and brand trust (Kervyn, Fiske, \& Malone 2012).

Finally, I seek to provide marketing managers with knowledge to effectively develop online and mobile brand strategies that will help improve the dynamics of the consumer-brand relationship. Importantly, information derived from this dissertation clarifies that the benefits of using emojis are not restricted to facial emojis, which have been the focus of past research studies in the marketing field. For example, marketing managers can plan to use all emojis in the emoji keyboard to communicate promotions and brand information with consumers through social media, mobile, apps and e-mail. This understanding will equip marketing decision makers with empirical knowledge to effectively implement emojis in brand communications and improve brand metrics such as willingness to pay, word of mouth, and purchase behaviors.

\subsection{Research Questions}

Through this dissertation, I seek answers to the following questions:

1. Compared to text-only brand communications, does the use of emojis in brand communications lead to more favorable consumption consequences? 
2. What is the underlying process of the effects of emojis on consumption consequences?

3. Are there any circumstances that will moderate the effects of emojis on consumption consequences?

\subsection{Summary}

This dissertation is structured as follows. First, I provide a literature review of the key constructs, including a conceptualization of emojis, anthropomorphism, self-brand connections, and consumer-brand relationships. Next, I develop hypotheses to answer the research questions presented above and introduce the conceptual model. Then, I present the research methodology to assess my prediction that emojis have a positive effect on consumption consequences, and that these effects are sequentially mediated by brand anthropomorphism and self-brand connections. Further, I also predict brand role as moderator of these effects. Across eight studies I examine these propositions.

I begin with a set of four empirical studies that demonstrate the main effects of emojis on consumption behaviors. Study la involves a taste test to evaluate the effects of facial emojis on brand attitudes. Study $1 \mathrm{~b}$ uses a social media post to evaluate the effects of artifact emojis on purchase intentions, while study $1 \mathrm{c}$ replicates these findings by evaluating the effects of facial + artifact emojis on click through rates. Given that these outcomes are self-reported, study $1 \mathrm{~d}$ is a field study designed to evaluate the effects of facial + artifact emojis on actual purchase behavior involving monetary transactions.

Next, I conducted three studies that evaluate and confirm the underlying mechanism involving brand anthropomorphism and self-brand connections as serial mediators of the effects of emojis on consumption consequences. Study $2 \mathrm{a}$ uses a social 
media post to evaluate the effects of facial + artifact emojis on self-brand connections. Study $2 \mathrm{~b}$ replicates these results and confirms the effects of emojis on self-brand connections are mediated by anthropomorphism. Study 2c was designed to evaluate the conceptual model to confirm that the effects of emojis on consumption consequences are sequentially mediated by anthropomorphism and self-brand connections. Across these three studies I use facial and artifact emojis, as well as established and fictitious brands in different product categories to increase the generalizability of these findings.

Then, I present study 3, which aimed to evaluate the predicted moderating effect of brand role. While results provide evidence of an interaction effect between emojis and brand role, findings do not reveal evidence of the predicted moderating effect of brand role.

Among these eight studies, studies 1a, 2a, 2b and 2c were previously presented during my proposal defense. In addition, I include the two studies (study $1 \mathrm{~d}$ and study 3 ) that I proposed to conduct as part of my proposal defense in May 2019, to which I have integrated the suggestions made by the members of my dissertation committee. For instance, in study 1d (field study), I adapted the main stimuli to involve a cover story that more closely relates to digital contexts. Also, since this study involves actual purchase, I conducted a pretest to determine the type of product to use, as suggested by dissertation committee members. For study 3, I adapted the stimuli such that it no longer involves mentions of a possible brand transgression, as in my original proposal.

Finally, I have included two new studies (study 1 b and study 1c), which I believe reinforce initial findings and provide further support for the predictions made in this dissertation. Study $1 \mathrm{~b}$ uses a social media post with artifact emojis replacing text to asses 
purchase intentions. Study 1c uses both facial and artifact emojis to assess their effects on click through rates, which is another important metric in digital transactions.

After presenting all eight studies, I discuss the key theoretical and managerial contributions of this work, address limitations and discuss future research avenues. 
CHAPTER 2. THEORETICAL FRAMEWORK 


\subsection{Emojis: Background and Conceptualization}

In their work on emojis, Kaye, Malone, and Wall (2017) argue that our daily interactions with other people include communication in the form of verbal (written and spoken) and non-verbal language (mannerisms and expressions) to relay information and emotion. In the digital world, they find the use of verbal, text-based communication is predominant; therefore, interaction among people is informational but lacking in nonverbal cues that help clarify intent as well as convey emotions and affect. However, consumers have compensated for this lack of non-verbal, physical interaction through the use of subtle cues, such as emoticons and emojis. Rezabek and Cochenour (1998) also found that emoticons help convey sentiments, thereby increasing the meaning of computer-mediated communications. Further, they found that emoticons are used as visual cues in digital messages to replace the function of body language in human communication, allowing messages to be understood more clearly and to augment their effectiveness.

Emoticons are short-character strings usually using colons, semi-colons and parentheses, that represent expressions and feelings, such as :-) for happiness or :( for sadness (Rezabek and Cochenour 1998). The pervasive use of emoticons gave rise to the creation of emojis in the late 1990s by Shigetaka Kurita, the creative director of Japanese mobile carrier DoCoMo, along with Softbank and KDDI, as these platforms were incompatible with each other. As a result, emojis were standardized using Unicode Standard 6.0 (Kralj et al. 2015).

Emojis are small pictorial representations of facial expressions, concepts and ideas meant to convey sentiments, enhance meaning and provide clarity of intent in 
online, mobile and digital communications (Kralj et al. 2015; Filik et al. 2016). Emojis are a type of textual paralanguage that may replace or supplement language; they are expressed through the use of symbols and images to help convey information and emotion, making messages easier to process and understand (Phelps 2006; Luangrath, Peck, and Barger 2017). Textual paralanguage consists of five main categories: voice qualities, vocalization, tactile kinesics, visual kinesics and artifacts, which I describe below (see table 1 for examples).

\begin{tabular}{|c|c|}
\hline Category & Example of TPL per Category \\
\hline Tactile kinesics & $($ kiss $),($ hug $)$ \\
\hline Visual kinesics & $($ wink $),-($ smile $)$ \\
\hline Artifacts & Crazy!, OMG, LOL \\
\hline Voice Qualities & ugh, sigh, hmm \\
\hline Vocalizations & \\
\hline
\end{tabular}

Table 1. Textual Paralanguage Categories

Voice qualities include capitalization and the use of punctuation marks to emphasize a word or text fragment, while vocalization refers to the use of text to spell out a particular sound. Tactile kinesics are graphic representations of interpersonal touch, such as (kiss), (hug). Emojis in this category represent human dynamics and motion between people and are emotionally charged (i.e. love, happy). Similarly, visual kinesics relate to representations of individual body movements, for example, (wink), (smile), (laughter), which also denote emotion (i.e. happiness). Both types of kinesic 
emojis help augment message clarity by providing emotion to textual information in CMC. Contrary to the above two categories, artifact emojis are visual representations of non-kinesic items, such as 茼 (house), (ball), (hamburger).

Based on the five types of textual paralanguage presented by Luangrath et al. (2017), emojis can be classified within the following three categories: tactile kinesics, visual kinesics and artifacts (Luangrath, et al. 2017; see Table 2). It is important to note that as with other research studies, I also use the term facial emojis to refer to emojis that depict a human face regardless of whether they fall into the tactile or visual kinesic categories (Luangrath, et al. 2017; Riordan 2017).

Past research suggests that images used in marketing communications influence persuasion and attitudes by evoking brand or product characteristics (Miniard et al. 1991). Visual representations of words are considered a form of typeface semantic that enhance consumers' brand perceptions and recall of brand benefits compared to verbalonly information (Childers and Houston 1984; Childers and Jass 2002). Unlike facial emojis, artifact emojis are devoid of emotional cues but influence brand perceptions and attitudes by evoking brand-relevant characteristics that help consumers make associations between the brand and its benefits. Furthermore, Riordan (2017) found that like facial emojis, artifact emojis also help clarify messages. Thus, while artifact emojis are not necessarily affect laden, they can help improve communication clarity.

As of January 2020, a total of 3,053 emojis have been developed using Unicode Standard version 12.0, with the latest 230 emojis launched in the first quarter of 2019 (Unicode 2019). The 230 most recent emojis are inclusive of gender and skin variations; they also include various representations of people with disabilities and cultural icons. 
According to Emojipedia (2019), these latest emojis are designed to be more inclusive so that audiences worldwide, despite different backgrounds and spoken languages, are represented and able to use the emojis in a myriad of online and mobile contexts. Further, using sentiment analysis on Twitter, Kralj et al. (2015) found no significant differences in the frequency of emoji use across 13 languages, concluding that emojis are used widely across cultures and languages.

\begin{tabular}{|c|c|c|}
\hline Category & $\begin{array}{c}\text { Example of Emojis per } \\
\text { Category }\end{array}$ & $\begin{array}{c}\text { Example of Text + Emoji per } \\
\text { Category }\end{array}$ \\
\hline Tactile kinesics & & You came in first place! \\
\hline Visual kinesics & You came in first place! \\
\hline Artifacts & 0 & You came in first place! \\
\hline
\end{tabular}

Table 2. Emoji Categories

Unicode Standard is developed by the Unicode Consortium, a non-profit 501(c)(3) organization consisting of a group of corporate, individual and government members who oversee the creation, implementation and standardization of graphic character text across software providers and platforms. Some members include Adobe, Apple, Facebook, Emojipedia, Google, the Government of India, IBM, Microsoft, Netflix and University of California at Berkley who have voting rights to accept or reject emoji requests by individuals and corporations. To this end, the Unicode Consortium regulates the creation and launch of emojis to ensure uniform and universal functionality across all 
software platforms (Lufkin 2018). While brands and individual entities can petition for the addition of new emojis by submitting emoji renditions, the Unicode Consortium members must approve them. A notable example occurred when Taco Bell gathered 33,000 consumer signatures to petition the approval of a taco emoji, which was launched in July 2015 (Robles 2015). A less successful example is contraceptive brand Durex, who launched an emoji petition campaign in 2015, which has not been approved to date. Like these examples, other brands across product categories recognize the importance of using emojis in online communications as a standardized digital language that allows them to connect with consumers in numerous digital platforms.

In their study of the social motives that drive emoticon use in computer-mediated communications, Derks, Bos, and von Grumbkow (2007) found that consumers use emoticons as nonverbal cues to express emotions. In fact, their findings demonstrate that consumers use more emoticons in positive contexts (i.e. to express humor) than in negative contexts (i.e. to express irony), and generally, people are more likely to use emoticons when communicating with friends than they are to use them with strangers. Additionally, they found that emoticons provide a paralinguistic component that helps clarify information and intent, while adding emotions to digital communications. For example:

1. Anna is having too much fun

2. Anna is having too much fun $\odot$

In the case of the above statements, both messages contain the same text, but the emojis provide the emotion to clarify the statement's true meaning and intention. In the 
first statement, the sender reinforces pleasure and joy through emoji while the sender in the second statement demonstrates a degree of annoyance. According to Derks, Bos, and von Grumbkow (2007), these emotionally charged non-verbal cues can help further clarify $\mathrm{CMC}$ by providing information, regulating interaction and expressing intimacy, as nonverbal cues do in face-to-face communications. For instance, a congratulatory hug and high-five add special meaning to the expression "Congratulations!" Extending this example into a digital setting, the hug and high-five emojis could replace the physical hug and high-five in CMC.

Nevertheless, related research has found the meaning of emojis may have various interpretations (Miller et al. 2016). First, in some cases, emojis may look differently across platforms (i.e. in Apple iOS versus in Twitter). Second, their meaning can vary individually from consumer to consumer, depending on the symbolism the consumer may assign to any particular emoji (Highfield and Leaver 2016), For instance, the water droplets emoji ( $0_{8}$ ) can be used to represent water, sweat or stress. However, sources like Emojipedia.org (the official emoji website powered by Unicode Consortium) and the inclusion of emojis in commercial reference sources (i.e. Dictionary.com) are available to help marketers and consumers compare how emojis look across platforms as well as learn the original meaning assigned to any emoji while understanding the different meanings attributed to them in the marketplace. These sources help clarify the symbolism of an emoji while presenting the many ways emojis can be used. In the studies presented herein, we pretested all stimuli to ascertain that the emojis used were understood with the intended meaning and interpretation. In sum, emojis are graphic characterizations of human emotions (i.e. happiness, sadness, anger), actions (i.e. hug, thumbs up) and objects 
(i.e. doll, ball) that allow the user to represent and clarify his/her emotions and intentions in CMC.

The focus of this dissertation is to explore the influence of brands' use of emojis in CMC on the consumer-brand relationship. Specifically, I am interested in understanding how emojis can help augment consumer-brand connections as a measure of consumer-brand relationship strength that translates into greater consumption consequences. The latter constitutes an important contribution of this dissertation as it reveals that emojis can impact consumption behaviors positively in terms of willingness to pay, word of mouth, purchases and attitudes. I also seek to determine that no significant differences exist between the two main emoji categories (facial and artifact emojis) on the predicted effects of emojis. To my knowledge, previous marketing studies have not addressed this contribution. Finally, although I measured and controlled for mood across studies, it is beyond the scope of this dissertation to evaluate any distinctions between positive and negative emojis (i.e. happy versus sad emoji face).

\subsection{Emojis in Brand Marketing}

Social media, mobile and web contexts have proven to be ideal digital environments for brands to interact directly with current consumers and acquire new consumers. Kelleher (2009) argues that in digital settings, consumers have control of what they watch according to their preferences. In fact, consumers are able to choose when, how much and what type of content to see at any given time. This control implies that when consumers choose to see commercial content in digital settings, they already are motivated to interact with brands, allowing brands ample opportunities to connect, 
engage and build strong relationships that can lead to favorable consumption outcomes. Furthermore, Beese (2015) explains that social media provides marketers creative opportunities that can be fulfilled with visual content and, of particular importance, emojis. Therefore, it is important for marketers to understand the elements and techniques that can significantly enhance their participation in digital media and capitalize on its potential.

Social media marketing firms have reported on the influence of emojis by revealing significant increases in brand engagement and mobile usage (i.e. e-mail, social media posts and mobile notification open rates, among others). For example, Leanplum, a leading marketing corporation that helps brands further establish their presence in online media, issued a report on the influence of emojis in e-mail and mobile brand engagement. Specifically, they found the inclusion of emojis in messages (app push notifications and e-mail) rose from 15\% to almost 30\% from 2017 to 2018 (Schrock, 2018). Most importantly, they observed the open rates of app push notifications that contained emojis were $10.67 \%$ compared to only $3.01 \%$ of push notifications that did not include emojis, a $254 \%$ increase. In the case of e-mail, open rates for e-mails containing emojis were $16.06 \%$, compared to a $9.67 \%$ open rate for emails that did not contain emojis, a $66 \%$ increase. Schrock (2018) also noted 26\% fewer uninstalls of those apps using emojis in their push notifications. Reduced uninstalls percentages combined with greater open rates provide marketers with substantial opportunities to connect and create value for their brand and customers in online and mobile settings.

In academic research, the study of emojis has gained increased attention over the last few years. Pancer, McShane, and Poole (2017) observed a positive relationship 
between emoji use and brand engagement. Specifically, they found that organizations using facial emojis in their online communications exhibit an increase in overall engagement (i.e. likes, retweets). Li, Chan, and Kim (2018) established that facial emojis increase consumers' satisfaction toward service providers in communal relationships given an increase in their perceptions of the provider's warmth. However, they also found that emojis decrease consumers' service satisfaction in exchange relationships due to a decrease in their perceptions of the provider's competence. These findings suggest that emojis influence consumers' satisfaction toward the service provider, and that these effects are mediated by perceptions of a brand's warmth and competence and moderated by the commercial relationship norm (i.e. exchange versus communal). Communal relationships are a type of relationship norm in which one cares for the other, much like a friend or family. In the context of business, an example of a communal relationship are those service providers that seem caring and friendly, like a preschool. On the contrary, exchange relationships are those in which one provides benefits for others in exchange for something of value to them. In business, an example of an exchange relationship norm is a service provider that seems to be more professional, like a financial institution (Aggarwal 2004).

Additionally, Das, Wiener, and Kareklas (2019) also demonstrated a positive relationship between the use of facial emojis and purchase intentions. They found that advertisements that included facial emojis led to an increase in purchase intentions compared to advertisements that did not include emojis at all. This effect is mediated by positive affect and moderated by the product type (hedonic versus utilitarian). Similarly, in studying the effects of emojis on consumers' recall of information, Yu-Buck, Mishra, 
and Mishra (working paper) have found that positive emojis help consumers more easily recall online consumer reviews.

Further, in their study of the influence of consumer engagement in social networking sites in India, Arya, Sethi, and Verma (2018) found that emojis moderated the effects of consumer engagement in social media, leading to greater attachment to brands. However, their study is not clear regarding the reason this occurs, nor do they evaluate subsequent consumption behaviors as a result of brand use of emojis. Finally, their research is limited to one study that only considers consumers in India and does not specify the type of emojis employed in their stimuli. I build upon these findings by first addressing how and which types of emojis impact self-brand connections and more importantly, consumption consequences. Second, I also predict possible moderating variables to clarify the role of emojis in digital brand communications.

Although some of these research studies demonstrate the influence of emojis on consumption consequences (see Table 3), they have yet to identify why and under which instances emojis drive consumer-brand connections to strengthen the consumer-brand relationship. Therefore, in this dissertation, I aim to explore the process through which emojis can influence consumer-brand connections as a valuable component in online marketing strategies that can result in favorable consumption outcomes, such as willingness to pay, word of mouth and sharing behaviors, purchase decisions and attitudes.

Understanding the impact emojis can have on self-brand connections provides important insight into the relationship quality between the consumer and the brand. In the next section, I present a review of the self-brand connection literature to predict the 
connections consumers can build with brands imbued with human characteristics. I follow with a review of the brand anthropomorphism literature, which identifies the process through which consumers assign human qualities to a brand. Finally, I predict the serial mediation of brand anthropomorphism and self-brand connections on the effects of emojis on consumption behaviors and propose the moderating effect of brand roles. 


\begin{tabular}{|c|c|c|c|c|c|c|c|}
\hline Source & Journal & Scope & Methods & $\begin{array}{c}\text { Sample } \\
\text { Population }\end{array}$ & $\begin{array}{l}\text { SBC* as } \\
\text { DV }\end{array}$ & $\begin{array}{c}\text { Other Consumption } \\
\text { Behaviors }\end{array}$ & Main Findings \\
\hline $\begin{array}{l}\text { Arya, Sethi, } \\
\text { and Verma } \\
(2018)\end{array}$ & $\begin{array}{l}\text { Corporate } \\
\text { Communications: } \\
\text { An International } \\
\text { Journal }\end{array}$ & $\begin{array}{l}\text { Consumer } \\
\text { engagement on } \\
\text { social networking } \\
\text { sites }\end{array}$ & Experiment & $\begin{array}{l}\text { Adults } \\
\text { from India }\end{array}$ & Yes & No & $\begin{array}{l}\text { When consumers interact with } \\
\text { brands in social networking } \\
\text { sites, their attachment to a } \\
\text { brand will increase, which is } \\
\text { mediated by the brand's digital } \\
\text { communication and moderated } \\
\text { by the use of emojis. }\end{array}$ \\
\hline $\begin{array}{l}\text { Boman, } \\
\text { Urumutta } \\
\text { Hewage, and } \\
\text { Hasford }\end{array}$ & Working Paper & $\begin{array}{l}\text { Dark and light } \\
\text { colored Emojis on } \\
\text { Conservative and } \\
\text { Liberal Brands }\end{array}$ & Experiment & $\begin{array}{l}\text { US adults } \\
\text { (Students } \\
\text { and } \\
\text { MTurk) }\end{array}$ & No & $\begin{array}{l}\text { Brand attitudes and } \\
\text { purchase intentions }\end{array}$ & $\begin{array}{l}\text { Conservative brands that use } \\
\text { dark colored emojis can } \\
\text { increase brand attitudes and } \\
\text { purchase intentions }\end{array}$ \\
\hline $\begin{array}{l}\text { Das, Wiener, } \\
\text { and Kareklas } \\
(2019)\end{array}$ & $\begin{array}{l}\text { Journal of } \\
\text { Business } \\
\text { Research }\end{array}$ & $\begin{array}{l}\text { Influence of emojis } \\
\text { on positive affect } \\
\text { and purchase } \\
\text { intentions }\end{array}$ & Experiment & $\begin{array}{l}\text { US adults } \\
\text { (Students } \\
\text { and } \\
\text { MTurk) }\end{array}$ & No & Purchase Intentions & $\begin{array}{l}\text { Emojis help increase purchase } \\
\text { intentions, particularly for } \\
\text { hedonic products. Positive } \\
\text { affect mediated this effect. }\end{array}$ \\
\hline $\begin{array}{l}\text { Derks, Bos, } \\
\text { and von } \\
\text { Grumbkow } \\
(2007)\end{array}$ & $\begin{array}{l}\text { Computers in } \\
\text { Human } \\
\text { Behaviors }\end{array}$ & $\begin{array}{l}\text { Emoticons in } \\
\text { computer- } \\
\text { mediated- } \\
\text { communications as } \\
\text { a means of } \\
\text { expressing } \\
\text { emotions }\end{array}$ & Experiment & $\begin{array}{c}\text { Adults } \\
\text { from the } \\
\text { Netherlands }\end{array}$ & No & No & $\begin{array}{l}\text { Consumers use positive } \\
\text { (negative) emoticons in } \\
\text { positive (negative) contexts. In } \\
\text { general, emoticons are used in } \\
\text { socio-emotional rather than } \\
\text { task-oriented contexts, which } \\
\text { suggests that people use them } \\
\text { to express emotions and } \\
\text { augment meaning in digital } \\
\text { communications }\end{array}$ \\
\hline $\begin{array}{l}\mathrm{Li}, \text { Chan, and } \\
\text { Kim (2018) }\end{array}$ & $\begin{array}{l}\text { Journal of } \\
\text { Consumer } \\
\text { Research }\end{array}$ & $\begin{array}{l}\text { Emojis in Service } \\
\text { Encounters (i.e. e- } \\
\text { mail, chat) }\end{array}$ & $\begin{array}{l}\text { Experiments } \\
\text { and Field } \\
\text { study }\end{array}$ & $\begin{array}{l}\text { Adults in } \\
\text { China; } \\
\text { Students } \\
\text { and MTurk }\end{array}$ & No & $\begin{array}{l}\text { Attitudes toward } \\
\text { Service Employees }\end{array}$ & $\begin{array}{l}\text { Emojis increase consumers' } \\
\text { service satisfaction in } \\
\text { communal relationships given } \\
\text { an increase in their perceptions } \\
\text { of the provider's warmth. } \\
\text { However, emojis can decrease } \\
\text { consumers' satisfaction in } \\
\text { exchange relationships due to }\end{array}$ \\
\hline
\end{tabular}




\begin{tabular}{|c|c|c|c|c|c|c|c|}
\hline & & & & & & & $\begin{array}{l}\text { decreased perceptions of the } \\
\text { provider's competence. }\end{array}$ \\
\hline $\begin{array}{l}\text { Luangrath, } \\
\text { Peck, and } \\
\text { Barger } 2017\end{array}$ & $\begin{array}{l}\text { Journal of } \\
\text { Consumer } \\
\text { Psychology }\end{array}$ & $\begin{array}{l}\text { Influence of } \\
\text { Textual } \\
\text { Paralanguage on } \\
\text { Consumer } \\
\text { Behavior }\end{array}$ & Field study & $\begin{array}{l}\text { Twitter, } \\
\text { Instagram } \\
\text { and } \\
\text { Facebook } \\
\text { posts }\end{array}$ & No & No & $\begin{array}{l}\text { Introduces the expected } \\
\text { impact of textual } \\
\text { paralanguage, including } \\
\text { emojis on consumer behavior } \\
\text { and marketing consequences }\end{array}$ \\
\hline $\begin{array}{l}\text { Pancer, } \\
\text { McShane, } \\
\text { and Poole } \\
(2017)\end{array}$ & $\begin{array}{l}\text { Advances in } \\
\text { Consumer } \\
\text { Research }\end{array}$ & $\begin{array}{l}\text { Facial emojis } \\
\text { increase consumer } \\
\text { brand engagement }\end{array}$ & $\begin{array}{l}\text { Field } \\
\text { studies }\end{array}$ & $\begin{array}{l}\text { Twitter } \\
\text { posts }\end{array}$ & No & Brand engagement & $\begin{array}{l}\text { Organizations using emojis in } \\
\text { CMC enhance brand } \\
\text { engagement specifically when } \\
\text { using facial emojis. }\end{array}$ \\
\hline $\begin{array}{l}\text { Rezabek and } \\
\text { Cochenour } \\
(1998)\end{array}$ & $\begin{array}{l}\text { Journal of Visual } \\
\text { Literacy }\end{array}$ & $\begin{array}{l}\text { Emoticons help } \\
\text { clarify content in } \\
\text { CMC }\end{array}$ & $\begin{array}{l}\text { Field } \\
\text { studies }\end{array}$ & $\begin{array}{c}\text { Listserv } \\
\text { participants }\end{array}$ & No & No & $\begin{array}{l}\text { Visual Cues such as emoticons } \\
\text { in CMC help clarify } \\
\text { communications }\end{array}$ \\
\hline $\begin{array}{l}\text { Smith and } \\
\text { Rose (2019) }\end{array}$ & $\begin{array}{l}\text { International } \\
\text { Journal of } \\
\text { Research in } \\
\text { Marketing }\end{array}$ & $\begin{array}{l}\text { Emotional } \\
\text { Contagion } \\
\text { (Positive Affect) of } \\
\text { Smiley Emojis }\end{array}$ & $\begin{array}{l}\text { Biometric } \\
\text { Studies and } \\
\text { Experiments }\end{array}$ & $\begin{array}{l}\text { Students } \\
\text { and MTurk }\end{array}$ & No & Purchase Intentions & $\begin{array}{l}\text { Smiley emojis increase } \\
\text { perceptions of relationship } \\
\text { strength for communal (vs. } \\
\text { exchange relationships. }\end{array}$ \\
\hline $\begin{array}{l}\text { Urumutta } \\
\text { Hewage, Liu } \\
\text { and Wang }\end{array}$ & Working Paper & $\begin{array}{l}\text { Influence of Facial } \\
\text { Emojis on Brand } \\
\text { evaluations }\end{array}$ & Experiments & $\begin{array}{l}\text { Students } \\
\text { and MTurk }\end{array}$ & No & Brand evaluations & $\begin{array}{l}\text { Asymmetrical facial } \\
\text { expressions yield more } \\
\text { positive evaluations than } \\
\text { symmetric facial expressions }\end{array}$ \\
\hline $\begin{array}{l}\text { Yu-Buck, } \\
\text { Mishra and } \\
\text { Mishra }\end{array}$ & Working Paper & $\begin{array}{l}\text { Smile emojis help } \\
\text { recall online } \\
\text { product reviews }\end{array}$ & Experiments & $\begin{array}{l}\text { Students } \\
\text { and MTurk }\end{array}$ & No & $\begin{array}{l}\text { Consumers recall of } \\
\text { product reviews }\end{array}$ & $\begin{array}{l}\text { Consumers recall words-plus- } \\
\text { emojis reviews better than } \\
\text { words-only reviews }\end{array}$ \\
\hline $\begin{array}{l}\text { Garcia- } \\
\text { Collart and } \\
\text { Sinha }\end{array}$ & Working Paper & $\begin{array}{l}\text { Emojis enhance } \\
\text { consumer-brand } \\
\text { connections }\end{array}$ & $\begin{array}{l}\text { Experiments } \\
\text { and Field } \\
\text { study }\end{array}$ & $\begin{array}{l}\text { US adults } \\
\text { (Students) } \\
\text { and MTurk }\end{array}$ & Yes & $\begin{array}{l}\text { Willingness to pay, } \\
\text { word of mouth, } \\
\text { purchase intentions, } \\
\text { brand attitudes, click } \\
\text { through rates, and } \\
\text { actual purchase } \\
\text { (amount paid in } \$ \text { ) }\end{array}$ & $\begin{array}{l}\text { Emojis (facial and artifact) } \\
\text { increase consumer-brand } \\
\text { connections, which lead to } \\
\text { favorable consumption } \\
\text { consequences such as } \\
\text { willingness to pay, word of } \\
\text { mouth and purchase behaviors }\end{array}$ \\
\hline
\end{tabular}

Table 3. Overview of existing emoji studies in marketing contexts 


\subsection{Consumer-Brand Relationships: Building Self-Brand Connections}

Marketing scholars have defined the term brand as a word or group of words used to describe and identify a product, company or good (Kotler, Armstrong and Cunningham 2005). Apple, Google, Disney, Kate Spade, and Volvo are some examples of brands in the marketplace. Importantly, a brand is an asset used to generate value for the product by means of awareness, associations and loyalty (Grewal and Levy 2018). Similar to human relationships, consumers form relationships with a brand - sometimes strong enough that consumers can feel elevated degrees of loyalty (Fournier 1998) and even brand love (Batra et al. 2012). Brand love is an emotional measure of consumers' attachment to a brand (Carroll and Ahuvia 2006) and leads to increased brand loyalty. According to Fournier (1998), brand loyalty is a core measure of the consumer-brand relationship, as it defines how uniquely committed a consumer feels toward a brand that would continue to buy it even when competing options are readily available.

Miller (2001, pp.180) defined consumer-brand relationship quality as an "attempt to capture the strength of the connection formed between the consumer and the brand toward a prediction of relationship stability over time." Consequently, the more strongly consumers feel connected to a brand, the more likely they are to value and preserve such relationships (MacInnis 2012). In fact, Fournier (1998) established that self-brand connections help explain brand relationship quality. Related literature defines self-brand connections as the degree of overlap between consumer and brand (Ferraro, Kirmani and Matherly 2013), which refers to the extent to which the consumer feels the brand represents his/her identity and determines the closeness between the consumer and the brand (Chang and Chieng 2006). Escalas and Bettman (2009) also explained that 
consumers are more likely to develop strong, lasting relationships with brands they feel represent their self-identities and form strong connections to brands that help construct their self-concept, particularly with brands related to an aspirational group to which they wish to feel a part of or belong.

Similar to interpersonal relationships, consumers and brands build relationships that require active participation and interdependence of the consumer and brand (Fournier 2009). Thus, consumer-brand relationship strength can be determined by the extent to which the consumer engages or interacts with a brand and vice-versa (Alvarez and Fournier 2016). In online settings, this interaction is of especial importance given the opportunities brands have to interact directly with their consumers through posts, comments, responses, and e-mails, therefore taking an active role in building connections with their consumers.

Social media and mobile communications were created initially to connect people with each other (Fournier and Avery 2011) and quickly became dominant cyber spaces for consumers to connect with brands and influencers (Chappuis, Gaffey, and Parvizi 2011). As these methods of communication became more technologically advanced, they presented an opportunity for brands and corporations to connect with their consumers in a more relatable, casual manner, as one would connect with a close friend. According to marketing firm Sprout Social (2019), 91\% of consumers believe brands can use social media to connect people and consider social media to be the optimal medium for brands to create connections with their consumers. These findings also reveal that over half of consumers who feel connected with brands through social media will increase their brand purchases by an average of 76\% and build brand loyalty as well (Sprout Social 2019). 
Because brands are entities that can be connected intimately with a consumer forming strong consumer-brand connections that lead to consumer-brand relationship strength (Fournier 2009), everything the brand represents and does, including its marketing communications, affects the consumer-brand relationship (Aaker, Fournier, and Brasel 2004). Given this prospect, brands look for smarter, more effective ways to create a strong online presence through which they can connect with their consumers (Forbes 2019). Particularly in the context of social networks, brands are able to directly communicate and connect with their customers by sharing content that will result in conversions, loyalty, and engagement in the form of likes, comments, shares, and purchases (Pinto et al. 2018). More recently, with the use of emojis in CMC, brands have the opportunity to better engage and connect with their consumers (Pancer, McShane, and Poole 2017) given these convey emotions and clarify intent in CMC (Luangrath, et al. 2017), which can lead to important consumption consequences that benefit the brand.

\subsection{Carryover Effects of Self-Brand Connections}

Brands value a strong degree of connection with their consumers given the downstream benefits to the brand. For instance, the stronger connection a consumer shares with a brand, the less impact negative brand information will have on consumers' attitudes and reactions (Ferraro, Kirmani and Matherly 2013). This suggests that consumers will maintain a positive view of the brand with which they possess a strong connection, despite negative publicity, associations or even brand transgressions (Ahluwalia, Burnkrant, and Unnava 2000). In fact, Cheng, White and Chaplin (2012) found that despite receiving negative information about the brand, consumers with strong 
self-brand connections maintained such positive attitudes toward the brand as a means to protect the self. In this sense, strong self-brand connections serve a shielding function that protects the brand against potentially damaging information that could discourage the use of or consumption of the brand.

Additionally, strong self-brand connections lead to increased brand attitude strength and evaluations by creating links between the brand and the self (Moore and Homer 2008; Escalas 2004). These connections also increase actual purchase behaviors and brand purchase share, which means consumers will likely purchase the brand they feel most connected with even in the presence of similar competing brands (Park et al. 2010). Further, consumer-brand connections help foster local brand advocacy among city residents (Kemp, Childers, and Williams 2012) and greater loyalty and product involvement (Kressmann et al. 2006). Finally, Batra, Ahuvia, and Bagozzi (2012) find that similar to human relationships, strong connections between a consumer and a brand are an important component of brand love and are conducive to important consumption consequences, such as word of mouth and referral behaviors (Kwon and Mattila 2015).

Importantly, these positive effects of self-brand connections on consumption behaviors and intent can be bolstered by external marketing elements. For example, celebrity endorsers have been found to enhance self-brand connections, leading to more favorable brand equity (Dwivedi, Johnson, and McDonald, 2015). Additional research has found that advertising narrative increases brand attitudes and purchase intentions through enhanced self-brand connections (Escalas 2004); reference groups also influence consumer-brand connections (Escalas and Bettman 2003). In sum, brands should actively seek instances and implement marketing strategies that will allow them to further 
enhance consumer-brand connections that will lead to beneficial downstream consumption consequences.

Related marketing research proposes that consumers are able to develop strong connections to brands, just as they would in interpersonal relationships (Alvarez and Fournier 2016; Fetscherin and Heinrich 2015). However, interpersonal relationships are largely formed by face-to-face communications, which include nonverbal cues (i.e. mannerisms, facial expressions) that are rich in relational and emotional information, thus making communication more effective and easier to understand (Walther 1992). In the case of brands communicating in online contexts through CMC (i.e. social media posts, text messages), the lack of non-verbal cues is a disadvantage in effective communication with consumers. However, given that emojis help express emotions and clarify text-based communications by acting as non-verbal cues, I argue that consumers will find it easier to connect with brands that use emojis in addition to text. Thus, I predict that emojis will help improve the consumer-brand relationship, particularly by facilitating positive consumption behaviors as a consequence to increased self-brand connections. Formally:

H1: Compared to online textual brand communications that do not include emojis, brand communications that employ emojis in addition to text will lead to more positive consumption consequences.

H2: Compared to online textual brand communications that do not include emojis, brand communications that employ emojis in addition to text will lead to enhanced self-brand connections. 


\subsection{The Role of Brand Anthropomorphism and SBC on Consumption}

Anthropomorphism is the process by which consumers attribute human features to non-human objects and entities by assigning humanlike physical characteristics (i.e. hand, eyes, mouth) or humanlike minds (i.e. intentions, cognition, motivations, emotions) (Epley et al. 2007; Waytz, Epley and Cacioppo 2010). Furthermore, the process of anthropomorphism can attribute human characteristics, such as mental capacity and voice, to inanimate objects (Puzakova and Kwak 2017).

While individual tendencies to anthropomorphize a brand or product exist, Churches et al. (2014) found that humans process emoticons as they process human faces through neural mechanisms in occipitotemporal sites given their familiar configuration. Relatedly, Landwehr, McGill and Herrmann (2011) remind us that certain types of facial expressions (upward smile and slightly slanted eyes) can increase consumers' positive affect toward the product, which is amplified by anthropomorphism. Consequently, the presence of emojis in brands' digital communications could facilitate the assignment and perception of human characteristics of such brands, leading to increased connections as described in the SEEK model (Epley et al. 2007).

In their SEEK model (Sociality, Effectance, Elicited agent Knowledge), Epley et al. (2007) outline three determinants of consumers' tendency to anthropomorphize nonhuman objects. The first, is to access and apply anthropocentric knowledge (elicited agent knowledge), to activate that knowledge (effectance), and apply such knowledge to a nonhuman entity given the desire for social affiliation (sociality). For example, a consumer has knowledge of what a human looks and acts like (elicited agent knowledge) and may come across a stimulus that activates this knowledge, such as a brand logo that seems to 
have eyes and mouth shaped graphics (effectance). Thus, the consumer responds positively to this (sociality). This process helps explain that consumers anthropomorphize as a need for social connection. Thus, the anthropomorphized entity exerts a significant social influence on the perceiver.

In fact, anthropomorphism is considered to be an important precursor in the development of consumer-brand relationships (Fournier, 1998) and, according to MacInnis and Folkes (2017), can be achieved when consumers find that the brand has either human physical traits (i.e. brand looks like a human), personality traits (i.e. brand acts like a human), seems like it has human intentions (i.e. brand has agency) or is similar to the self (i.e. brand is/looks/acts like me). Therefore, consistent with the SEEK model, consumers can connect more easily with brands they perceive as human, particularly when they feel the brand looks or acts like them (has emotions, motivations, agency; MacInnis and Folkes 2017).

In this dissertation, I suggest that emojis can enhance perceptions of anthropomorphism given that like in human communications, they are used by humans to clarify and enhance the emotional content of textual communications. Thus, they are used to express emotions in digital communications, which can bring about feelings that the brand has emotions, agency and intentions. I extend this prediction by proposing that enhanced humanization of a brand as a result of emoji use will facilitate consumer-brand connections. Below I explain the importance of these predictions and the marketing implications they entail.

Research in human-computer interaction (i.e. artificial intelligence, robots) demonstrates the importance of anthropomorphism given that technological advances 
have made it possible for robots and machines to appear and act more human by expressing emotions (Breazeal and Aryananda 2002). In the marketing domain, anthropomorphism is of particular importance given many brands use artificial intelligence in customer service encounters to provide more customized experiences, despite the lack of physical presence of a human being (van Doorn et al. 2017). Similarly, in brand CMC, understanding elements that can help anthropomorphize a brand is important as consumers demand a more personalized experience in digital settings that lack a "human voice" (Kelleher 2009). In their research, Barcelos et al. (2018) emphasize the more human voice brands use in social media contexts, the more affective and hedonic values consumers assign to the brand, which increase purchase intentions. Since consumer interaction with brands in social media spaces increases emotional connections and engagement with the brand, when anthropomorphism is high (Hudson et al. 2015), I argue that emojis in brand communications can help enhance brand anthropomorphism by providing a human voice to the brand, allowing for greater connections with consumers (Kelleher 2009; Luangrath, Peck, and Barger 2017; Barcelos et al. 2018).

Epley et al. (2007) found consumers tend to anthropomorphize as a need for social connection; thus, the anthropomorphized entity exerts a significant social influence on the perceiver. In fact, anthropomorphism is considered to be an important precursor in the development of consumer-brand relationships (Fournier, 1998) and, according to MacInnis and Folkes (2017), this can be achieved when consumers find the brand has human physical traits (i.e. brand looks like a human), personality traits (i.e. brand acts like a human), seems like it has human intentions (i.e. brand has agency) or is similar to the self (i.e. brand is/looks/acts like me). Therefore, consumers can connect more easily 
with brands they perceive as human, particularly when they feel the brand looks or acts like them (MacInnis and Folkes 2017). We therefore posit that both types of emojis (facial and artifact) can enhance perceptions of anthropomorphism given that first, they are used by humans and exist in human communications, and second, they are used to express emotions in textual communications. We extend this prediction by proposing that enhanced humanization of the brand as a result of emoji use will facilitate consumerbrand connections with important marketing implications they entail.

Research in human-computer interaction (i.e. artificial intelligence, robots) demonstrates the importance of anthropomorphism given that technological advances have made it possible for robots and machines to appear and act more human by expressing emotions (Breazeal and Aryananda 2002). In the marketing domain, anthropomorphism is of particular importance given many brands use artificial intelligence in customer service to provide more customized experiences, despite the physical presence of a human being (van Doorn et al. 2017). Similarly, in brand CMC, understanding elements that can help anthropomorphize a brand is important as consumers demand a more personalized experience in digital settings that lack a "human voice" (Kelleher 2009). In their research, Barcelos et al. (2018) emphasize the more human voice brands use in social media contexts, the more affective and hedonic values consumers assign to the brand, which increase purchase intentions. Since consumer interaction with brands in social media spaces increases emotional connections and engagement with the brand, when anthropomorphism is high (Hudson et al. 2015), I argue that emojis in brand communications can help enhance brand anthropomorphism 
by providing a human voice to the brand, allowing for greater connections with consumers (Kelleher 2009; Luangrath, Peck, and Barger 2017; Barcelos et al. 2018).

Finally, research on anthropomorphism has demonstrated that it positively influences consumption behaviors, such as favorable product evaluations (Aggarwal and McGill, 2012), brand love and loyalty (Rauschnabel and Ahuvia 2014), as well as increases consumer vitality and self-control (Chen, Sengupta and Adaval 2018). Additionally, brand anthropomorphism can occur due to consumers' perceived congruity between the brand and their self-concept (Aaker, Fournier and Brasel 2004), leading to enhanced consumer-brand connections (MacInnis and Folkes 2017). Thus, consumers will interact more with these brands that consumers perceive to be more "human" (Guido and Peluso 2015). Further, when consumers perceive brands to have human personality traits (Aaker 1997), they form stronger bonds with brands (Fournier 1998; Aggarwal 2004), leading to brand love (Batra, Ahuvia, and Bagozzi 2012), trust and forgiveness (MacInnis 2012), among other emotionally charged manifestations that strengthen relationships between consumers and brands (Kervyn, Fiske and Malone 2012).

To summarize, since emojis convey emotions and intent in textual communications (Luangrath, Peck, and Barger 2017), they may help consumers perceive the brand as more human, which improves consumer brand closeness and connections. Therefore, I argue the presence of emojis in brand communications will facilitate brand anthropomorphism and enhance consumer-brand connections, leading to favorable consumption consequences. Formally: 
H3a: Compared to online textual brand communications that do not include emojis, brand communications that employ emojis in addition to text will increase consumer perceptions of brand anthropomorphism.

H3b: Brand anthropomorphism and self-brand connections will sequentially mediate the effects of the presence of emojis in brand online communications on favorable consumption behaviors, such as (a) willingness to pay, (b) word of mouth, (c) purchase intentions and (d) attitudes.

\subsection{The Moderating Role of Brand as Partners versus Brand as Servants}

Related research on emojis and their influence on attitudes toward service providers has examined the influence of communal and exchange relationships ( $\mathrm{Li}$, Chan and Kim 2018). In communal relationships, emojis can enhance attitudes given they increase consumer perceptions of warmth. However, in exchange relationships, emojis lower consumer perceptions of brand competence, thereby negatively affecting attitudes toward the service provider. Though their research highlights the influence of the type of relationship between a consumer and a brand, I find it necessary to consider the hierarchical role consumers assign to a brand in this dissertation, particularly because my predictions suggest that emojis can help consumers imbue brands with human characteristics and increase social connections. Furthermore, it is important to consider the hierarchical structure in the study of consumer-brand relationships because marketers intentionally present brands in human roles so consumers can anthropomorphize the 
brand effectively (Kim and Kramer 2015) in order to motivate consumers to interact with the brand, leading to positive consumption outcomes (Aggarwal and MacGill 2012).

Past research suggests that consumers assign roles to brands similarly to roles in interpersonal relationships. MacInnis and Folkes (2017) suggest that brands can be anthropomorphized even when lacking human physiognomy by being personified, which can be achieved by portraying the brand in human roles. Some of these roles include brand as hero (brand rescues consumers), brand as outlaw (brand breaks rules), and brand as caregiver (brand provides care to the consumer) (Mark and Pearson 2001; MacInnis and Folkes 2017). Similarly, Aggarwal and McGill (2012) introduce two additional anthropomorphized brand roles in consumption behavior: brands as partners and brands as servants. Brands as relationship partners involve a co-dependent relationship in which brands and consumers co-create value, which means that brands in a partner role work with the consumer to create value. Kim and Kramer (2015) give the example of State Farm, which advertises its services as co-creator of consumer-brand value by promoting "like a good neighbor, State Farm is there," or Lowe's "Let's build something together!" Consequently, brand as partners foster a closer relationship with the consumer, allowing greater interactions and connections (Aggarwal and McGill 2012).

Conversely, consumers can assign brands the role of a servant, one that involves a master-servant relationship in which a brand creates value for the consumer, thereby emphasizing the position of the consumer as a master-consumer. Burger King is an example of a brand as servant role when it advertises "have it your way," or SC Johnson's Scrubbing Bubbles “We work hard, so you don't have to" (Kim and Kramer 2015). Visa also assumes a servant role when it advertises "Visa is everywhere you want 
it to be." In sum, the brand as servant fulfills consumer needs and desires, creating a distant relationship between both entities.

These contradictory roles can predict consumers' disposition or motivation to interact with a brand, which can influence positive or negative consumption outcomes. Aggarwal and McGill (2012) ascertain that the goal of anthropomorphism is to have an increased social interaction with the non-human entity. Therefore, consumers have a stronger motivation to interact with brand as partner who is already seen as more similar to the consumer compared to a brand in a servant role, who is seen as provider of benefits.

Consequently, I predict brand role as an important moderator of the effects of emojis on consumption consequences, such that emojis will help connect consumers with brands when consumers view the brand as a partner compared with brands viewed in a servant role (see figure 1). Formally, I propose the following:

H4: Brand role will moderate the effect of brand anthropomorphism on self-brand connections, such that that brands as partners will increase self-brand connections compared to brand as servants. 


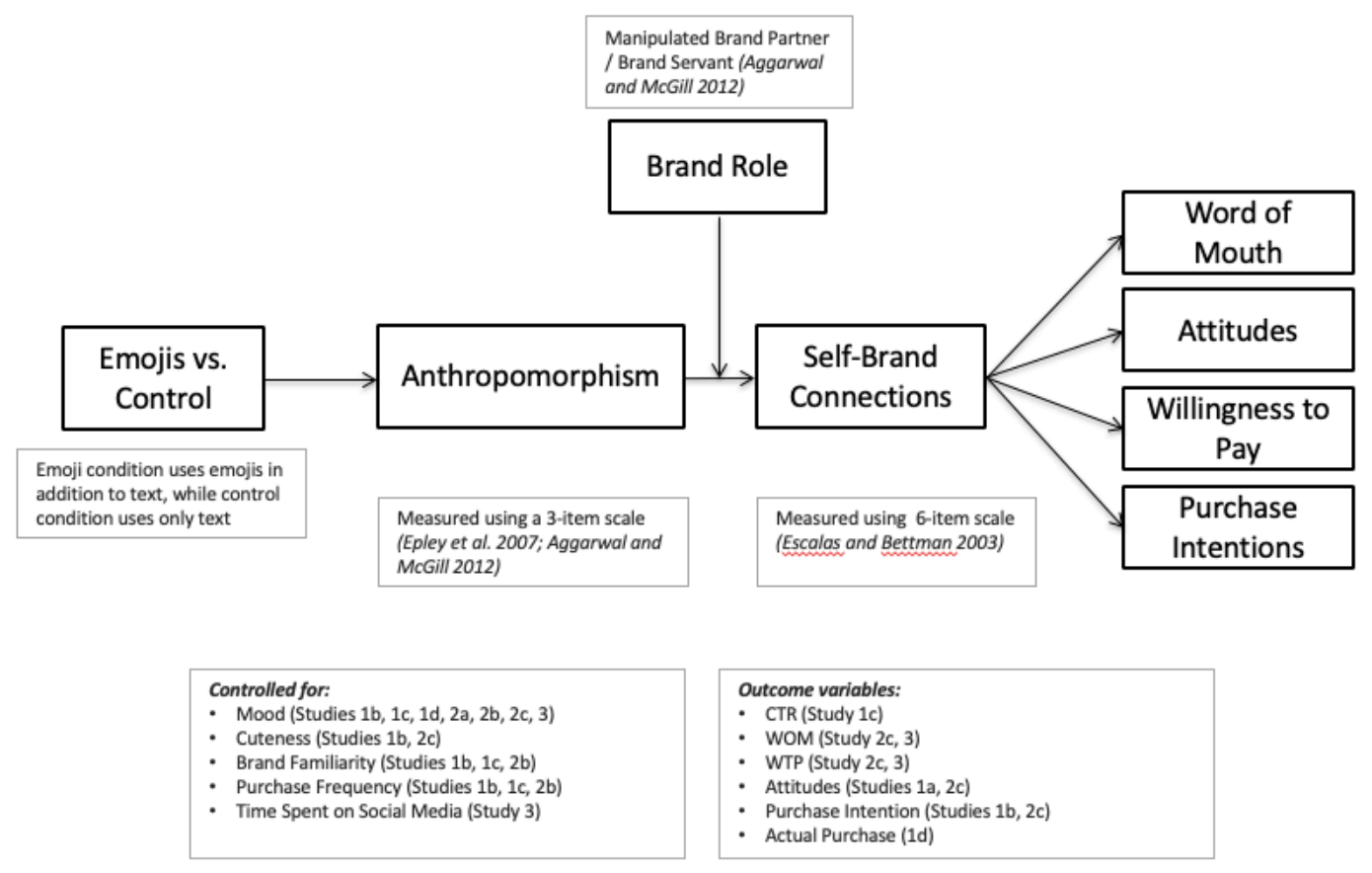

Figure 1. Conceptual model and operationalization of key constructs

\subsection{Alternate accounts}

As with all studies, alternative explanations should be considered and evaluated to confirm that the observed effects are a function the predicted variable. In this dissertation, I have identified alternative explanations and have addressed these by measuring and statistically controlling for these variables throughout my analyses.

The first alternative explanation I have identified is mood. Given that in some studies I used happy face emojis, one could argue these may increase positive mood in participants, thereby affecting their responses. In fact, Smith and Rose (2019) found that facial emojis do increase positive affect. Additionally, emojis are considered to be fun (Gn 2018) thus, even when using only artifact emojis in the main stimuli, I have 
statistically controlled for the effects of mood (Roehm and Roehm 2005) in studies $1 \mathrm{~b}$ 3 , and report results with mood as a covariate.

Second, research has shown that cuteness influences greater food indulgence (Nenkov and Scott 2014). Although this dissertation does not predict an effect of emojis on indulgence or food intake, emojis are considered cute (Gn 2018). Thus, I have statistically controlled for cuteness to ascertain that the observed effects are a function of the presence of emojis and not their cuteness. To this extent, in study $1 \mathrm{~b}$ I control for cuteness of the social media post, and in study $2 \mathrm{c}$, I control for cuteness of the brand. Furthermore, in the field study (study 1d), I used a non-food item to avoid any possible interaction of cuteness and indulgence on the predicted effects of emojis on consumption choice.

Third, across these studies I used non-branded items, established brands and fictitious brands. In particular, studies $1 \mathrm{~b}, 1 \mathrm{c}$, and $2 \mathrm{~b}$, used either the Starbucks or Nike brands in the main stimuli. Given that these are well-known brands, it is possible that participants have prior attitudes toward these brands. Thus, in these studies I statistically control for purchase frequency of (Starbucks or Nike) branded products, as well as for brand familiarity to avoid these variables from confounding the studies.

Fourth, in study 1d, I used a fictitious brand of personal care. Given that participants may have different purchase patterns of personal care products, I statistically control for skin care use and purchase frequency of skin care.

Finally, in study 3, I introduce time spent on social media (Ellison et al. 2007) as a covariate given that consumers can be very unfamiliar or familiar with brands' use of emojis in digital settings depending on the amount of time they spend on social media. 


\subsection{Overview of studies}

Across eight studies, including laboratory and field experiments, I find support for the effects of emojis on consumption behavior. Study 1a demonstrates that facial emojis (such as $:-$ ) ) lead to favorable product attitudes. Study $1 \mathrm{~b}$ shows the influence of artifact emojis (such as - ) in a social media post ostensibly created by the Starbucks brand on purchase intentions of Starbucks branded products. Study 1c shows the influence of facial + artifact emojis (such as $:+\notin$ ) in a social media post allegedly created by the Nike brand on click through rates. Study $1 \mathrm{~d}$ is a field study which demonstrates that both facial and artifact emojis (such as $: \dot{\theta}+W$ ) in a social media post for a fictitious brand also influence greater purchases, even in the presence of monetary tradeoffs. This study helps confirm the influence of emojis beyond hypothetical intention and in a real consumption setting. In support of $\mathrm{H} 1$, the objective of these first set of studies is to establish the effects of both types of emojis (facial and artifact) on consumption behavior, such as click through rates, brand attitudes, purchase intention and actual purchase behavior $(\$$ amount spent).

The next set of studies are designed to help explain the underlying process. Specifically, study 2 a uses a social media post supposedly created by the Adidas brand to demonstrate that facial + artifact emojis ( such as $:-\theta)$ in brand digital communications enhance self-brand connections (H2). In study $2 \mathrm{~b}$, I use a social media post allegedly created by the Starbucks brand to observe the effects of facial + artifact emojis (such as $:++^{-}$) on brand anthropomorphism $(\mathrm{H} 3 \mathrm{a})$ and self-brand connections. Findings from this study reveal that emojis increase anthropomorphism and that anthropomorphism mediates the effects of emojis on self-brand connections. 
Furthermore, to examine the predicted serial mediation of anthropomorphism and self-brand connections (H3b), study 2c examines and finds support for the effects of artifact emojis (such as + ) on consumption consequences through brand anthropomorphism and self-brand connections. I achieve this by using a social media post created by a fictitious brand of sunscreen. Findings revealed that emojis increase willingness to pay, word of mouth, attitudes and purchase intention by first, enhancing brand anthropomorphism, leading to stronger self-brand connections.

Finally, study 3 examines the predicted moderation of brand role (brand partner versus brand servant) on the effects of facial + artifact emojis (such as ) on consumption behaviors (H4). In this study I used a social media post by a fictitious brand of wearable technology. While results give evidence of an interaction effect, a follow-up moderation analysis revealed non-significant effects of brand role as moderating the effects of emojis on consumption behavior.

Collectively, findings from these studies provide empirical support of the effects of emojis in the context of online brand communications by establishing that brand digital messages that contain (facial, artifact or both) emojis (versus not), lead to positive consumption behaviors, and that these effects happen through a sequential mediation of brand anthropomorphism and self-brand connections. 
CHAPTER 3. RESEARCH METHODOLOGY 


\section{Study 1: Effects of Emojis on Brand Preference}

In this first set of four studies, I aimed to empirically examine the influence of emojis on consumption behavior. Specifically, these studies were designed to answer the first research question concerning how emojis impact downstream consumption consequences. In order to answer this question and on the basis of my prediction (H1) that emojis will positively influence consumption behavior in digital settings, I designed four studies that evaluate consumption outcomes including attitudes toward the product, click through rates, purchase intentions and actual purchase behavior, which are important measures of brands' market performance. Further, across these four studies I used stimuli that include non-branded, fictitious or established brands, as well as using facial, artifact or the combination of facial + artifact emojis compared against control conditions (text only).

In study 1a, I used facial emojis to evaluate their influence on consumer product attitudes after a taste test for non-branded cupcakes. Study $1 \mathrm{~b}$ evaluated the effects of artifact emojis on purchase intentions using a Starbucks social media post. Study 1c was designed to evaluate the effects of using both facial + artifact emojis in a Nike social media post to evaluate click through rates. While results were consistent and replicated across these first three studies, the outcome variables were self-reported, and thus, observing the effects of emojis on actual consumption would increase the robustness of

these findings. Consequently, I followed up with a field study (study 1d) that introduced a social media post for a fictitious brand of personal hygiene to evaluate actual product purchases involving money. 
In sum, the use of non-branded products, fictitious or established brands to evaluate the effects of facial and artifact emojis on consumption behavior, highlight the positive impact of emojis on multiple consumption outcomes. Importantly, I was able to determine that these effects persist even when statistically controlling for mood, perceptions of cuteness of the social media post and when applicable, purchase frequency of brand or product type.

\section{Study 1a: Influence of (Facial) Emojis on Attitude toward a Product}

The main goal of this study was to present initial evidence of the effects of emojis on consumers' attitudes toward a product, as a measure of consumption consequence. I achieved this by conducting a taste test that required participants to evaluate a nonbranded cupcake presented either on an emoji-themed plate or on a white paper plate. Specifically, participants were asked to take part in a taste test to examine whether their attitudes toward a product would differ in the presence (absence) of emojis. Consistent with H1, I predicted a positive effect of emojis on product attitudes.

\section{Method}

Participants and Design. A single factor, two-level (emoji versus no emoji) between-subjects factorial design was used to evaluate the influence of emojis on consumption behavior. In exchange for course credit, 80 undergraduate students $(56.3 \%$ female; $M_{\text {age }}=21.96, \mathrm{SD}=3.33$ ) from a public university in the United States completed a taste test. A post-hoc power analysis was conducted using G*Power v3.1 (Faul, 
Erdfelder, Lang and Buchner 2007). Given the sample size, the achieved power to detect a medium effect of .05 at an alpha level .05 was 0.95 , indicating the sample size was adequate for this analysis.

Stimuli. I employed the emoji manipulation (facial emoji vs. no-emoji control) in product (cupcake) as well as serving plate. The cupcakes used were purchased in a popular low-cost retail store and served either on a white paper plate (no emoji condition) or an emoji-themed paper plate (emoji condition). See figure 2 for stimuli details.

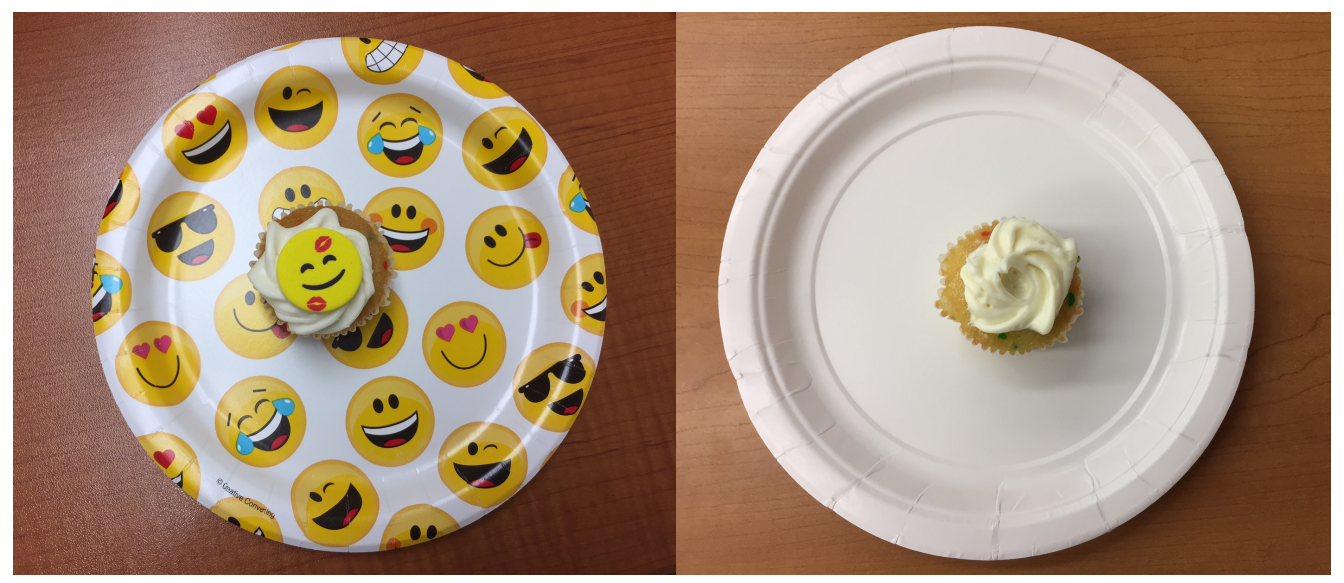

Figure 2. Stimuli, Study 1a

Procedure. In two classrooms of 40 students each (separated by condition) and during two consecutive days, participants were told they would participate in a taste test for a new brand of cupcakes coming to their community. Since cupcakes would be distributed in either an emoji-themed or a white paper plate in an open classroom (no divisions as in a behavioral lab), participants were separated by condition to avoid 
exposure to both stimuli, thereby alleviating any contamination bias concerns (Krishna, Maithreyi, and Surapaneni 2010).

Upon entering the classroom, all participants were given a short survey that read: "Welcome to this Taste Test! Please leave this survey on your desk and come upfront to sample a cupcake." Then, participants approached the front desk in the classroom and took a plate with a cupcake. Next, participants went back to their seats and read: "You may now proceed to sample the cupcake and complete the questions below after sampling the cupcake." Afterwards, participants proceeded to evaluate the cupcake using 7-point bipolar attitude toward the product measures ("Bad - Good," "Unfavorable Favorable," "Dislike - Like," "Unpleasant - Pleasant," "Distasteful - Tasteful," "Negative - Positive," "Low quality - Good Quality"), followed by basic demographic questions (age, gender). Details on this study can be found in Appendix B.

Results

Attitudes toward the product. The attitude measures were averaged to form a composite measure of attitude score $(\alpha=.97)$. A one-way ANOVA on the attitude score showed the use of emojis had a marginally significant main effect $(F(1,79)=3.30, p=$ $.073, d=.41)$ : participants in the emoji condition reported more positive attitudes toward the cupcake $\left(\mathrm{M}_{\mathrm{emoji}}=5.81, \mathrm{SD}=1.16\right)$ compared to participants in the no emoji condition $\left(\mathrm{M}_{\mathrm{no}-\mathrm{emoji}}=5.22, \mathrm{SD}=1.70\right)$. 


\section{Discussion}

Results from this analysis provide initial evidence that the presence of emojis can increase favorable attitudes toward a product, thereby indicating a positive effect of emojis on consumption. Nevertheless, one limitation of this study is participants were not randomly assigned, but each classroom tasted either the cupcake on emoji plate or the cupcake on the white paper plate. I did so to avoid participants from being exposed to both conditions, which could potentially lead to contamination bias. However, I am aware that this may also raise randomization concerns, which I address in subsequent studies. Finally, the emoji plate only had facial emojis, and neither mood, nor cuteness were considered in this study as alternative explanations. These limitations and randomization concerns are addressed in the following studies.

\section{Study 1b: Effects of (Artifact) Emojis on Purchase Intentions}

The main objective of this study was to support the findings of the previous study by evaluating the effects of artifact emojis on purchase intentions. I achieved this by using a social media post from the Starbucks brand to analyze the effects of artifact emojis when replacing text in brands' online communications. Specifically, participants were asked to report their intention to purchase Starbucks branded products after being shown a social media post with artifact emojis compared to a post without emojis. Consistent with H1, I predicted a positive effect of artifact emojis on purchase intent.

Furthermore, in this study, I statistically controlled for mood, brand familiarity, cuteness of the social media post and purchase frequency to confirm the observed effects 
of emojis on purchase intentions persist even when controlling for these potential confounding factors. The significance of ruling out brand familiarity and purchase frequency was important given that I was using the Starbucks brand, for which participants may already have established attitudes and purchase patterns. Similarly, ruling out mood and cuteness was important because emojis are perceived as fun and cute (Gn 2018) and thus, I needed to confirm that the observed effects were not due to an increase in mood or perceived cuteness.

Pretest

Participants and Design. 76 participants were recruited from MTurk (65.8\% female; $\left.M_{a g e}=34.6, \mathrm{SD}=11.64\right)$ and completed a pretest in exchange for monetary compensation. A post-hoc power analysis was conducted using G*Power v3.1 (Faul, Erdfelder, Lang and Buchner 2007). Given the sample size, the achieved power to detect a medium effect of .25 at an alpha level .05 was 0.60 , indicating the sample size was adequate for this analysis.

Stimuli. I employed the emoji manipulation (artifact emoji vs. no-emoji control) in a social media post ostensibly created by the Starbucks brand that either included artifact emojis or did not include artifact emojis at all. Importantly, in this study I replaced text (word "coffee" for a coffee emoji). See figure 3 for stimuli details. 


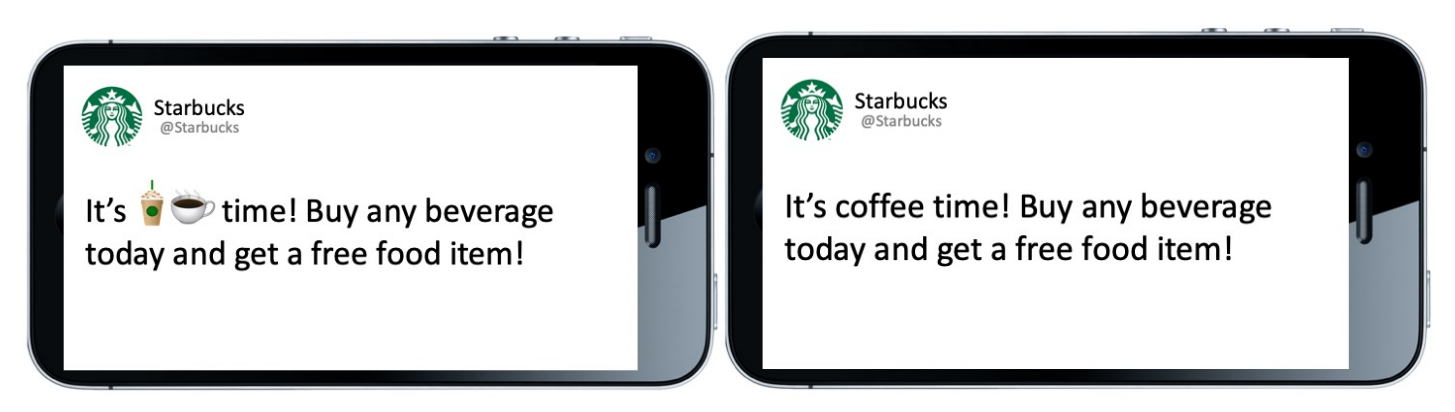

Figure 3. Stimuli, Study $1 \mathrm{~b}$

Procedure. Participants were asked to rate one of two social media posts ostensibly created by the Starbucks brand and were prompted with the following: "Please carefully analyze the following post and answer the questions that follow, with your honest opinion and choices." First, participants in the emoji condition only completed measures to assess the intended meaning of the emojis used in the post. The items used were: "The emoji intends to graphically represent an iced coffee," "The - emoji intends to graphically represent a hot coffee" $(1=$ "strongly disagree," and 7 = "strongly agree"). In this condition, I also pretested the appropriate use of the emojis within the textual message by using the following three items, "The emojis used in this post fit what is said in the textual message," "The types of emoji used in this post are appropriate," "The emojis within the post are placed appropriately" $(1=$ "strongly disagree," and $7=$ “strongly agree").

Participants across both conditions reported their attitudes toward the message using a 7-point semantic scale ("Unfavorable - Favorable," "Bad - Good," "Really Dislike - Really Like," "Negative - Positive"). Next, participants completed items used to assess how clearly they perceived to comprehend the message within the post: "The 
message in the advertisement you saw was:" ( 1 = "not easy to understand," 7 = "very easy to understand"; and 1 = "not clear," 7 = "very clear"). Finally, all participants completed basic demographic questions (age, gender).

\section{Pretest Results}

Meaning of Emojis. In the emoji condition, I compared the means with the midpoint to ensure all participants understood the meaning of each emoji as intended (Miller et al. 2016; Highfield and Leaver 2016): iced coffee $\left(\mathrm{M}_{\mathrm{iced}}=5.92, \mathrm{SD}=1.53 ; t=\right.$ $9.75, p<.001)$, and hot coffee $\left(\mathrm{M}_{\text {coffee }}=6.61, \mathrm{SD}=.595 ; t=32.20, p<.001\right)$, indicating that participants interpreted the emojis as intended in the social media post.

Appropriate use of Emojis. The measures used to assess if the emojis in the post were used appropriately and fit the narrative of the message were averaged to form a composite measure of fit score $(\alpha=.78)$ and compared against midpoint $\left(\mathrm{M}_{\mathrm{fit}}=6.18, \mathrm{SD}\right.$ $=.76 ; t=21.75, p<.001)$, indicating that the emojis fit the message in the social media post.

Perceived Message Comprehension. The measures used to assess perceived comprehension were averaged to form a composite measure of perceived message comprehension score $(\alpha=.87)$. As expected, results were non-significant on the perceived message comprehension score $\left(\mathrm{M}_{\mathrm{emoji}}=6.61, \mathrm{SD}=.76, \mathrm{M}_{\text {no-emoji }}=6.76, \mathrm{SD}=\right.$ $.48 ; F(1,75)=1.17, p=.283, d=.25)$, indicating that participants felt that the message was equally clear in both conditions

Attitudes toward the social media post. The measures used to assess attitudes toward the social media post were averaged to form a composite measure of attitude 
score $(\alpha=.92)$. Results from a one-way ANOVA on the attitudes index revealed no significant differences between conditions $\left(\mathrm{M}_{\mathrm{emoji}}=5.89, \mathrm{SD}=.865, \mathrm{M}_{\mathrm{no}-\mathrm{emoji}}=6.30, \mathrm{SD}\right.$ $=1.04 ; F(1,75)=3.44, p=.07, d=.43)$, indicating that participants had equal attitudes toward the social media post in both conditions.

\section{Pretest Discussion}

Results from this pretest indicate that the social media posts in both conditions are perceived to be equally clear, and that participants did not demonstrate different attitudes toward the social media post across conditions. Additionally, I was able to assert that emojis used in the emoji condition were appropriate and related to the textual message in the post. Finally, I also confirmed that participants interpreted the emojis as I intended to in the social media post.

\section{Main Study}

Participants and Design. In exchange for extra course credit, 93 undergraduate students $\left(46.2 \%\right.$ female; $\left.M_{\mathrm{age}}=22.4, \mathrm{SD}=5.59\right)$ from a public university in the United States were randomly assigned to the artifact emoji or no emoji control experimental condition to evaluate the influence of emojis on purchase intentions. A post-hoc power analysis was conducted using G*Power v3.1 (Faul, Erdfelder, Lang and Buchner 2007). Given the sample size, the achieved power to detect a medium effect of .50 at an alpha level .05 was 0.99 , indicating the sample size was adequate for this analysis.

Stimuli. I employed the emoji manipulation (artifact emoji vs. no-emoji control) in a social media post ostensibly created by the Starbucks brand that either included 
artifact emojis or did not include artifact emojis at all. Importantly, in this study I replaced text (word "coffee" for a coffee emoji). See figure 3 for stimuli details.

Procedure. Upon entering the behavioral laboratory, participants took a seat and were given a survey that introduced the study and were prompted with the following cover story: "We are a marketing firm looking for your opinion to evaluate brands' social media posts. Today we are asking you to evaluate a preliminary post for the Starbucks brand, as they communicate a new promotion via social media." Participants were randomly assigned to either the artifact emoji or control condition.

After seeing the social media post, participants completed three 7-point bipolar purchase intention measures ("Not at all likely - Very Likely," "Highly Improbable Highly Probable," "No chance at all - Very Good Chance"), then indicated how familiar they were with the Starbucks brand using a 5-pt bipolar brand familiarity measure, ("Not Familiar at all - Extremely Familiar;" Simonin and Ruth 1998), and the frequency with which they purchase Starbucks branded products using a 7-pt bipolar measure ("Not at all - Very often"). Next, they reported how cute they thought the social media post was using 7-point Likert scale measures (“Cute," "Adorable," "Endearing,” Nenkov and Scott 2014), and reported their mood using 7-point bipolar measures ("Bad - Good," "Sad Happy," "Negative - Positive," “Unpleasant - Pleasant;” Roehm and Roehm 2005). Finally, participants completed basic demographics questions (age, gender). See details from this study in Appendix C. 
Results

Purchase Intentions. The purchase intention scales were averaged to form a composite measure of purchase intention score $(\alpha=.97)$. A one-way ANOVA on the purchase intention score revealed a significant main effect of emoji $\left(M_{\mathrm{emoji}}=5.04, \mathrm{SD}=\right.$ $\left.1.95, M_{\text {no-emoji }}=4.00, \mathrm{SD}=2.05 ; F(1,92)=6.34, p=.014, d=.52\right)$, indicating when brands include emojis in their brand communications, they increase consumers' purchase intentions.

Brand Familiarity. A one-way ANOVA on the brand familiarity measure revealed a non-significant main effect of emoji $\left(\mathrm{M}_{\mathrm{emoji}}=4.39, \mathrm{SD}=.88, \mathrm{M}_{\text {no-emoji }}=4.19\right.$, $\mathrm{SD}=.97 ; F(1,92)=1.08, p=.302, d=.22)$, indicating that participants felt equally familiar with the Starbucks brand across conditions.

Purchase Frequency. A one-way ANOVA on the purchase frequency measure revealed a non-significant main effect of emoji $\left(\mathrm{M}_{\mathrm{emoji}}=3.50, \mathrm{SD}=1.88, \mathrm{M}_{\text {no-emoji }}=3.13\right.$, $\mathrm{SD}=1.57 ; F(1,92)=1.08, p=.302, d=.22)$, indicating that participants purchased Starbucks branded products with similar frequency across conditions.

Mood. The mood scales were averaged to form a composite measure of mood score $(\alpha=.92)$. A one-way ANOVA on the mood measure revealed a non-significant main effect of emoji $\left(\mathrm{M}_{\mathrm{emoji}}=5.59, \mathrm{SD}=1.55, \mathrm{M}_{\text {no-emoji }}=5.30, \mathrm{SD}=1.44 ; F(1,92)=\right.$ $.893, p=.347, d=.20)$, indicating that participants mood did not vary across conditions.

Cuteness of the Social Media Post. The cuteness scales were averaged to form a composite measure of cuteness score $(\alpha=.83)$. A one-way ANOVA on the cuteness measure revealed a significant main effect of emoji $\left(\mathrm{M}_{\mathrm{emoji}}=4.49, \mathrm{SD}=1.17, \mathrm{M}_{\text {no-emoji }}=\right.$ $3.65, \mathrm{SD}=1.43 ; F(1,92)=9.72, p=.002, d=.65)$, indicating that participants 
considered the artifact emoji post significantly cuter. However, these results were expected given that emojis are perceived as cute (Gn 2018). Thus, I use cuteness, mood, purchase frequency and brand familiarity as covariates in the next analysis to confirm that the effects of emojis on purchase intentions persist when statistically controlling for these variables.

Analysis using covariates. An analysis of variance with mood, cuteness of the social media post, brand familiarity and purchase frequency as covariates (ANCOVA) on the purchase intention score revealed a significant main effect of emoji $\left(M_{\mathrm{emoji}}=5.04, \mathrm{SD}\right.$ $\left.=1.95, M_{\text {no-emoji }}=4.00, \mathrm{SD}=2.05 ; F(1,92)=4.34, p=.040, d=.52\right)$, thus corroborating that results remain significant after statistically controlling for mood, cuteness of the social media post, brand familiarity and purchase frequency.

\section{Discussion.}

Study $1 \mathrm{~b}$ supports the proposition that artifact emojis in brand digital communications increase purchase intentions even when controlling for mood, cuteness, brand familiarity and purchase frequency. Finally, since in this study I replaced text (word "coffee" for a coffee emoji) and used only artifact emojis, I designed the following study using the combination of facial + artifact emojis supplementing (not replacing) text to examine yet another important measure in digital marketing: click through rates.

Click through rates are a metric used to measure the number of clicks on digital ads per impression (Richardson, Dominowska and Ragno 2007). It is an important metric of digital marketing performance as it quantifies how successful any particular digital ad has been in enticing customers to click and learn more about a product, brand or 
promotion. According to leading marketing firm Hubspot, the average CTR for a display ad is $0.35 \%$ and $1.91 \%$ for a search ad (Volovich 2020). Thus, any digital strategy to improve this metric is welcomed by marketing managers and decision makers. In the next study, I evaluate how (facial + artifact) emojis used within a social media post can help increase click through rates.

\section{Study 1c: Effects of (Facial + Artifact) Emojis on Click Through Rates}

The main objective of this study was to analyze the effects of using facial + artifact emojis on consumption consequences - particularly, click through rates (CTR). I achieved this by using a social media post ostensibly created by the Nike brand to analyze the effects of combined facial + artifact emojis in brands' online communications. Specifically, participants were asked to report their intention to click a post to learn more about a new collection the brand was launching after being shown a social media post with facial + artifact emojis compared to a post without emojis. Consistent with H1, I predicted a positive effect of facial + artifact emojis on click through rates.

Furthermore, in this study, I statistically controlled for mood, brand familiarity and purchase frequency to confirm the observed effects of emojis persist even when controlling for these potential confounding factors. Similar to the previous study, the significance of ruling out brand familiarity and purchase frequency was important given that I was using the Nike brand, for which participants may already have established attitudes and purchase patterns. Ruling out mood was important because the stimuli 
includes a happy facial emoji, which could lead to increased positive affect (Smith and Rose 2019) and thus, I needed to confirm that the observed effects were not due to an increase in mood.

Pretest

Participants and Design. Eighty participants were recruited from MTurk (66.3\% female; $M_{\text {age }}=35.9, \mathrm{SD}=12.84$ ) and completed a pretest in exchange for monetary compensation. A post-hoc power analysis was conducted using G*Power v3.1 (Faul, Erdfelder, Lang and Buchner 2007). Given the sample size, the achieved power to detect a medium effect of .25 at an alpha level .05 was 0.60 , indicating the sample size was adequate for this analysis.

Stimuli. I employed the emoji manipulation (facial + artifact emoji vs. no-emoji control) in a social media post ostensibly created by the Nike brand. See figure 4 for stimuli details.
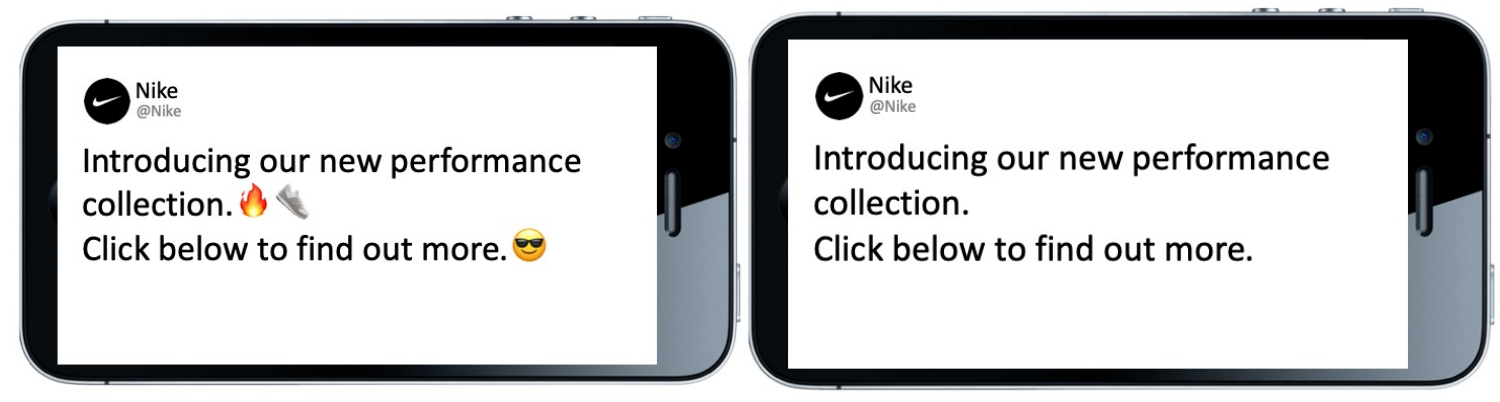

Figure 4. Stimuli, Study 1c 
Procedure. Participants were asked to rate one of two social media posts ostensibly created by the Nike brand and were prompted with the following: "Please carefully analyze the following post and answer the questions that follow, with your honest opinion and choices." First, participants in the emoji condition only completed measures to assess the intended meaning of the emojis used in the post. The items used were: "The emoji intends to graphically represent a cool face," "The emoji intends to graphically represent something hot," and "The emoji intends to graphically represent an athletic shoe" ( $1=$ "strongly disagree," and $7=$ "strongly agree"). In this condition, I also pretested the appropriate use of the emojis within the textual message by using the following three items, "The emojis used in this post fit what is said in the textual message," "The types of emoji used in this post are appropriate," "The emojis within the post are placed appropriately" $(1=$ "strongly disagree," and 7 = "strongly agree").

Participants across both conditions reported their attitudes toward the message using a 7-point semantic scale (“Unfavorable - Favorable," "Bad - Good," "Really Dislike - Really Like," "Negative - Positive"). Next, participants completed items used to assess how clearly they perceived to comprehend the message within the post: "The message in the advertisement you saw was:" ( $1=$ "not easy to understand," 7 = "very easy to understand"; and 1 = "not clear," 7 = "very clear"). Finally, all participants completed basic demographic questions (age, gender). 


\section{Pretest Results}

Meaning of Emojis. In the emoji condition, I compared the means with the midpoint to ensure all participants understood the meaning of each emoji as intended (Miller et al. 2016; Highfield and Leaver 2016): $\operatorname{cool}$ face $\left(\mathrm{M}_{\text {face }}=6.18, \mathrm{SD}=.781 ; t=\right.$ $21.67, p<.001)$, fire $\left(\mathrm{M}_{\text {fire }}=6.15, \mathrm{SD}=.662 ; t=25.31, p<.001\right)$, and athletic shoe $\left(\mathrm{M}_{\text {shoe }}=6.10, \mathrm{SD}=.982 ; t=16.75, p<.001\right)$, indicating that participants interpreted the emojis as intended in the social media post.

Appropriate use of Emojis. The measures used to assess if the emojis in the post were used appropriately and fit the narrative of the message were averaged to form a composite measure of fit score $(\alpha=.83)$ and compared against midpoint $\left(\mathrm{M}_{\mathrm{fit}}=5.38, \mathrm{SD}\right.$ $=1.12 ; t=10.65, p<.001)$, indicating that the emojis fit the social media message.

Perceived Message Comprehension. The measures used to assess perceived comprehension were averaged to form a composite measure of perceived message comprehension score $(\alpha=.89)$. As expected, results were non-significant on the perceived message comprehension score $\left(\mathrm{M}_{\mathrm{emoji}}=6.08, \mathrm{SD}=1.02, \mathrm{M}_{\text {no-emoji }}=5.56, \mathrm{SD}=\right.$ $1.54 ; F(1,79)=3.08, p=.083, d=.39)$, indicating that participants felt that the message was equally clear in both conditions

Attitudes toward the social media post. The measures used to assess attitudes toward the social media post were averaged to form a composite measure of attitude score $(\alpha=.95)$. Results from a one-way ANOVA on the attitudes index revealed no significant differences between conditions $\left(\mathrm{M}_{\mathrm{emoji}}=5.16, \mathrm{SD}=1.41, \mathrm{M}_{\mathrm{no}-\mathrm{emoji}}=4.77, \mathrm{SD}\right.$ $=1.50 ; F(1,79)=1.46, p=.230, d=.27)$, indicating that participants had equal attitudes toward the social media post in both conditions. 


\section{Pretest Discussion}

Results from this pretest indicate that the social media posts in both conditions are perceived to be equally clear, and that participants did not demonstrate different attitudes toward the social media post across conditions. Additionally, I was able to assert that emojis used in the emoji condition were appropriate and related to the textual message in the post. Finally, I also confirmed that participants interpreted the emojis as I intended to in the social media post.

\section{Method}

Participants and Design. In exchange for extra course credit, 89 undergraduate students $\left(57.3 \%\right.$ female; $\left.M_{\text {age }}=20.9, \mathrm{SD}=2.25\right)$ from a public university in the United States were randomly assigned to the facial + artifact emoji or control experimental condition to evaluate the influence of emojis on click through rates. A post-hoc power analysis was conducted using G*Power v3.1 (Faul, Erdfelder, Lang and Buchner 2007). Given the sample size, the achieved power to detect a medium effect of .50 at an alpha level .05 was 0.99 , indicating the sample size was adequate for this analysis.

Stimuli. I employed the emoji manipulation (facial + artifact emoji vs. no-emoji control) in a social media post ostensibly created by the Nike brand. See figure 4 for stimuli details.

Procedure. Upon entering the behavioral laboratory, participants took a seat and were given a survey that introduced the study and were prompted with the following cover story: "We are a marketing firm looking for your opinion to evaluate brands' social media posts. Today we are asking you to evaluate a preliminary post for the Nike brand, 
as it launches a new product collection." Participants were randomly assigned to either the facial + artifact emoji or control condition.

After seeing the social media post, participants completed two 7-point bipolar click through rates (CTR) measures ("Not at all likely - Very Likely," "Not at all likely Very Likely"), then indicated how familiar they were with the Nike brand using a 5-pt bipolar brand familiarity measure, ("Not Familiar at all - Extremely Familiar;" Simonin and Ruth 1998), and the frequency with which they purchase Nike branded products using a 7-pt bipolar measure ("Not at all - Very often"). Next, they reported their mood using 7-pt bipolar measures ("Bad - Good," "Sad - Happy," "Negative - Positive," "Unpleasant - Pleasant;" Roehm and Roehm 2005). Finally, participants completed basic demographics questions (age, gender). See details from this study in Appendix D.

\section{Results}

Click Through Rates. The CTR measures were averaged to form a composite measure of CTR score $(\alpha=.98)$. A one-way ANOVA on the CTR score revealed a significant main effect of emoji $\left(M_{\mathrm{emoji}}=3.98, \mathrm{SD}=1.71, M_{\mathrm{no}-\mathrm{emoji}}=2.93, \mathrm{SD}=1.83\right.$; $F(1,89)=7.71, p=.007, d=.59)$, indicating when brands use both artifact and facial emojis in digital messages, they increase the likelihood of CTR.

Brand Familiarity. A one-way ANOVA on the brand familiarity measure revealed a non-significant main effect of emoji $\left(\mathrm{M}_{\mathrm{emoji}}=4.77, \mathrm{SD}=.57, \mathrm{M}_{\mathrm{no-emoji}}=4.73\right.$, $\mathrm{SD}=.69 ; F(1,88)=.087, p=.769, d=.06)$, indicating that participants felt equally familiar with the Nike brand across conditions. 
Purchase Frequency. A one-way ANOVA on the purchase frequency measure revealed a non-significant main effect of emoji $\left(\mathrm{M}_{\mathrm{emoji}}=4.45, \mathrm{SD}=1.55, \mathrm{M}_{\mathrm{no}-\mathrm{emoji}}=4.40\right.$, $\mathrm{SD}=1.67 ; F(1,92)=.026, p=.873, d=.03)$, indicating that participants purchased Nike branded products with similar frequency across conditions.

Mood. The mood scales were averaged to form a composite measure of mood score $(\alpha=.88)$. A one-way ANOVA on the mood measure revealed a significant main effect of emoji $\left(\mathrm{M}_{\mathrm{emoji}}=5.93, \mathrm{SD}=1.04, \mathrm{M}_{\mathrm{no-emoji}}=5.11, \mathrm{SD}=1.47 ; F(1,87)=9.03, p=\right.$ $.003, d=.64$ ), indicating that participants' mood in the emoji condition was significantly more positive. While these results are significant, in the following analysis I statistically controlled for mood, in addition to brand familiarity and purchase frequency.

Analysis using covariates. An analysis of variance with mood, brand familiarity and purchase frequency as covariates (ANCOVA) on the click through rate score revealed a marginally significant main effect of emoji $\left(M_{\mathrm{emoji}}=3.98, \mathrm{SD}=1.73, M_{\text {no-emoji }}\right.$ $=2.93, \mathrm{SD}=1.83 ; F(1,87)=3.57, p=.06, d=.59)$, thus revealing that results are marginally significant after controlling for mood, brand familiarity and purchase frequency.

\section{Discussion}

Study 1c supports the proposition that using both artifact and facial emojis concurrently in brand digital communications influence positive consumption consequences - in this study, click through rates. Further findings also reveal that these effects persist (although marginally) even when controlling for mood, brand familiarity and purchase frequency. As with the previous study, ruling out these variables was 
important given that I used a known brand for which participants may have prior attitudes. Second, ruling out mood was important given that I used a (positive) facial emoji, which could have affected participants positive mood (Smith and Rose 2019). Finally, while studies 1a-1c establish the positive main effects of emojis on consumption, I designed study $1 \mathrm{~d}$ as a field study to observe the effects of emojis in actual consumption behavior involving monetary exchanges to provide further confirmation of these results. A summary of findings for studies $1 \mathrm{a}, 1 \mathrm{~b}$ and $1 \mathrm{c}$ can be seen in Table 4 .

\begin{tabular}{|c|c|c|c|c|c|c|c|}
\hline \multirow[b]{2}{*}{ Study and Condition } & \multicolumn{3}{|c|}{ Brand Attitude } & \multicolumn{2}{|c|}{ Purchase Intention } & \multicolumn{2}{|c|}{ Click Through Rates } \\
\hline & $\mathbf{N}$ & $\mathbf{M}$ & SD & $M$ & SD & $\mathbf{M}$ & SD \\
\hline \multicolumn{8}{|l|}{ Study 1a } \\
\hline Emoji & 40 & 5.81 & 1.16 & - & - & - & - \\
\hline No Emoji & 40 & 5.22 & 1.70 & _- & _- & _- & _- \\
\hline \multicolumn{8}{|l|}{ Study 1b } \\
\hline Emoji & 47 & _- & _ & $5.04^{*}$ & 1.95 & _ & _- \\
\hline No Emoji & 46 & _- & _- & 4.00 & 2.05 & _- & _- \\
\hline \multicolumn{8}{|l|}{ Study 1c } \\
\hline Emoji & 44 & - & _- & - & - & $3.98^{*}$ & 1.71 \\
\hline No Emoji & 45 & - & - & - & - & 2.93 & 1.83 \\
\hline
\end{tabular}

* Significantly greater than comparison cell at $p<.05$, indicating support of $\mathrm{H1}$.

Table 4. Summary of Findings, Studies 1a, 1b and 1c 


\section{Study 1d. Field Study - Carryover Effects of (Facial + Artifact) Emojis on Actual Purchase}

While the previous studies present initial evidence of the influence of emojis on consumption consequences, I considered that a field study involving actual purchase would emphasize the effects of emojis beyond self-reported consumption and purchase intentions. Thus, the main objective of this study was to lend further empirical support that emojis lead to more positive consumption consequences (in support of H1) in a realistic setting that evaluates actual purchases and monetary transactions. I achieved this by using a social media post by a fictitious brand of personal care, CarePlus to analyze the effects of facial + artifact emojis in brands' online communications. Specifically, participants were given the opportunity to purchase a dental kit after being shown a social media post with facial + artifact emojis compared to a post without emojis. The significance of using a fictitious brand is to demonstrate that the effect of (facial + artifact) emojis on purchase behavior persists with unknown brands as well, and in the presence of monetary tradeoffs.

Finally, although the observed transactions were in a non-digital context, both the stimuli and cover story relate to digital experiences in order to support the scope of this dissertation, which is the study of emojis in digital settings. It is important to note that oftentimes consumers are presented with digital marketing advertising that lead to nondigital purchases (i.e. retail store, restaurant). For instance, brands use geolocation tracking data gathered through consumers' mobile devices to display targeted ads that are 
meant to motivate retail purchases. This field study attempts to replicate this type of sales and marketing contexts to evaluate the effects of emojis on purchase behavior.

Pretest

Participants and Design. In exchange for extra course credit, 42 students $(68.3 \%$ female; $M_{\text {age }}=26.7, \mathrm{SD}=29.6$ ) from a public university in the United States completed a within-subjects survey that was designed to evaluate which product type to use in the main study. A post-hoc power analysis was conducted using G*Power v3.1 (Faul, Erdfelder, Lang and Buchner 2007). Given the sample size, the achieved power to detect a medium effect of .50 at an alpha level .05 was 0.94 , indicating the sample size was adequate for this analysis.

Procedure. Participants were asked to take part in a survey that read: "In this university we strive to ensure that our students have access to basic products on campus, such as food, drinks, and school supplies. However, some students have expressed the need to have personal care products available for sale on campus. For this reason, please indicate the extent to which you agree that it is important for the following products to be available for sale on campus." After reading this, they were shown a list of 8 products that included hand sanitizer, hand lotion, insect repellent, toothbrush and toothpaste (dental) kit, individual toothbrush, mouthwash, tissue packs, and lip balm, which they had to rate using a 7-point Likert scale measure $(1=$ Strongly Disagree $-7=$ Strongly Agree).

Next, participants again saw the above list of products and were asked to choose one product after reading the following prompt: "From the previous list, if you had to 
choose only one item to be available for sale on campus, which one would it be? Please select the product you believe is most important to be available for sale on campus." Finally, participants were asked basic demographic questions (age, gender).

Pretest Results

Individual Product Importance. A t-test was used to evaluate how important participants felt that the university sells each of the listed products: hand sanitizer ( $M=$ $6.27, \mathrm{SD}=1.25)$, hand lotion $(M=5.46, \mathrm{SD}=1.23)$, insect repellent $(M=4.98, \mathrm{SD}=$ 1.39), dental kit $(M=6.29, \mathrm{SD}=1.25)$, individual toothbrush $(M=5.88, \mathrm{SD}=1.44)$, mouthwash $(M=6.02, \mathrm{SD}=1.07)$, tissue packs $(M=6.10, \mathrm{SD}=1.06)$, and lip balm $(M=$ $5.56, \mathrm{SD}=1.38)$

Frequencies. To evaluate product choice preference, I checked the frequency with which each of the products were chosen: hand sanitizer (26.2\%), hand lotion (0\%), insect repellent (0\%), dental kit (38.6\%), individual toothbrush (0\%), mouthwash (4.5\%), tissue packs (18.2\%), and lip balm (9.1\%). Given these frequencies, I ran a paired samples t-test to assess the top-rated products, specifically comparing the dental kit, hand sanitizer, mouthwash and tissue packs. Results indicated significant differences between dental kit and mouthwash $(t=1.72, p<.001)$, non-significant differences between dental kit and hand sanitizer $(t=-.103, p=.12)$, and non-significant differences between dental kit and tissue packs $(t=.88, p=.13)$. 


\section{Pretest Discussion}

Findings from this pretest combined participants' product choice and ratings of each product to reveal that the two highest rated options were dental kit $(M=6.29, \mathrm{SD}=$ $1.25)$ and hand sanitizer $(M=6.27, \mathrm{SD}=1.25)$. However, given the multiple, easily accessible and free hand sanitizer stations across the university campus, the dental kit was the ideal product to use in the main study.

\section{Main Study}

Participants and Design. In exchange for one dollar, 156 students (56.4\% female; $\left.M_{\mathrm{age}}=21.94, \mathrm{SD}=5.62\right)$ from a public university in the United States were randomly assigned to the emoji or no emoji control experimental condition to evaluate the influence of emojis on purchase behavior. A post-hoc power analysis was conducted using G*Power v3.1 (Faul, Erdfelder, Lang and Buchner 2007). Given the sample size, the achieved power to detect a medium effect of .50 at an alpha level .05 was 0.99 , indicating the sample size was adequate for this analysis.

Stimuli. I employed the emoji manipulation (facial + artifact emoji vs. no-emoji control) in a social media post by the CarePlus brand. See figure 5 for stimuli details.

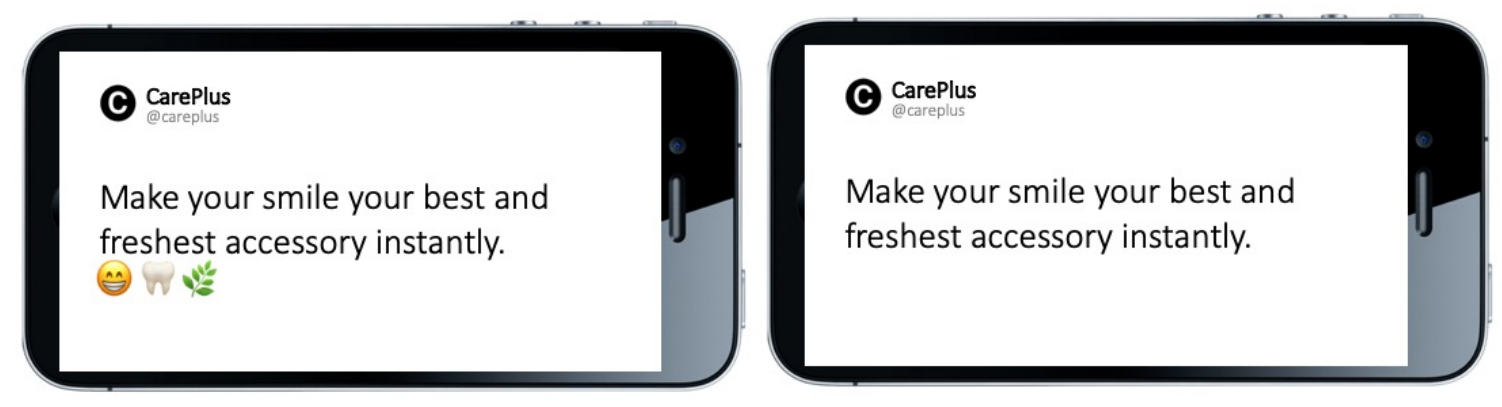

Figure 5. Stimuli, Study 1d 
Procedure. Two research assistants stood in a highly trafficked area of the university distributing surveys on a clipboard with pencil, in exchange for one dollar (given in four quarters) to be granted upon completing the study. Participants were told that a new brand of personal hygiene products, CarePlus would be selling a toothbrush and toothpaste (dental) kit within the university grounds and wanted to know their opinion of a social media post to be used to promote this product, and were prompted with: "We are evaluating social media messages for a new brand of personal care and hygiene products CarePlus, which will be sold in our community. This brand is preparing a social media campaign that includes multiple posts like the one below to launch their newest product, a dental kit (toothbrush and toothpaste) ideal for on the go. We would like you to evaluate one of the brand's social media posts to promote their new dental kit. Please read the following message the way you normally read social media posts and answer the questions that follow."

Next, participants saw a social media post, which either included (facial + artifact) emojis or not include emojis, and completed five 7-point bipolar attitudes toward the social media post measures ("Bad - Good," "Unfavorable - Favorable," "Don't like it at all - Like it very much," "Not at all enjoyable - Very much enjoyable," "Very low quality - Very high quality”), and indicated their quality expectations of the product using a 7-point Likert measure ("To what extent do you agree that CarePlus dental kit will be a high-quality product?" with anchors $1=$ "Strongly Disagree" - 7 = "Strongly Agree"). I used the attitude and expected quality measures as part of the cover story and did not expect these to reveal any significant differences. Participants then reported their mood using 7-point bipolar measures ("Bad - Good," "Sad - Happy," "Negative - 
Positive," "Unpleasant - Pleasant;" Roehm and Roehm 2005). I planned to used mood as a covariate in the analysis given that the social media post included a happy face emoji.

After evaluating the social media post, participants were given the option to purchase one, two or no samples of the dental kit for $\$ 0.50$ cents each. In a designated space in the survey, participants indicated whether they wanted to purchase 1,2 or no sample kits. Finally, participants reported basic demographics (age, gender). See study details in Appendix E.

Once completed the survey, the research assistants directed the students to a table where they could purchase the dental kits. The dental kits were packaged individually and had no emojis in their packaging. They were sold throughout different times of day (morning and afternoon), and the research assistants took turns in distributing either survey depending on condition, so that the order and time in which they were distributed did not affect sales of the product. See pictures of the dental kit in Appendix F.

Based on their choice, participants were either given 4 quarters (\$1) if they decided not to purchase any dental kits at all and keep their money; 2 quarters $(\$ 0.50)$ if they decided to purchase one dental kit and retain $\$ 0.50$, or no quarters at all ( $\$ 0$ ) if they decided to purchase two dental kits and forego their study-earned money on this purchase. The amount purchased and dollar amount spent constituted the main dependent variables in this study.

Results

Attitudes toward the Social Media Post. The attitude measures were averaged to form a composite measure of attitude score $(\alpha=.93)$. As expected, an ANOVA on the 
attitude score revealed non-significant effects of emojis on attitudes toward the social media post $\left(M_{\mathrm{emoji}}=5.21, \mathrm{SD}=1.31 ; M_{\mathrm{no}-\mathrm{emoji}}=5.33, \mathrm{SD}=1.27 ; F(1,155)=.297, p=\right.$ $.587, d=.09)$. Results remained non-significant when statistically controlling for mood $\left(M_{\mathrm{emoji}}=5.21, \mathrm{SD}=1.31 ; M_{\mathrm{no}-\mathrm{emoji}}=5.33, \mathrm{SD}=1.27 ; F(1,155)=1.24, p=.267, d=\right.$ .09), indicating that attitudes toward the social media post did not differ across conditions.

Product Quality Expectations. As predicted, an ANOVA on the expected quality measure revealed non-significant effects of emojis on expected product quality $\left(M_{\mathrm{emoji}}=\right.$ $\left.5.14, \mathrm{SD}=1.36 ; M_{\text {no-emoji }}=5.15, \mathrm{SD}=1.25 ; F(1,155)=.004, p=.951, d=.01\right)$. Results remained non-significant when statistically controlling for $\operatorname{mood}\left(M_{\mathrm{emoji}}=5.30, \mathrm{SD}=\right.$ $\left.1.44 ; M_{\text {no-emoji }}=5.26, \mathrm{SD}=1.19 ; F(1,155)=.031, p=.860, d=.01\right)$, indicating that expectations of the product quality did not differ across conditions.

Mood. The mood measures were averaged to form a composite measure of mood score $(\alpha=.92)$. A one-way ANOVA on the mood measure revealed non-significant effects of emojis on $\operatorname{mood}\left(M_{\mathrm{emoji}}=6.13, \mathrm{SD}=.95 ; M_{\text {no-emoji }}=5.81, \mathrm{SD}=1.32 ; F(1,155)\right.$ $=3.02, p=.84, d=.28)$. Further, among those who made a purchase, results from a oneway ANOVA on the mood measure also revealed non-significant effects of emojis on $\operatorname{mood}\left(M_{\mathrm{emoji}}=6.18, \mathrm{SD}=.88 ; M_{\text {no-emoji }}=6.22, \mathrm{SD}=1.16 ; F(1,52)=.023, p=.88, d=\right.$ $.04)$, indicating that mood did not differ across conditions or even for those participants who made a purchase.

Dollar Amount Spent. A one-way ANOVA on dollar amount spent revealed a significant effect of emoji $\left(M_{\mathrm{emoji}}=.72, \mathrm{SD}=.86 ; M_{\text {no-emoji }}=.31, \mathrm{SD}=.61 ; F(1,155)=\right.$ $11.70, p=.001, d=.55)$. Results remained significant when statistically controlling for 
$\operatorname{mood}\left(M_{\mathrm{emoji}}=.72, \mathrm{SD}=.86 ; M_{\text {no-emoji }}=.31, \mathrm{SD}=.61 ; F(1,155)=10.69, p=.001, d=\right.$ $.55)$, thus indicating that participants in the (facial + artifact) emoji condition spent significantly more money purchasing dental kits compared to participants in the control condition.

Purchase Quantity. Regarding purchase quantity, I expected three possible actions: participants might purchase (1) no sample kits and keep \$1, (2) one sample kit and keep $\$ .50$, (3) two sample kits and keep $\$ 0$. A chi-square analysis revealed that participants in the emoji condition significantly purchased more dental kits $\left(\chi^{2}=11.29, p\right.$ $=.004 ; 17.9 \%$ purchased one kit, and $26.9 \%$ purchased two kits), compared to the noemoji condition (15.4\% purchased one kit; and 7.7\% purchased two kits).

Among those who made a purchase, a chi-square analysis revealed a similar pattern of results, such that participants in the emoji condition purchased more dental kits $\left(\chi^{2}=3.38, p=.066 ; 40 \%\right.$ purchased one kit; and $60 \%$ purchased two kits), compared to those in the no-emoji condition $(66.7 \%$ purchased one kit; and $33.3 \%$ purchased two kits).

\section{Discussion}

Results from this study demonstrate that the use of (facial + artifact) emojis in brand digital communications lead to increased purchases. This is of special importance as results confirm that the influence of emojis on consumption consequences surpasses intentions and actually influences greater purchases in the marketplace. While these purchases were observed in non-digital contexts, participants were prompted with a cover story and stimuli that pertain to digital settings, which is representative of actual 
marketplace transactions. Oftentimes consumers are targeted with digital messages (i.e. app push notifications, mobile text messages and social media ads) that attempt to persuade them to purchase products or services in non-digital, retail settings. As previously described, these targeted digital ads result from geolocation mobile tracking that is meant for consumers to spend more money in retail versus e-commerce. Thus, this field study simulates actual marketplace transactions after exposure to digital ads.

In sum, this first set of studies confirm the predicted main effects of both facial and artifact emojis on consumption behavior (H1). Prior related research on emoji marketing had been limited to evaluating the effects of facial emojis only. Thus, the present work contributes to those findings by evaluating the effects of all types of emojis (facial and artifacts) on several consumption consequences including brand attitudes, click through rates, purchase intentions and purchase behavior. Furthermore, I use nonbranded, established and fictitious brands, across multiple product categories (apparel, food and personal care), thereby contributing to the generalizability of these findings. Subsequently, I examine the underlying process of the effects of emojis on consumption consequences through a serial mediation of brand anthropomorphism and self-brand connections, evaluated through three empirical studies presented in the next section.

\section{Study 2: Underlying Process}

In this second set of three studies, I aimed to empirically examine the serial mediation model of brand anthropomorphism and self-brand connections to further clarify the influence of emojis on the consumer-brand relationship. Specifically, these 
studies were designed to answer the second research question concerning the underlying mechanism of the effects of emojis on consumption consequences. In order to answer this question and on the basis of my proposition that emojis will positively influence selfbrand connections (H2) and brand anthropomorphism (H3a) in digital settings, I designed three studies to evaluate these predictions. Further, across these three studies I used stimuli that included both fictitious or established brands, as well as facial and / or artifact emojis compared against control conditions (text only).

In study 2a, I used (facial + artifact) emojis to evaluate their effects on self-brand connections using a social media post ostensibly created by the Adidas brand. Study $2 \mathrm{~b}$ evaluates the mediating effect of anthropomorphism on the effects of (facial + artifact) emojis on self-brand connections by using a Starbucks social media post. Study 1c was designed to evaluate the serial mediation model of anthropomorphism and self-brand connections ( $\mathrm{H} 3 \mathrm{~b}$ ) by using a social media post created by a fictitious brand of sunscreen, Allie. In this study, I also observe the effects of emojis on consumption consequences including brand attitudes, click through rates, word of mouth and purchase intentions.

In sum, the use of fictitious or established brands to evaluate the mediation role of brand anthropomorphism and self-brand connection help clarify the process through which emojis positively impact consumption outcomes. As with previous studies, I was able to determine that these effects persist even when statistically controlling for mood, time spent on social media, perceptions of cuteness of the brand and when applicable, brand familiarity and purchase frequency of brand or product type. 


\section{Study 2a: (Facial + Artifact) Emojis on Self-Brand Connections}

The main objective of this study was to present initial evidence of the influence of facial + artifact emojis on self-brand connections. I achieved this by using a social media post ostensibly created by the Adidas brand to analyze the effects of facial + artifact emojis in brands' online communications. Specifically, participants were asked to report self-brand connections to the Adidas brand after being shown a social media post with facial + artifact emojis compared to a post without emojis. Consistent with H2, I predicted a positive effect of artifact emojis on self-brand connections.

\section{Pretest.}

Participants and Design. Forty-nine undergraduate students (45.5\% female; $M_{\text {age }}$ $=21.3, \mathrm{SD}=2.15)$ from a public university in the United States completed this pretest in exchange for extra course credit. A post-hoc power analysis was conducted using G*Power v3.1 (Faul, Erdfelder, Lang and Buchner 2007). Given the sample size, the achieved power to detect a medium effect of .25 at an alpha level .05 was 0.96 , indicating the sample size was adequate for this analysis.

Stimuli. I employed the emoji manipulation (facial + artifact emoji vs. no-emoji control) in a social media post ostensibly created by the Adidas brand. Since this study ran during the FIFA World Cup 2018, I used message and emojis that closely related to this event. The Adidas brand has traditionally been a main partner of this event by supplying the official soccer ball for all FIFA World Cup matches (fifa.com). See figure 6 for stimuli details. 
Figure 6. Stimuli, Study 2a

Procedure. Participants were asked to rate one of two social media posts ostensibly created by the Adidas brand and were prompted with the following: "Please carefully analyze the following post and answer the questions that follow, with your honest opinion and choices." First, participants in the facial + artifact emoji condition completed measures to assess the intended meaning of the emojis used in the post. The items used were: "The $\odot$ emoji intends to graphically represent a soccer ball," "The emoji intends to graphically represent the planet earth," "The emoji intends to graphically represent a trophy," "The emoji intends to graphically represent a 'wink' face" $(1$ = "strongly disagree," and 7 = "strongly agree"). In this condition, I also pretested the appropriate use of the emojis within the textual message by using the following three items, "The emojis used in this post fit what is said in the textual message," "The types of emoji used in this post are appropriate," "The emojis within the post are placed appropriately" ( $1=$ "strongly disagree," and 7 = "strongly agree").

Participants across both conditions completed items used to assess how clear they perceived the message to be: "The message in the advertisement you saw was:" ( 1 = "not 
easy to understand," 7 = "very easy to understand;" and 1 = "not clear," 7 = "very clear.") Finally, all participants completed basic demographic questions (age, gender).

\section{Pretest Results}

Meaning of Emojis. In the facial + artifact emoji condition, I compared the means with the midpoint to ensure all participants understood the meaning of each emoji as intended (Miller et al. 2016; Highfield and Leaver 2016): wink face $\left(\mathrm{M}_{\text {wink }}=5.92, \mathrm{SD}=\right.$ $1.59 ; t=7.47, p<.001)$, trophy $\left(\mathrm{M}_{\text {trophy }}=6.67, \mathrm{SD}=.565 ; t=27.47, p<.001\right)$, planet earth $\left(\mathrm{M}_{\text {earth }}=6.38, \mathrm{SD}=.770 ; t=18.30, p<.001\right)$, soccer ball $\left(\mathrm{M}_{\mathrm{ball}}=6.67, \mathrm{SD}=.482 ; t\right.$ $=32.22, p<.001$ ), indicating that participants interpreted the emojis as intended in the social media post.

Appropriate use of Emojis. The measures used to assess if the emojis in the post were used appropriately and fit the narrative of the message were averaged to form a composite measure of fit score $(\alpha=.76)$ and compared against midpoint $\left(\mathrm{M}_{\mathrm{fit}}=5.26\right.$, SD $=1.12 ; t=7.68, p<.001)$, indicating that all emojis fit with the social media message.

Perceived Message Comprehension. The measures used to assess perceived comprehension were averaged to form a composite measure of perceived message comprehension score $(\alpha=.86)$. As expected, results from a one-way ANOVA on the perceived message comprehension score were non-significant $\left(\mathrm{M}_{\mathrm{emoji}}=5.59, \mathrm{SD}=1.42\right.$, $\left.\mathrm{M}_{\text {no-emoji }}=4.85, \mathrm{SD}=1.34 ; F(1,44)=3.27, p=.08, d=.54\right)$, indicating that participants felt that the message was equally clear in both conditions 


\section{Pretest Discussion}

Results from this pretest indicate that the social media posts in both conditions are perceived to be equally clear. Additionally, I was able to assert that the facial and artifact emojis used in the emoji condition were appropriate and related to the textual message in the post. Finally, I also confirmed that participants interpreted the emojis as I intended to in the social media post.

\section{Main Study}

Participants and Design. In exchange for course credit, 125 undergraduate students $\left(46.3 \%\right.$ female; $\left.M_{\text {age }}=22.2, \mathrm{SD}=4.55\right)$ from a public university in the United States were randomly assigned to either the facial + artifact emoji or control condition to evaluate the effects of emojis on self-brand connections. A post-hoc power analysis was conducted using G*Power v3.1 (Faul, Erdfelder, Lang and Buchner 2007). Given the sample size, the achieved power to detect a medium effect of .25 at an alpha level .05 was 0.79 , indicating the sample size was adequate for this analysis. All student responses were used in this analysis.

Stimuli. I employed the emoji manipulation (facial + artifact emoji vs. no-emoji control) in a social media post ostensibly created by the Adidas brand that included facial + artifact emojis or did not include artifact emojis at all. See figure 6 for stimuli details.

Procedure. Participants were given a survey that introduced the study and were prompted with the following cover story: "We are looking for your opinion to evaluate brands' social media posts. Today we are asking you to evaluate a preliminary social media post for the Adidas brand, which is one of the sponsor brands for the FIFA World 
Cup 2018." Participants were randomly assigned to either the facial + artifact emoji or control condition.

After seeing the social media post, participants completed six 7-point Likert selfbrand connection measures: ("I feel Adidas can help reflect who I am," "This post helps me identify with the Adidas brand," "This post helps me connect with the Adidas brand," "This post helps me feel that I can create an emotional bond with Adidas," "I feel I can use this brand to communicate who I am," "This post helps me feel that I can use Adidas to communicate the type of person I want to be," with anchors 1 = "Strongly Disagree" 7 = "Strongly Agree;" Escalas and Bettman 2003). Next, participants completed perceived message comprehension checks ("The message in the advertisement you saw was:" 1 = "not easy to understand," 7 = "very easy to understand;" and 1 = "not clear," 7 $=$ "very clear"). Finally, participants completed basic demographic questions (age, gender). Details of this study can be found in Appendix G.

Results

Self-Brand Connections. The self-brand connections scales were averaged to form a composite measure of self-brand connection score $(\alpha=.91)$. A one-way ANOVA on the self-brand connection score revealed a significant main effect of emojis $(F(1,124)=$ 4.08, $p=.046, d=.36$ ): participants in the emoji condition reported higher self-brand connection to the Adidas brand $\left(\mathrm{M}_{\mathrm{emoji}}=4.31, \mathrm{SD}=1.34\right)$ compared to participants in the no emoji condition, who reported lower connections to the Adidas brand $\left(\mathrm{M}_{\mathrm{no}-\mathrm{emoji}}=3.83\right.$, $\mathrm{SD}=1.31)$. These results suggest that emojis have a positive effect on self-brand connections, and thus can enhance connections between consumer and brand. 
Perceived Message Comprehension. As with the pretest, to confirm that participants perceived to comprehend the message in the social media post across both conditions, I averaged the 2-item perceived comprehension scales to form a composite measure of perceived comprehension score $(\alpha=.90)$. As intended, results from a oneway ANOVA on the perceived message comprehension score indicated that participants felt that the message was equally clear in both conditions $\left(\mathrm{M}_{\mathrm{emoji}}=5.63, \mathrm{SD}=1.64, \mathrm{SE}=\right.$ $\left..21 ; \mathrm{M}_{\mathrm{no-emoji}}=5.28, \mathrm{SD}=1.51, \mathrm{SE}=.19 ; F(1,123)=1.57, p=.213, d=.23\right)$.

\section{Discussion}

Results from this analysis provide support for the main hypothesis that emojis in brand communications help enhance self-brand connections. However, one may argue that brand familiarity and purchase frequency of Adidas branded products could influence the observed effects. Moreover, given that the facial emoji employed was a smiley face (positive affect), one could argue that mood also could be a potential confounding factor. Thus, I address these concerns in the next studies by statistically controlling for mood, brand familiarity and purchase frequency. Furthermore, in the next study I also evaluate the effects of emojis on brand anthropomorphism.

\section{Study 2b: (Facial + Artifact) Emojis on Anthropomorphism and Self-Brand}

\section{Connections}

The main objective of this study was to ascertain whether consumers feel more connected with brands that include emojis in their textual online communications and 
examine brand anthropomorphism as mediator of these effects. I achieved this by using a social media post from the Starbucks brand to analyze the effects of facial + artifact emojis in brands' online communications. Specifically, participants were asked to report self-brand connection and perceptions of brand anthropomorphism after being shown a social media post with facial + artifact emojis compared to a post without emojis. Consistent with my hypotheses, I predicted a positive effect of facial + artifact emojis on self-brand connections (H2) and on brand anthropomorphism (H3a).

Additionally, in this study, I included mood, brand familiarity and purchase frequency as covariates to confirm the observed effects of emojis on self-brand connections persist even when statistically controlling for these potential confounding factors. It was important to control for brand familiarity and purchase frequency given that I was using the Starbucks brand, for which participants may already have established attitudes and purchase patterns. Ruling out mood was important because the stimuli includes a happy facial emoji, which could lead to increased positive affect (Smith and Rose 2019).

\section{Pretest}

Participants and Design. 80 participants were recruited from MTurk (62.5\% female; $\left.M_{\text {age }}=34.7, \mathrm{SD}=10.35\right)$ and completed a pretest in exchange for monetary compensation. A post-hoc power analysis was conducted using G*Power v3.1 (Faul, Erdfelder, Lang and Buchner 2007). Given the sample size, the achieved power to detect a medium effect of .25 at an alpha level .05 was 0.99 , indicating the sample size was adequate for this analysis. 
Stimuli. I employed the emoji manipulation (facial + artifact emoji vs. no-emoji control) in a social media post ostensibly created by the Starbucks brand. Importantly, in this study I replaced text (word "coffee" for a coffee emoji) and used facial emojis to supplement text. See figure 7 for stimuli details.
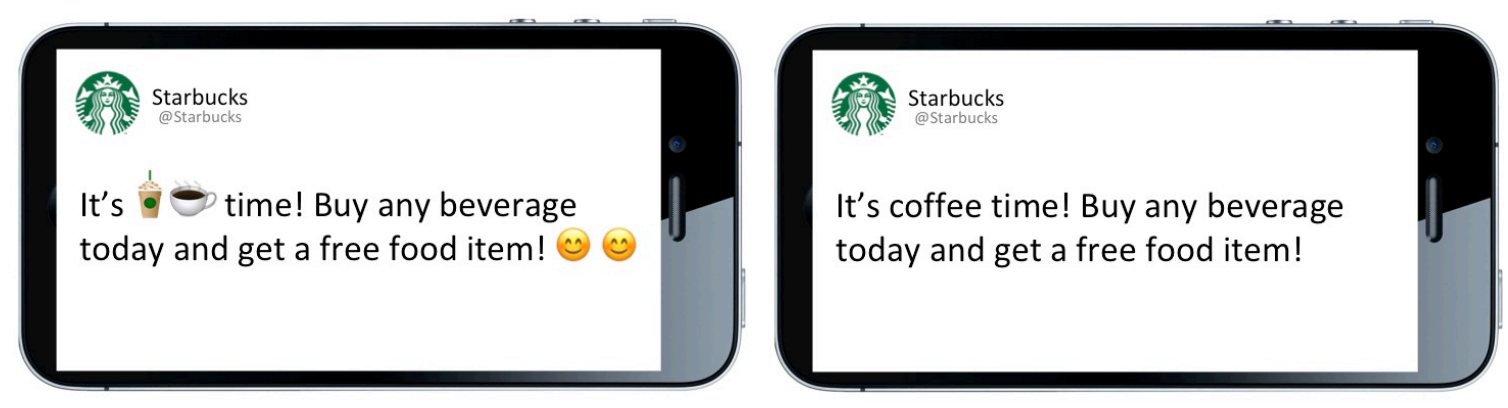

Figure 7. Stimuli, Study 2b

Procedure. Participants were asked to rate one of two social media posts ostensibly created by the Starbucks brand and were prompted with the following: "Please carefully analyze the following post and answer the questions that follow, with your honest opinion and choices." First, participants in the facial + artifact emoji condition completed measures to assess the intended meaning of the emojis used in the post. The items used were: “The emoji intends to graphically represent a smiley face," "The emoji intends to graphically represent a hot coffee" ( 1 = "strongly disagree," and $7=$ "strongly agree"). In this condition, I also pretested the appropriate use of the emojis within the textual message by using the following three items, "The emojis used in this post fit what is said in the textual message," "The types of emoji used in this post are appropriate," "The 
emojis within the post are placed appropriately" $(1=$ "strongly disagree," and $7=$ "strongly agree").

Participants across both conditions reported their attitudes toward the message using a 7-point semantic scale ("Unfavorable - Favorable," "Bad - Good," "Really Dislike - Really Like," "Negative - Positive"). Next, participants completed items used to assess how clearly they perceived to comprehend the message within the post: "The message in the advertisement you saw was:" ( 1 = "not easy to understand," 7 = "very easy to understand"; and 1 = "not clear," 7 = "very clear"). Then, participants completed four measures to assess how informative they perceived the message to be: ("Please indicate the extent to which you agree that the following words describe the post you just saw: "Informative," "Useful," "Understandable," "Sufficient," with anchors 1 = "strongly disagree," and 7 = “strongly agree," Edwards, Li, and Lee 2002). Finally, all participants completed basic demographic questions (age, gender).

\section{Pretest Results}

Meaning of Emojis. In the emoji condition, I compared the means with the midpoint to ensure all participants understood the meaning of each emoji as intended (Miller et al. 2016; Highfield and Leaver 2016): smiley face $\left(\mathrm{M}_{\text {smiley }}=6.35, \mathrm{SD}=1.12 ; t\right.$ $=16.06, p<.001)$, iced coffee $\left(\mathrm{M}_{\mathrm{iced}}=5.48, \mathrm{SD}=1.34 ; t=9.33, p<.001\right)$, hot coffee $\left(\mathrm{M}_{\text {coffee }}=5.90, \mathrm{SD}=1.17 ; t=12.95, p<.001\right)$, indicating that participants interpreted the emojis as intended in the social media post.

Appropriate use of Emojis. The measures used to assess if the emojis in the post were used appropriately and fit the narrative of the message were averaged to form a 
composite measure of fit score $(\alpha=.87)$ and compared against midpoint $\left(\mathrm{M}_{\mathrm{fit}}=5.96, \mathrm{SD}\right.$ $=1.00 ; t=15.65, p<.001)$, indicating that the emojis fit the social media message.

Perceived Message Comprehension. The measures used to assess perceived comprehension were averaged to form a composite measure of perceived message comprehension score $(\alpha=.92)$. As expected, results were non-significant on the perceived message comprehension index $\left(\mathrm{M}_{\mathrm{emoji}}=6.41, \mathrm{SD}=.91, \mathrm{M}_{\text {no-emoji }}=6.44, \mathrm{SD}=\right.$ $1.03 ; F(1,79)=.013, p=.909, d=.03)$, indicating that participants felt that the message was equally clear in both conditions

Perceived Ad Informativeness. Similarly, measures used to assess how informative consumers perceived the message to be were averaged to form a composite measure of ad informativeness score $(\alpha=.80)$. Results were non-significant $\left(\mathrm{M}_{\mathrm{emoji}}=\right.$ $\left.5.86, \mathrm{SD}=.85, \mathrm{M}_{\mathrm{no}-\mathrm{emoji}}=5.92, \mathrm{SD}=.92 ; F(1,79)=.081, p=.777, d=.06\right)$, indicating that participants felt that the message was equally informative in both conditions.

Attitudes toward the social media post. The measures used to assess attitudes toward the social media post were averaged to form a composite measure of attitude score $(\alpha=.95)$. Results from a one-way ANOVA on the attitudes index revealed no significant differences between conditions $\left(\mathrm{M}_{\mathrm{emoji}}=5.91, \mathrm{SD}=1.15, \mathrm{M}_{\text {no-emoji }}=6.13, \mathrm{SD}\right.$ $=1.10 ; F(1,79)=.758, p=.387, d=.20)$, indicating that participants had equal attitudes toward the social media post in both conditions.

Pretest Results.

Results from this pretest indicate that the social media posts in both conditions are perceived to be equally informative and clear, and that participants did not demonstrate 
different attitudes toward the social media post in both conditions. Further, I was able to assert that emojis used in the emoji condition were appropriate and related to the textual message in the post. Finally, I also confirmed that participants interpreted the emojis as I intended to in the social media post.

\section{Main Study}

Participants and Design. In exchange for monetary compensation, 140 Amazon MTurk workers $\left(62.9 \%\right.$ female; $\left.M_{a g e}=36.13, \mathrm{SD}=11.98\right)$ participated in a single factor, two-level (facial + artifact emoji versus control) between-subjects factorial design to evaluate the influence of emojis on self-brand connection and the mediating role of anthropomorphism. A post-hoc power analysis was conducted using G*Power v3.1 (Faul, Erdfelder, Lang and Buchner 2007). Given the sample size, the achieved power to detect a medium effect of .25 at an alpha level .05 was 0.84 , indicating the sample size was adequate for this analysis.

Stimuli. I employed the emoji manipulation (facial + artifact emoji vs. no-emoji control) in a social media post ostensibly created by the Starbucks brand. Importantly, in this study I replaced text (word "coffee" for a coffee emoji) and used facial emojis to supplement text. All elements within the social media post, including text, fonts and element sizes, were kept constant. See figure 7 for stimuli details.

Procedure. Participants were asked to take part in a brand communications study and were prompted with the following cover story: "We are looking for your opinion to evaluate brands' social media posts. Today we are asking you to evaluate a preliminary post for the Starbucks brand, as they communicate a new promotion via social media." 
After seeing the social media post, participants completed manipulation checks to evaluate perceived message comprehension using the same items as in the pretest. Next, participants completed self-brand connections measures (Escalas and Bettman 2003) using items: "I feel Starbucks can help reflect who I am," "This post helps me identify with this brand," "This post helps me connect with this brand," "This post helps me feel that I can create an emotional bond with Starbucks," "I feel I can use this brand to communicate who I am," "This post helps me feel that I can use Starbucks to communicate the type of person I want to be," $(1=$ "strongly disagree," and 7 = "strongly agree"). Then, participants completed brand anthropomorphism measures (Epley et al. 2007; Aggarwal and McGill, 2012) using items: "This post makes me feel Starbucks has positive intentions," “This post makes me feel Starbucks is human like," "This post makes me feel Starbucks is like a person," (1 = "strongly disagree," and 7 = "strongly agree").

Participants then indicated how familiar they were with the Starbucks brand (Simonin and Ruth 1998), by answering: "Please indicate how familiar you are with the Starbucks brand," with anchors $1=$ Not familiar at all; $7=$ Extremely familiar and reported purchase frequency of the Starbucks brand on a single 7-point bipolar measure by answering "How often do you buy Starbucks branded coffee / food products?” with anchors $1=$ Not at all, and $5=$ Very often.

Next, participants indicated their mood (Roehm and Roehm 2005) on four 7-point bipolar measures ("Bad - Good," "Unpleasant - Pleasant," "Negative - Positive," "Sad Happy”) and reported the time they spend in social media per day (Ellison et al. 2007) by selecting one of the following options: "Less than 10 minutes," "10-30 minutes," "31-60 
minutes," "1-3 hours," "More than 3 hours". Finally, participants completed basic demographics (age, gender). Details from this study can be found in Appendix H.

Results.

Perceived Message Comprehension. As with the pretest, to confirm that participants perceived to understand the message in the social media post across both conditions, I averaged the 2-item perceived message comprehension scales to form a composite measure of perceived message comprehension score $(\alpha=.81)$. Results from a one-way ANOVA on the perceived message comprehension index indicated no significant differences between the social media posts in terms of clarity $\left(\mathrm{M}_{\mathrm{emoji}}=6.15\right.$, $\left.\mathrm{SD}=1.03, \mathrm{M}_{\mathrm{no}-\mathrm{emoji}}=6.29, \mathrm{SD}=1.00 ; F(1,139)=.698, p=.405, \mathrm{~d}=.14\right)$, suggesting that in both conditions, participants felt they clearly understood the message despite the absence or presence of emojis.

Brand Familiarity. A one-way ANOVA on the brand familiarity measure revealed a non-significant main effect of emoji $\left(\mathrm{M}_{\mathrm{emoji}}=4.37, \mathrm{SD}=.80, \mathrm{M}_{\text {no-emoji }}=4.41\right.$, $\mathrm{SD}=.89 ; F(1,139)=.089, p=.766, d=.05)$, indicating that participants felt equally familiar with the Starbucks brand across conditions.

Purchase Frequency. A one-way ANOVA on the purchase frequency measure revealed a non-significant main effect of emoji $\left(\mathrm{M}_{\mathrm{emoji}}=4.23, \mathrm{SD}=1.82, \mathrm{M}_{\mathrm{no-emoji}}=4.35\right.$, $\mathrm{SD}=1.78 ; F(1,139)=.152, p=.697, d=.07)$, indicating that participants purchased Starbucks branded products with similar frequency across conditions.

Mood. The mood scales were averaged to form a composite measure of mood score $(\alpha=.96)$. A one-way ANOVA on the mood measure revealed a non-significant 
main effect of emoji $\left(\mathrm{M}_{\mathrm{emoji}}=5.59, \mathrm{SD}=1.30, \mathrm{M}_{\text {no-emoji }}=5.84, \mathrm{SD}=1.17 ; F(1,139)=\right.$ $1.35, p=.247, d=.20$ ), indicating that participants' mood did not differ across conditions.

Self-Brand Connection. The self-brand connection scales were averaged to form a composite measure of self-brand connection score $(\alpha=.93)$. A one-way ANOVA on the self-brand connection score revealed a significant main effect of emoji $\left(\mathrm{M}_{\mathrm{emoji}}=4.45, \mathrm{SD}\right.$ $\left.=1.27, \mathrm{M}_{\text {no-emoji }}=3.98, \mathrm{SD}=1.39 ; F(1,139)=4.26, p=.041, d=.35\right)$, indicating when brands include emojis in their brand communications, they increase consumers' connection with the brand. Thus, emojis can help strengthen the consumer brand relationship by enhancing self-brand connections. Results are also significant after controlling for mood, brand familiarity and purchase frequency $(F(1,143)=7.60, p=$ $.007, d=.35)$.

Anthropomorphism. The anthropomorphism scales were averaged to form a composite measure of anthropomorphism $(\alpha=.88)$. A one-way ANOVA on the anthropomorphism score showed a significant main effect of emoji $\left(\mathrm{M}_{\mathrm{emoji}}=5.00, \mathrm{SD}=\right.$ $\left.1.40, \mathrm{M}_{\text {no-emoji }}=4.50, \mathrm{SD}=1.58 ; F(1,139)=3.93, p=.049, d=.34\right)$, indicating that emojis in brand communications increase consumers' perceptions of brand anthropomorphism. Results from this analysis remain significant after controlling for mood, brand familiarity and purchase frequency $(F(1,143)=5.94, p=.016, d=.34)$.

Mediation Analysis. A mediation analysis using bootstrapping method with biascorrected confidence estimates was performed to test the causal path: emoji $\rightarrow$ brand anthropomorphism $\rightarrow$ self-brand connection (PROCESS MODEL 4; Hayes, 2017). As expected, brand anthropomorphism mediated the effects of emojis (coded: $0=$ no emoji, 
$1=$ emoji) on self-brand connections $(b=.284, S E=.15,95 \% C I=.011$ to .605$)$, indicating that emojis increase consumers' perceptions of brand anthropomorphism, which translates to greater self-brand connections (see Table 5 for details). In this analysis, I also controlled for mood, brand familiarity and purchase frequency $(b=.265$, $S E=.13,95 \% C I=.038$ to .542$)$. These results revealed a significant mediation of emojis on self-brand connections through anthropomorphism, even when statistically controlling for the effects of mood, brand familiarity and purchase frequency.

\begin{tabular}{lcccc}
\hline & \multicolumn{5}{c}{ Self-Brand Connections } \\
\cline { 2 - 5 } & Coeff. & SE & $\mathrm{t}$ & $p$ \\
\hline Antecedent & 0.2786 & 0.1687 & 1.6515 & 0.1010 \\
Emoji (X) & 0.4583 & 0.0602 & 7.6169 & 0.0000 \\
Anthropomorphism (M) & -0.0572 & 0.1268 & -0.4512 & 0.6526 \\
Brand Familiarity & 0.3619 & 0.0591 & 6.1263 & 0.0000 \\
Purchase Frequency & 0.1236 & 0.0847 & 1.4589 & 0.1469 \\
Mood & \multicolumn{5}{c}{$F(4,134)=13.73, p=.000$} \\
\hline Model Summary & $\mathrm{R}^{2}=.2907$ \\
\hline
\end{tabular}

Note: Emoji is coded as 0 if no-emoji and 1 if emoji.

Table 5. Mediating Role of Anthropomorphism

\section{Discussion}

Results from this study support the prediction that brand communications that include emojis in addition to text (compared to text only) will increase brand anthropomorphism, which will translate into stronger self-brand connection, an important indicator of consumer brand relationship strength. Importantly, I was able to statistically 
control for mood, purchase frequency and brand familiarity as alternative explanations for the effects of emojis on self-brand connections.

In conclusion, results from this study further support the positive influence of (facial and artifacts) emojis on the consumer-brand relationship by demonstrating that emojis help enhance self-brand connections (H2) and brand anthropomorphism (H3a). In the next study, I assessed the influence of emojis on consumption consequences and the underlying serial mechanism of brand anthropomorphism and self-brand connections on these effects (H3b).

\section{Study 2c: Serial Mediation by Anthropomorphism and Self-Brand Connections}

The main objective of this study was twofold. First, I aimed to replicate previous findings by testing the complete conceptual model of the effects of emojis on consumption behavior through a sequential mediation of anthropomorphism and selfbrand connection. Second, I used only artifact emojis in the stimuli to confirm the observed effect of emojis is not constrained to only facial emojis or the combination of facial + artifact emojis. I achieved this by using a social media post from a fictitious brand of sunscreen, Allie to analyze the effects of artifact emojis in brands' online communications. Specifically, participants were asked to report self-brand connection and perceptions of brand anthropomorphism after being shown a social media post with artifact emojis compared to a post without emojis. Consistent with my hypotheses, I predicted a positive effect of artifact emojis on self-brand connections (H2), brand 
anthropomorphism (H3a), and a serial mediation of the effects of emojis on consumption consequences through anthropomorphism and self-brand connections (H3b).

Additionally, in this study, I statistically controlled for mood, cuteness, skin care use and purchase frequency of skin care products to confirm the observed effects of emojis on self-brand connections persist even when statistically controlling for these potential confounding factors. It was important that I controlled for brand familiarity and purchase frequency given that I was using the Starbucks brand, for which participants may already have established attitudes and purchase patterns. Ruling out mood was important because the stimuli includes a happy facial emoji, which could lead to increased positive mood. Finally, I used a fictitious brand of sunscreen, "Allie," to seek confirmation that the observed effects of emoji also persist across non-familiar brands.

\section{Pretest}

Participants and Design. 36 undergraduate students (52.9\% female; $M_{\text {age }}=21.6$, $\mathrm{SD}=2.05$ ) from a public university in the United States completed a pretest in exchange for extra course credit. A post-hoc power analysis was conducted using G*Power v3.1 (Faul, Erdfelder, Lang and Buchner 2007). Given the sample size, the achieved power to detect a medium effect of .25 at an alpha level .05 was 0.83 , indicating the sample size was adequate for this analysis.

Stimuli. I employed the emoji manipulation (artifact emoji vs. no-emoji control) in a social media post created by the Allie brand. See figure 8 for stimuli details. 
Figure 8. Stimuli, Study 2c

Procedure. Participants were asked to rate one of two social media posts created by the Allie brand and were prompted with the following: "Please carefully analyze the following post and answer the questions that follow, with your honest opinion and choices." First, participants in the facial + artifact emoji condition completed measures to assess the appropriate use of the emojis within the textual message by using the following three items, "The emojis used in this post fit what is said in the textual message," "The types of emoji used in this post are appropriate," "The emojis within the post are placed appropriately" ( 1 = "strongly disagree," and 7 = "strongly agree").

Participants across both conditions reported their attitudes toward the message using a 7-point semantic scale ("Unfavorable - Favorable," "Bad - Good," "Really Dislike - Really Like," "Negative - Positive"). Next, participants completed items used to assess how clearly they perceived to comprehend the message within the post: "The message in the advertisement you saw was:" ( 1 = "not easy to understand," 7 = "very easy to understand"; and $1=$ "not clear," 7 = "very clear"). Then, participants completed four measures to assess how informative they perceived the message to be: ("Please indicate the extent to which you agree that the following words describe the post you just 
saw: "Informative," "Useful," "Understandable," "Sufficient," with anchors 1 = "strongly disagree," and 7 = "strongly agree;" Edwards, Li, and Lee 2002). Finally, all participants completed basic demographic questions (age, gender).

\section{Pretest Results}

Appropriate use of Emojis. The measures used to assess if the emojis in the post were used appropriately and fit the narrative of the message were averaged to form a composite measure of fit score $(\alpha=.87)$ and compared against midpoint $\left(\mathrm{M}_{\mathrm{fit}}=4.77, \mathrm{SD}\right.$ $=1.41 ; t=3.60, p=.003)$, indicating that the emojis fit the message in the social media post.

Perceived Message Comprehension. The measures used to assess perceived comprehension were averaged to form a composite measure of perceived message comprehension score $(\alpha=.89)$. As expected, results were non-significant on the perceived message comprehension index $\left(\mathrm{M}_{\mathrm{emoji}}=5.47, \mathrm{SD}=1.31, \mathrm{M}_{\text {no-emoji }}=5.89, \mathrm{SD}=\right.$ $.92 ; F(1,33)=1.20, p=.282, d=.38)$, indicating that participants felt that the message was equally clear in both conditions

Perceived Ad Informativeness. Similarly, measures used to assess how informative consumers perceived the message to be were averaged to form a composite measure of ad informativeness score $(\alpha=.87)$. Results were non-significant $\left(\mathrm{M}_{\mathrm{emoji}}=\right.$ $\left.4.70, \mathrm{SD}=1.29, \mathrm{M}_{\mathrm{no}-\mathrm{emoji}}=5.17, \mathrm{SD}=1.50 ; F(1,33)=.922, p=.344, d=.33\right)$ indicating that participants felt that the message was equally informative in both conditions. 
Attitudes toward the social media post. The measures used to assess attitudes toward the social media post were averaged to form a composite measure of attitude score $(\alpha=.93)$. Results from a one-way ANOVA on the attitudes index revealed no significant differences between conditions $\left(\mathrm{M}_{\mathrm{emoji}}=5.14, \mathrm{SD}=1.19, \mathrm{M}_{\mathrm{no}-\mathrm{emoji}}=5.71, \mathrm{SD}\right.$ $=1.21 ; F(1,33)=1.88, p=.179, d=.47)$, indicating that participants had equal attitudes toward the social media post in both conditions.

\section{Pretest Results.}

Results from this pretest indicate that the social media posts in both conditions were perceived to be equally informative and clear, and that participants did not demonstrate different attitudes toward the social media post in both conditions. Further, I was able to assert that emojis used in the emoji condition were appropriate and related to the textual message in the post.

\section{Main Study.}

Participants and Design. In exchange for extra course credit, 136 undergraduate students $\left(53.4 \%\right.$ female; $\left.M_{\text {age }}=21.9, \mathrm{SD}=3.18\right)$ from a public university in the United States participated in a single factor, two-level (artifact emoji versus control) betweensubjects study design to evaluate the influence of emojis on consumption behavior as well as the serial mediating role of brand anthropomorphism and self-brand connections. Two participants were eliminated due to incomplete surveys, leaving 134 undergraduate students $\left(52.7 \%\right.$ female; $\left.M_{\text {age }}=21.9, \mathrm{SD}=3.19\right)$ for this analysis. A post-hoc power analysis was conducted using G*Power v3.1 (Faul, Erdfelder, Lang and Buchner 2007). 
Given the sample size, the achieved power to detect a medium effect of .50 at an alpha level .05 was 0.99 , indicating the sample size was adequate for this analysis.

Stimuli. I employed the emoji manipulation (artifact emoji vs. no-emoji control) in a social media post for a fictitious brand of sunscreen lotion Allie. All elements within the social media post, including text, font colors and element sizes, were held constant. Participants across conditions evaluated the same product. See figure 8 for stimuli details. Procedure. Upon entering the behavioral laboratory, participants were told they would participate in a two-part study in which they would evaluate a social media marketing campaign for a new sunscreen brand, Allie, and were given background information about the brand in a cover story that read: "Today, we are evaluating the Allie Sunscreen brand. Allie is a Japanese brand that specializes in skin care that protects from outdoor sun exposure. They are a preferred brand for their use of kind ingredients and zero chemicals. They also pride themselves in supporting initiatives that help people spend more time with nature. Now, they are expanding their brand globally and are preparing a social media campaign that includes multiple posts like the one below. We would like you to evaluate some of the brand's messages used in their social media as they promote their brand and products globally. Please read the following message the way you normally view social media messages and answer the questions that follow."

After reading the social media post that either contained or did not contain artifact emojis, depending on condition, participants were asked to start part one of the study and completed self-brand connection (Escalas and Bettman 2003) and brand anthropomorphism measures used in previous studies (Epley et al. 2007; Aggarwal and 
McGill, 2012). They also completed emotional attachment measures (Thomson, MacInnis and Whan Park 2005) by indicating the extent to which they felt the following words described their feelings toward the Allie brand: "Affectionate," "Friendly," "Lovable," "Peaceful," "Passionate," "Delighted," "Captivated," "Connected," "Bonded," "Attached," with anchors 1 = "Strongly Disagree," 7 = "Strongly Agree". Next, participants were asked to leave the survey in their desk in order to complete part two of the study and were asked to approach the laboratory assistant to sample the Allie sunscreen lotion (Appendix I). After sampling the lotion, they completed attitudes, purchase intention, willingness to pay and word of mouth measures (Carroll and Ahuvia 2006). The attitude measures used a 7-point bipolar scale that included: "Bad" "Good," "Unfavorable" - "Favorable," "Don't like it at all" - "Like it very much," "Not at all enjoyable" - "Very enjoyable," "Very low quality" - "Very high quality." Purchase intention was measured using a single 7-point scale that asked: "How likely would you be to purchase the Allie sunscreen lotion?" with anchors $1=$ "Not at all likely," 7 = "Very likely."

Willingness to pay was assessed on an open-ended question by asking: "Sunscreen lotions in the US typically range from a minimal price point of $\$ 10$ to the most expensive ones at $\$ 30$. What is the most you would pay for a full size (8 oz) Allie sunscreen lotion?" Finally, word of mouth was evaluated using six 7-point Likert measures (Carroll and Ahuvia 2006): "I would recommend the Allie sunscreen lotion to my friends and family," "If someone was looking for a new sunscreen lotion, I would recommend they try Allie," "I would recommend the Allie brand to lots of people," "I would "talk up" the Allie brand to my friends," "I would try to spread the good word 
about this brand," "I would give this brand tons of positive word-of-mouth advertising," with anchors 1 = "Strongly Disagree," 7 = "Strongly Agree."

Then, participants reported the extent to which they agreed the Allie brand was "Cute," “Adorable," "Endearing” on a 7-point Likert scale with anchors 1 = "Strongly Disagree," 7 = "Strongly Agree" (Nenkov and Scott 2014). Finally, participants completed mood measures (Roehm and Roehm 2005), time spent on social media, frequency of sunscreen use and purchase frequency of skin care products, followed by basic demographic questions (age, gender). Details from this study can be found in Appendix J.

\section{Results}

Cuteness of Brand. The cuteness measures were averaged to form a composite measure of attitudes $(\alpha=.91)$. A one-way ANOVA on the cuteness score showed a nonsignificant main effect of emoji $\left(\mathrm{M}_{\mathrm{emoji}}=4.75, \mathrm{SD}=1.39, \mathrm{M}_{\mathrm{no}-\mathrm{emoji}}=4.38, \mathrm{SD}=1.26\right.$; $F(1,133)=2.53, p=.11, d=.28)$, demonstrating no significant differences between conditions in terms of cuteness.

Mood. The mood scales were averaged to form a composite measure of mood score $(\alpha=.92)$. A one-way ANOVA on the mood measure revealed a non-significant effect of emoji $\left(\mathrm{M}_{\mathrm{emoji}}=5.42, \mathrm{SD}=1.53, \mathrm{M}_{\mathrm{no-emoji}}=5.34, \mathrm{SD}=1.51 ; F(1,133)=.099, p\right.$ $=.754, d=.06$ ), indicating that participants' mood did not differ across conditions.

Frequency of skin care use. A one-way ANOVA on the frequency of skin care use measure revealed a non-significant main effect of emoji $\left(\mathrm{M}_{\mathrm{emoji}}=8.48, \mathrm{SD}=11.12\right.$, 
$\left.\mathrm{M}_{\text {no-emoji }}=8.56, \mathrm{SD}=1.09 ; F(1,133)=2.05, p=.155, d=.04\right)$, indicating that

participants reported to use skin care products with equal frequency across conditions.

Purchase frequency of skin care products. A one-way ANOVA on the purchase frequency measure revealed a non-significant main effect of emoji $\left(\mathrm{M}_{\mathrm{emoji}}=4.71, \mathrm{SD}=\right.$ $\left.2.00, \mathrm{M}_{\text {no-emoji }}=4.63, \mathrm{SD}=1.95 ; F(1,133)=.056, p=.814, d=.07\right)$, indicating that participants purchased skin care products with similar frequency across conditions.

Self-brand Connections. The self-brand connections measures were averaged to form a composite measure of self-brand connection $(\alpha=.89)$. A one-way ANOVA on the self-brand connection score showed a significant main effect of emoji $\left(\mathrm{M}_{\mathrm{emoji}}=4.02, \mathrm{SD}\right.$ $\left.=1.33, \mathrm{M}_{\text {no-emoji }}=3.22, \mathrm{SD}=1.01 ; F(1,133)=15.59, p<.001, d=.68\right)$, indicating that emojis in brand communications increase consumers' connections to the brand. Results from this analysis remain significant after controlling for mood, cuteness, skin care use and purchase frequency of skin care products $(F(1,133)=8.37, p=.005)$.

Brand Anthropomorphism. The brand anthropomorphism measures were averaged to form a composite measure of anthropomorphism $(\alpha=.81)$. A one-way ANOVA on the anthropomorphism score showed a significant main effect of emoji $\left(\mathrm{M}_{\mathrm{emoji}}=5.03, \mathrm{SD}=\right.$ $\left.1.29, \mathrm{M}_{\text {no-emoji }}=4.30, \mathrm{SD}=1.27 ; F(1,133)=10.66, p=.001, d=.57\right)$, indicating that emojis in brand communications increase consumers' anthropomorphism of the brand. Results from this analysis remain significant after controlling for mood, cuteness, skin care use and purchase frequency of skin care products $(F(1,133)=4.46, p=.037)$.

Emotional Attachment. The emotional attachment measures were averaged to form a composite measure of attachment $(\alpha=.92)$. A one-way ANOVA on the attachment score showed a significant main effect of emoji $\left(\mathrm{M}_{\mathrm{emoji}}=5.01, \mathrm{SD}=1.04\right.$, 
$\left.\mathrm{M}_{\text {no-emoji }}=4.28, \mathrm{SD}=.97 ; F(1,133)=17.54, p=.001, d=.72\right)$, indicating that emojis in brand communications increase consumers' emotional attachment to the brand. Results from this analysis remain significant after controlling for mood, cuteness, skin care use and purchase frequency of skin care products $(F(1,133)=12.50, p=.001)$.

Attitude toward the brand. The attitude measures were averaged to form a composite measure of brand attitude $(\alpha=.95)$. A one-way ANOVA on the attitudes score showed a significant main effect of emoji $\left(\mathrm{M}_{\mathrm{emoji}}=4.94, \mathrm{SD}=1.36, \mathrm{M}_{\text {no-emoji }}=4.42, \mathrm{SD}\right.$ $=1.34 ; F(1,133)=5.06, p=.026, d=.39)$, indicating that emojis in brand communications increase consumers' attitudes toward the brand. Results from this analysis emerge marginally significant after controlling for mood, cuteness, skin care use and purchase frequency of skin care products $(F(1,133)=3.36, p=.07)$.

Purchase Intentions. A one-way ANOVA on the purchase intention measure showed a significant main effect of emoji $\left(\mathrm{M}_{\mathrm{emoji}}=4.21, \mathrm{SD}=1.64, \mathrm{M}_{\text {no-emoji }}=3.63, \mathrm{SD}\right.$ $=1.51 ; F(1,133)=4.55, p=.035, d=.37)$, indicating that emojis in brand communications increase consumers' purchase intentions. Results from this analysis remain significant after controlling for mood, cuteness, skin care use and purchase frequency of skin care products $(F(1,133)=4.09, p=.046)$.

Willingness to Pay. A one-way ANOVA on the willingness to pay measure showed a significant main effect of emoji $\left(\mathrm{M}_{\mathrm{emoji}}=12.52, \mathrm{SD}=4.24, \mathrm{M}_{\mathrm{no}-\mathrm{emoji}}=10.82\right.$, $\mathrm{SD}=4.08 ; F(1,133)=5.55, p=.020, d=.41)$, indicating that emojis in brand communications result in consumers' willingness to pay more for the brand. Results from this analysis emerge marginally significant after controlling for mood, cuteness, skin care use and purchase frequency of skin care products $(F(1,133)=3.82, p=.061)$. 
Word of Mouth (WOM). The WOM measures were averaged to form a composite measure of word of mouth $(\alpha=.96)$. A one-way ANOVA on the WOM score showed a significant main effect of emoji $\left(\mathrm{M}_{\mathrm{emoji}}=4.14, \mathrm{SD}=1.44, \mathrm{M}_{\mathrm{no}-\mathrm{emoji}}=3.41, \mathrm{SD}=1.41\right.$; $F(1,133)=8.78, p=.004, d=.51)$, indicating that emojis in brand communications increase consumers' word of mouth behaviors. Results from this analysis remain significant after controlling for mood, cuteness, skin care use and purchase frequency of skin care products $(F(1,133)=8.26, p=.005)$.

Results for all main variables in this analysis remain significant (or marginally significant in the case of brand attitudes and purchase intentions), when statistically controlling for mood, perceived cuteness of the brand, frequency of skin care product use and purchase frequency of skin care products. Results from this analysis are depicted in Figure 9.

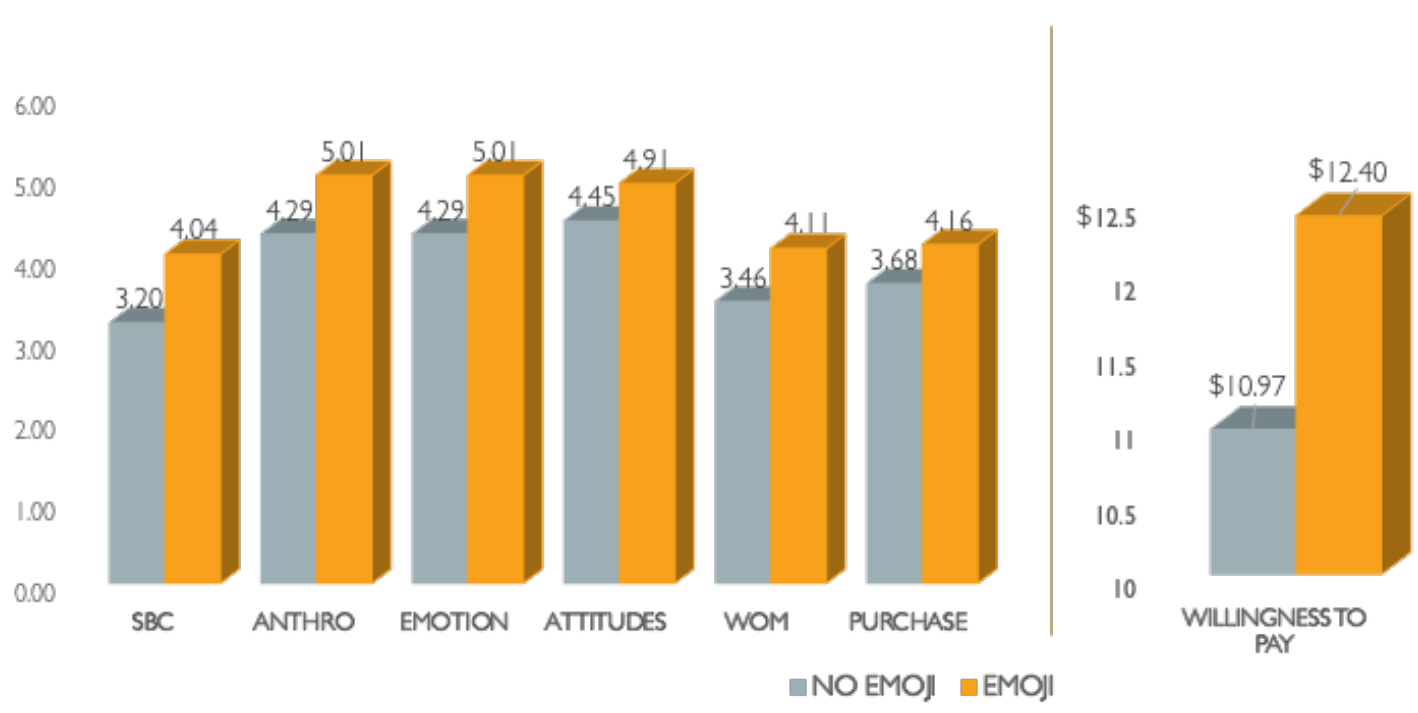

Figure 9. Study 2c, Results of the effects of emoji on consumption consequences 
Serial Mediation Analyses. To test the predicted underlying process of brand anthropomorphism and self-brand connection on the effects of emojis on consumption behaviors, I conducted separate serial mediation analyses using PROCESS macro Model 6 (Hayes 2017), with emoji as the independent variable (coded $0=$ no emoji, $1=$ emoji) and the individual consumption behaviors as main dependent variables. Anthropomorphism and self-brand connections served as the sequential mediators in the model, $M_{1}$ and $M_{2}$ respectively. From the first analysis, results revealed that anthropomorphism and self-brand connections sequentially mediated the effect of emoji use on attitudes $(b=.08, \mathrm{SE}=.05,95 \% \mathrm{CI}=.002$ to .178$)$. The second analysis also revealed a serial mediation of anthropomorphism and self-brand connections on the effects of emoji use on purchase intentions $(b=.12, \mathrm{SE}=.06,95 \% \mathrm{CI}=.017$ to .260$)$. Similarly, results from the third analysis revealed that anthropomorphism and self-brand connections sequentially mediated the effect of emoji use on willingness to pay $(b=.34$, $\mathrm{SE}=.15,95 \% \mathrm{CI}=.083$ to .649 ). Finally, the fourth analysis revealed a serial mediation of anthropomorphism and self-brand connections on the effects of emoji use on word of mouth $(b=.10, \mathrm{SE}=.06,95 \% \mathrm{CI}=.006$ to .216$)$. Results from these analyses can be seen in Table 6.

Finally, it is important to highlight that when the order of mediators was reversed (emoji $\rightarrow$ self-brand connections $\rightarrow$ anthropomorphism $\rightarrow$ consumption consequences), results from the serial mediation analysis were non-significant across all four outcome variables. Specifically, when I reversed the order of the mediators for brand attitudes ( $b=$ $.033, \mathrm{SE}=.029,95 \% \mathrm{CI}=-.022$ to .095$),$ purchase intentions $(b=.034, \mathrm{SE}=.028,95 \%$ $\mathrm{CI}=-.017$ to .095$)$, willingness to pay $(b=.08, \mathrm{SE}=.05,95 \% \mathrm{CI}=.002$ to .178$)$, and 
word of mouth $(b=.014, \mathrm{SE}=.011,95 \% \mathrm{CI}=-.008$ to .037$)$. Therefore, these findings reveal a statistically significant serial mediation on each outcome variable, with the mediators in the predicted order: brand anthropomorphism, followed by self-brand connections, thereby providing support for the mediating hypothesis (H3b).

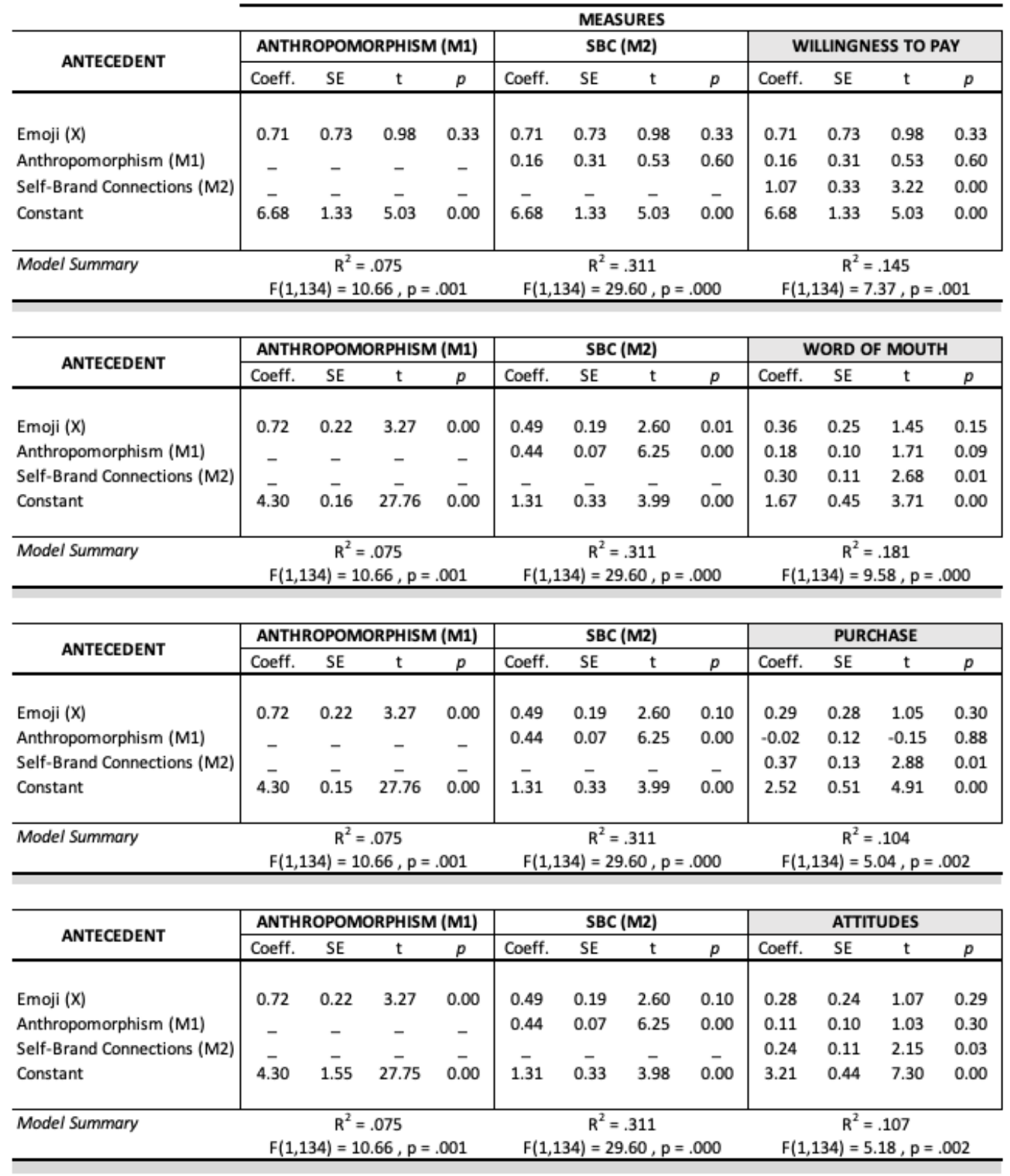

Note: Emoji is coded as 0 if no-emoji and 1 if emoji.

Table 6. Study 2c, Serial mediation pathway 


\section{Discussion.}

Findings from this study corroborate the prediction that brand messages that include emojis lead to greater perceptions of brand anthropomorphism, resulting in stronger self-brand connections with favorable consumption consequences, such as increased attitudes, purchase intentions, willingness to pay and word of mouth $(\mathrm{H} 3 \mathrm{~b})$. Importantly, these results demonstrate that artifact emojis can also help humanize a brand and create stronger consumer-brand connections. This confirms that including emojis in brand digital communications benefits the brand, and ultimately, the consumer-brand relationship.

While the combined findings of the last seven studies demonstrate the positive influence of emojis on consumption consequences, equally important is to understand instances in which the use of emojis might not produce the intended benefits. Thus, in the next study, I evaluate the predicted moderating effect of brand role $(\mathrm{H} 4)$ in response to the research question that inquires instances in which emojis might not benefit a brand. Aggarwal and McGill (2012) suggest that consumers are motivated to interact more closely with brands they consider partners versus brands considered as servants. For instance, a brand using marketing messages such as "let's work together," are perceived as brand partners or co-creators of value, while brands using messages such as "let us work for you," are considered brand servants or creators of value for the consumer. Thus, I aimed to evaluate the proposition that emojis will benefit brand partners versus brands servants, thereby emphasizing a boundary condition in the effects of emojis on consumption consequences. 


\section{Study 3: Predicted Boundary Condition - Brand Role}

The main objective of this study was to test the proposed moderation of brand role in the effects of emojis on consumption consequences. I achieved this by conducting a 2 (brand role : partner / servant) x 2 (emoji: facial + artifact / control) between subjects factorial design study that used a social media post from a fictitious brand of wearable technology, SmartWrist to analyze the effects of facial + artifact emojis in brands' online communications. Specifically, participants were manipulated with an either a brand partner or brand servant message and were asked to report their intention to purchase SmartWrist branded products (i.e. smart watch) after being shown a social media post that either contained facial + artifact emojis or none at all. Consistent with H4, I argue that emojis will benefit brands as partners by enhancing purchase intent, compared to those brands positioned in a servant role.

Furthermore, in this study, I statistically controlled for mood to confirm the observed effects of emojis on purchase intentions persist even when controlling for this potential confounding factor. The significance of ruling out mood and was important because emojis are perceived as fun (Gn 2018) and thus, could lead to an increase in positive mood or.

Pretest

Participants and Design. In exchange for monetary compensation, 166 Amazon MTurk workers $\left(61.4 \%\right.$ female; $\left.M_{a g e}=37.4, \mathrm{SD}=13.36\right)$ participated in a 2 (emoji / control ) x 2 (brand role: partner / servant) between-subjects design pretest. A post-hoc 
power analysis was conducted using $\mathrm{G}^{*}$ Power v3.1 (Faul, Erdfelder, Lang and Buchner 2007). Given the sample size, the achieved power to detect a medium effect of .25 at an alpha level .05 was 0.99 , indicating the sample size was adequate for this analysis.

Stimuli. I employed the emoji manipulation (facial + artifact emoji vs. no-emoji control) in a social media post ostensibly created by the fictitious brand of wearable technology, SmartWrist. Further, the message within the social media post was manipulated to make the brand appear either as partner or servant. See figure 10 for stimuli details.

\begin{tabular}{|c|c|c|}
\hline & No Emoji & Emoji \\
\hline 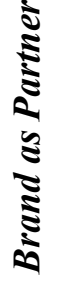 & $\begin{array}{l}\text { sw } \\
\text { @marmartwrist } \\
\text { Introducing the new SmartWrist, } \\
\text { your new partner working with you } \\
\text { to achieve your goals! }\end{array}$ & $\begin{array}{l}\text { sw } \\
\text { Smartwritwrist } \\
\text { Introducing the new SmartWrist, } \\
\text { your new partner working with you } \\
\text { to achieve goals together! }\end{array}$ \\
\hline 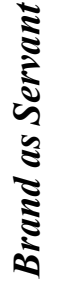 & $\begin{array}{l}\text { sw SmartWrist } \\
\text { @smartwrist } \\
\text { Introducing the new SmartWrist, } \\
\text { your new assistant working for you } \\
\text { to achieve your goals! }\end{array}$ & $\begin{array}{l}\underline{\text { sw SmartWrist }} \\
\text { Intmartwrist } \\
\text { Introducing the new SmartWrist, } \\
\text { your new assistant working for you } \\
\text { to achieve your goals! }\end{array}$ \\
\hline
\end{tabular}

Figure 10. Stimuli, Study 3

Procedure. Participants were asked to rate one of four social media posts by the SmartWrist brand and were prompted with a cover story. In the servant condition participants read: "We are a marketing company interested in understanding your opinion about social media advertising of a new brand of tech wearable products, 
SmartWrist. SmartWrist is a new brand of smart watches and is positioning itself in the marketplace as a "servant brand" to the consumer (meaning it is an outsourced provider of benefits to the consumer and therefore, works for the consumer. Today, we would like you to evaluate a social media post used by the SmartWrist brand to promote its products online. Please carefully read the post, as you will answer questions in the next pages."

In the partner condition participants read: "We are a marketing company interested in understanding your opinion about social media advertising of a new brand of tech wearable products, SmartWrist. SmartWrist is a new brand of smart watches and is positioning itself in the marketplace as a "partner brand" to the consumer (meaning it is a co-producer of benefits with the brand, and therefore, works with the consumer). Today, we would like you to evaluate a social media post used by the SmartWrist brand to promote its products online. Please carefully read the post, as you will answer questions in the next pages."

Next, participants in the emoji condition completed measures to assess the intended meaning of the emojis used in the post. The items used were: "The emoji intends to graphically represent a person raising their hand," "The emoji intends to graphically represent a watch" ( $1=$ "strongly disagree," and $7=$ "strongly agree"). In this condition, I also pretested the appropriate use of the emojis within the textual message by using the following three items, "The emojis used in this post fit what is said in the textual message," "The types of emoji used in this post are appropriate," "The emojis within the post are placed appropriately" ( 1 = "strongly disagree," and 7 = "strongly agree"). 
Then, participants completed brand role manipulation check measures to confirm that the brand was perceived as intended to - partner or servant (Aggarwal and McGill 2012; Kim and Kramer 2015) by responding to six 7-point Likert scale measures ("SmartWrist is like a partner to the consumer," "SmartWrist co-creates value with the consumer," "SmartWrist s like a colleague," "SmartWrist is like a servant to the consumer," "SmartWrist works for the consumer," "SmartWrist is like an assistant;" with anchors 1 = "Strongly Disagree", 7 = "Strongly Agree"). Finally, all participants completed basic demographic questions (age, gender).

\section{Pretest Results}

Meaning of Emojis. In the emoji condition, I compared the means with the midpoint to ensure all participants understood the meaning of each emoji as intended (Miller et al. 2016; Highfield and Leaver 2016): person raising hand $\left(\mathrm{M}_{\text {person }}=5.77, \mathrm{SD}=\right.$ $1.33 ; t=15.58, p<.001)$, and watch $\left(\mathrm{M}_{\mathrm{watch}}=5.23, \mathrm{SD}=1.62 ; t=9.74, p<.001\right)$, indicating that participants interpreted the emojis as intended in the social media post.

Appropriate use of Emojis. The measures used to assess if the emojis in the post were used appropriately and fit the narrative of the message were averaged to form a composite measure of fit score $(\alpha=.85)$ and compared against midpoint $\left(\mathrm{M}_{\mathrm{fit}}=4.98, \mathrm{SD}\right.$ $=1.18 ; t=11.40, p<.001)$, indicating that the emojis appropriately fit the message in the social media post.

Brand Partner Role. The measures used to assess the brand as partner manipulation were averaged to form a composite measure of brand partner score $(\alpha=$ .86). As expected, an ANOVA with brand partner score as the dependent measure and 
emoji and brand role as the predictors elicited a main effect of brand role $(F(1,165)=$ $22.57, \mathrm{p}=.000)$. Participants in the brand partner condition perceived the brand to be positioned significantly more as a partner $\left(\mathrm{M}_{\text {partner }}=4.87 \mathrm{vs.} \mathrm{M}_{\text {servant }}=3.89\right)$. The effects of emoji $(F(1,165)=.642, \mathrm{p}=.424)$ and the emoji $\mathrm{x}$ brand role interaction $(F(1,165)=$ $.000, \mathrm{p}=.996)$ were not significant.

Brand Servant Role. The measures used to assess the brand as servant manipulation were averaged to form a composite measure of brand servant score $(\alpha=$ .74). As expected, an ANOVA with brand servant score as the dependent measure and emoji and brand role as the predictors elicited a main effect of brand role $(F(1,165)=$ $3.88, \mathrm{p}=.05)$. Participants in the brand servant condition perceived the brand to be positioned significantly more as a servant $\left(\mathrm{M}_{\text {partner }}=4.38 \mathrm{vs.} \mathrm{M}_{\text {servant }}=4.88\right)$. The effects of emoji $(F(1,165)=.012, \mathrm{p}=.915)$ and the emoji $\mathrm{x}$ brand role interaction $(F(1,165)=$ $.565, \mathrm{p}=.453)$ were not significant.

\section{Pretest Discussion}

Results from this pretest indicate that the brand role manipulation was successful in making the brand appear as either partner or servant. Additionally, I was able to confirm that emojis used in the emoji condition were appropriate and related to the textual message in the post. Finally, I was able to assert that participants interpreted the emojis as I intended to in the social media post. 
Main Study.

Participants and Design. 301 Amazon MTurk workers (41.9\% female; $M_{a g e}=$ $34.71, \mathrm{SD}=9.93)$ participated in a 2 (emoji / no emoji) x 2 (brand role: partner / servant) between-subjects study design to evaluate the influence of emojis on consumption behavior as well as the moderating effect of brand role. Seventy participants failed an attention check (Lu and Sinha 2017), leaving two-hundred and thirty-one participants $\left(45.9 \%\right.$ female; $\left.M_{\text {age }}=36.37, \mathrm{SD}=10.24\right)$ for this analysis. A post-hoc power analysis was conducted using G*Power v3.1 (Faul, Erdfelder, Lang and Buchner 2007). Given the sample size, the achieved power to detect a medium effect of .25 at an alpha level .05 was 0.97, indicating the sample size was adequate for this analysis.

Stimuli. I employed the emoji manipulation (facial + artifact emoji vs. no-emoji control) in a social media post ostensibly created by the fictitious brand of wearable technology, SmartWrist. The message within the social media post was manipulated to make the brand appear either as a partner or servant. See figure 10 for stimuli details.

Procedure. Participants were told they would participate in a study in which they would evaluate a social media marketing campaign for an ostensibly new smartwatch brand, SmartWrist, and were given background information about the brand in a cover story that read: "SmartWrist is a new brand of wearable technology (i.e. smart watches), and is adapting its brand positioning to fit its customers' needs. As such, we are interested in understanding this new brand positioning from a consumer outlook. Today we are interested in evaluating SmartWrist's new brand positioning from your perspective as a consumer. On the next page you will see a description of SmartWrist's intended new brand positioning." 
Next, participants were randomly assigned to either the brand partner or brand servant condition. In the brand partner condition, participants were prompted with: "SmartWrist Series 1: your new partner. SmartWrist is a new brand of wearable technology equipped with top of the line technology that co-creates value with the consumer, just like a friend. SmartWrist partners with the consumer to accomplish their individuals goals. A partner brand is one that creates value with the consumer (i.e. like a colleague, coworker or friend). This means that the "partner brand" is a co-producer of benefits with the consumer, and therefore, works together with the consumer. As part of this "partner brand" positioning strategy, the SmartWrist marketing team has prepared a social media campaign that includes multiple posts like the one below. Today, we would like you to evaluate the following social media brand message to be used to promote SmartWrist." Next, participants were assigned randomly to evaluate either an emoji or no emoji social media post.

In the brand servant condition, participants were prompted with: "SmartWrist Series 1: your new assistant. SmartWrist is a new brand of wearable technology equipped with top of the line technology that creates value for the consumer, just like an assistant. SmartWrist works for the consumer to accomplish their individuals goals. A servant brand is one that creates value for the consumer (i.e. like an assistant or outsourced provider). This means that the "servant brand" is an outsourced provider of benefits for the consumer, and therefore, works for the consumer. As part of this "servant brand" positioning strategy, the SmartWrist marketing team has prepared a social media campaign that includes multiple posts like the one below. Today, we would like you to evaluate the following social media brand message to be used to promote SmartWrist." 
Next, participants were assigned randomly to evaluate either an emoji or no emoji social media post.

After reading the social media message that either contained or did not contain emojis, depending on condition, participants completed manipulation checks (Aggarwal and McGill 2012; Kim and Kramer 2015) by responding to six 7-point Likert scale measures ("SmartWrist is like a partner to the consumer," "SmartWrist co-creates value with the consumer," "SmartWrist s like a colleague," "SmartWrist is like a servant to the consumer," "SmartWrist works for the consumer," "SmartWrist is like an assistant;" with anchors 1 = "Strongly Disagree", 7 = "Strongly Agree").

Next, participants were asked how much they would be willing to pay for the SmartWrist smartwatch by using a slider bar (\$0 - \$500): "In the US, these type of wearable technology brands can be priced up to $\$ 500$. What is the most you would pay for the SmartWrist? Please use this slider bar to indicate your max dollar amount here." They also completed word of mouth measures (Carroll and Ahuvia 2006) by indicating the extent to which they agreed with the following statements: "I would recommend SmartWrist to my friends and family," "If someone was looking for a new smart watch, I would recommend they learn more about SmartWrist," "I would recommend SmartWrist o other people," "I would "talk up" SmartWrist to my friends," "I would spread the good word about SmartWrist," "I would give SmartWrist positive word-of-mouth advertising," with anchors 1 = "Strongly Disagree," 7 = "Strongly Agree".

Finally, participants completed mood measures (Roehm and Roehm 2005), time spent on social media (Ellison et al. 2007), followed by basic demographic questions (age, gender), and responded to an attention check measure that read "Finally, should we 
exclude your data from this study for any reason? For instance, were you distracted, or did you select answers randomly?" (Lu and Sinha 2017 ). Details from this study can be found in Appendix K.

Results

Brand Servant Manipulation Check. The brand as servant manipulation checks were averaged to form a composite measure of brand as servant score $(\alpha=.70)$. An ANOVA with brand servant score as the dependent measure and emoji and brand role as the predictors elicited a significant main effect of brand role $(F(1,230)=17.19, p=$ .000). Participants in the brand servant condition perceived the brand to be positioned more as a servant $\left(\mathrm{M}_{\text {partner }}=5.09, \mathrm{SD}=.91 \mathrm{vs} . \mathrm{M}_{\text {servant }}=5.62, \mathrm{SD}=1.03\right)$. The effects of emoji $(F(1,230)=.022, \mathrm{p}=.884)$, and the emoji $\mathrm{x}$ brand role interaction $(F(1,230)=$ $.000, \mathrm{p}=.983$ ) were not significant, indicating a successful manipulation of brand servant role.

Brand Partner Manipulation Check. The brand as partner manipulation checks were averaged to form a composite measure of brand as partner score $(\alpha=.83)$. An ANOVA with brand partner score as the dependent measure and emoji and brand role as the predictors elicited a significant main effect of brand role $(F(1,230)=7.45, \mathrm{p}=.007)$. Participants in the brand partner condition perceived the brand to be positioned more as a partner $\left(M_{\text {partner }}=5.44, \mathrm{SD}=.88\right.$ vs. $\left.M_{\text {servant }}=5.07, \mathrm{SD}=1.21\right)$. The effects of emoji $(F(1,230)=.952, \mathrm{p}=.330)$, and the emoji $\mathrm{x}$ brand role interaction $(F(1,230)=1.21, \mathrm{p}=$ .272) were not significant. 
Self-Brand Connections. The self-brand connection (SBC) measures were averaged to form a composite measure of SBC score $(\alpha=.83)$. An ANOVA with SBC score as the dependent measure and emoji and brand role as the predictors elicited a nonsignificant interaction effect of emojis $\mathrm{x}$ brand role $(F(1,230)=1.85, p=.176)$. The main effects of emoji $(F(1,230)=.051, \mathrm{p}=.821)$, and brand role $(F(1,230)=.189, p=.664)$ were also not significant.

Anthropomorphism. The anthropomorphism measures were averaged to form a composite measure of anthropomorphism score $(\alpha=.83)$. An ANOVA with anthropomorphism as the dependent measure and emoji and brand role as the predictors elicited a non-significant interaction effect of emojis $\mathrm{x}$ brand role $(F(1,230)=1.64, p=$ $.201)$. The main effects of emoji $(F(1,230)=.109, p=.742)$, and brand role $(F(1,230)=$ $1.68, p=.196)$ were also not significant.

Word of Mouth. An ANOVA with word of mouth (WOM) as the dependent measure and emoji and brand role as the predictors elicited a marginally significant interaction effect of emojis $\mathrm{x}$ brand role $(F(1,230)=3.48, p=.063)$. The main effects of emoji $(F(1,230)=.104, \mathrm{p}=.747)$, and brand role $(F(1,230)=.089, p=.765)$ were not significant. Follow-up analyses reveal non-significant differences in the brand servant condition $\left(\mathrm{M}_{\mathrm{emoji}}=4.60, \mathrm{SD}=1.45, \mathrm{M}_{\mathrm{no}-\mathrm{emoji}}=4.99, \mathrm{SD}=1.11 ; F(1,227)=2.40, p=\right.$ $.123)$, as well as in the brand partner condition $\left(\mathrm{M}_{\mathrm{emoji}}=4.88, \mathrm{SD}=1.42, \mathrm{M}_{\mathrm{no}-\mathrm{emoji}}=4.60\right.$, $\mathrm{SD}=1.41 ; F(1,227)=1.19, p=.277)$.

A similar pattern of results emerge from an ANCOVA with mood and time spent in social media as control variables on the WOM score, which revealed a significant interaction effect of emoji and brand role $(F(1,230)=4.48, p=.035)$. The main effects 
of emoji $(F(1,230)=.000, p=.99)$, and brand role $(F(1,230)=.264, p=.61)$. While results demonstrate a significant interaction of emoji and brand role on word of mouth, the simple effects in each condition do not reveal significant differences, and thus, do not support the moderating prediction of brand role $(\mathrm{H} 4)$ on the effects of emojis on WOM.

Willingness to Pay. An ANOVA with willingness to pay (WTP) as the dependent measure and emoji and brand role as the predictors elicited a marginally significant interaction effect of emojis $\mathrm{x}$ brand role $(F(1,230)=3.65, p=.058)$. The main effects of emoji $(F(1,230)=.275, \mathrm{p}=.600)$, and brand role $(F(1,230)=.082, p=.775)$ were not significant. As predicted, in the brand servant condition, participants who saw the post with emojis compared to control, reported marginally lower willingness to pay $\left(M_{\mathrm{emoji}}=\right.$ $\left.195.46, \mathrm{SD}=111.50, M_{\text {no-emoji }}=232.79, \mathrm{SD}=122.78 ; F(1,227)=2.97, p=.086\right)$. However, in the brand partner condition, the difference between emoji and no-emoji conditions was not evident $\left(M_{\mathrm{emoji}}=220.34, \mathrm{SD}=117.12, M_{\text {no-emoji }}=199.11, \mathrm{SD}=\right.$ $113.41 ; F(1,227)=.955, p=.330)$.

A similar pattern of results emerge from an ANCOVA with mood and time spent in social media as control variables on the WTP measure, which revealed a significant interaction effect of emoji and brand role $(F(1,230)=3.96, p=.048)$. The main effects of emoji $(F(1,230)=.192, p=.66)$ and brand role $(F(1,230)=.157, p=.69)$ were nonsignificant. While results demonstrate a significant interaction of emoji and brand role on willingness to pay, the simple effects in each condition do not reveal significant differences, and thus, do not support the moderating prediction of brand role (H4) on the effects of emojis on willingness to pay. 
Moderated Mediation. Given that the results from a 2 (emoji: absent / present) x 2 (brand role: partner / servant) ANOVA on the process measures (anthropomorphism and self-brand connections) were not significant, I did not conduct a moderated mediation analyses as proposed in the conceptual model. However, I conducted a moderation analysis of brand role on the effects of emojis on willingness to pay and word of mouth.

Moderation Analysis. A moderation analysis using PROCESS macro (Hayes 2017, model 1) with emoji as the independent variable, brand role as the moderator, and word of mouth as the dependent variable yielded a significant emoji $\mathrm{x}$ brand role interaction $(b=.666, \mathrm{SE}=.315, t(231)=2.12, p=.036)$. However, the confidence intervals for both levels of the moderator $(0=$ brand servant, $1=$ brand partner $)$ included zero: brand partner CI: -.1068 to .7755$)$, and brand servant (CI: -.7715 to .1080 ).

Similarly, a moderation analysis using PROCESS macro (Hayes 2017, model 1) with emoji as the independent variable, brand role as the moderator, and willingness to pay as the dependent variable yielded a significant emoji $\mathrm{x}$ brand role interaction $(b=$ $58.73, \mathrm{SE}=29.52, \mathrm{t}(231)=1.99, \mathrm{p}=.048)$. However, the confidence intervals for both levels of the moderator $(0=$ brand servant, $1=$ brand partner $)$ included zero: brand partner CI: -18.52 to 64.20$)$ or brand servant (CI: -77.11 to 5.34 ).

\section{Discussion}

Findings from this analysis revealed a significant interaction of emojis and brand role on WOM and WTP. However, analyses of brand role as moderator of the effects of emojis on each outcome variable revealed non-significant results, and thus do not support the proposition that brand role moderates the effects of emojis on consumption (H4). 
CHAPTER 4. GENERAL DISCUSSION 
Emojis are pictorial representations of emotions and objects that help clarify textual communication in online and mobile contexts. The focus of this dissertation was to investigate how facial and artifact emojis help cultivate the consumer-brand relationship in digital contexts. I argued that adding (facial or artifact) emojis to brands' text-based communications will yield positive consumption consequences. In accordance with my predictions and findings, this effect is due to a sequential underlying mechanism of brand anthropomorphism and self-brand connections, which is an indicator of the consumer-brand relationship strength.

To evaluate these predictions, I conducted eight empirical studies, including three studies that involved actual consumption, one of which involved actual monetary transactions. The combined results of the first four studies ascertain that both facial and artifact emojis act as nonverbal cues that influence positive carryover consumption effects, such as increased willingness to pay, word of mouth, click through rates, purchase intentions and actual purchase behaviors. Study 1a involved a taste test with participants reporting greater attitudes toward the product in the (facial) emoji condition versus control. Study $1 \mathrm{~b}$ involved a social media post for the Starbucks brand. Participants in the (artifact) emoji condition reported greater purchase intentions for the Starbucks brand. Study 1c sought to replicate these results by analyzing yet another important digital commerce metric, click through rates. As expected, participants in the $($ facial + artifact) emoji condition reported significantly greater click through rates when compared to a control condition. Study $1 \mathrm{~d}$ was a field study that examined the effects of facial + artifact emojis in a social media post for a fictitious brand of personal care (CarePlus), on actual purchases of a dental kit. 
Further, three studies were conducted to evaluate and confirm the predicted sequential mediation of emoji $\rightarrow$ brand anthropomorphism $\rightarrow$ self-brand connections $\rightarrow$ consumption behaviors. Specifically, study 2a, uses facial + artifact emojis in an Adidas social media post to confirm the positive effects of emojis on self-brand connections. Similarly, study $2 \mathrm{~b}$ uses a Starbucks social media post to observe the positive effects of facial + artifact emojis on anthropomorphism and self-brand connections. Further, study $2 \mathrm{c}$ provides support for the hypotheses that the presence of (artifact) emojis in brand communications influences positive downstream behaviors, and that these effects are due to a serial mediation process of brand anthropomorphism and self-brand connections.

In response to the third research question presented in this work, I conducted study 3 to evaluate the prediction that brand role moderates the observed effects of emojis on consumption behavior. Specifically, I aimed to answer the research question of when will emojis backfire or become unnecessary in consumer-brand digital interactions. However, while there is evidence of an interaction effect of emojis and brand role, results do not confirm the moderating prediction of brand role. Thus, in research stemming from this dissertation, I seek to evaluate other potential moderating variables in order to contribute with a more nuanced understanding of emojis in brand digital communications.

Collectively, these findings provide compelling evidence to establish that textbased brand messages that contain emojis can enhance brand anthropomorphism, lead to greater self-brand connections and consumption behaviors compared to text-based brand messages that do not contain emojis. In particular, these studies demonstrate enhanced 
willingness to pay, word of mouth, purchase behaviors, click through rates and brand attitudes as a consequence of the use of emojis.

These timely findings are supported by robust results from studies that considered unknown, fictitious or established brands. Furthermore, across all eight studies, I used different product categories including food / beverage, technology, apparel, and personal care. Additionally, studies were conducted in behavioral lab settings, online (Amazon MTurk) and on the field using student sample populations and online participants from different parts of the world. This allows for analyses to include a wider variety of age groups and gender, which contributes to the generalizability of findings.

Finally, another important aspect of these findings is that I am able to confirm the influence of both facial and artifact emojis on consumption metrics. Current research on emoji marketing has been limited to facial emojis, which are only a small fraction of the available emojis in the official emoji keyboard. This study significantly advances our knowledge of emoji marketing by unveiling the effects of artifact emojis in addition to facial emojis. In the next section, I detail the key theoretical and managerial contributions of this dissertation.

\subsection{Key Theoretical Implications}

This study provides further insight to the growing literature on emojis in marketing contexts by demonstrating the influence that emojis exert on brand communications by enhancing brand anthropomorphism, consumer-brand connections and subsequent consumption behaviors. 
First, these findings contribute to the technology and computer-mediated communication body of knowledge by establishing that brands' communications with consumers in digital settings can be more effective when using emojis than only with text alone. Luangrath et al. (2017) first proposed that textual paralanguage, such as emojis could improve consumer-brand connections. However, there was a lack of empirical evidence to support such a claim or understand the consumption implications of brands use of emojis. Thus, these valuable findings help explain how brands can use emojis in the absence of non-verbal physical interactions (i.e. mannerisms, gestures, human touch and human voice) to complement and enhance their communications with humans.

Second, findings from this dissertation contribute to the brand anthropomorphism literature that describe the benefits of humanizing brands (Aggarwal and McGill 2012; Epley et al. 2008). In particular, these findings provide evidence that emojis can increase brand anthropomorphism in digital contexts with desirable consumption effects. Importantly, results derived from this dissertation help establish that not only facial emojis help imbue brands with human characteristics, but also artifact emojis help humanize brands. The latter is especially relevant since it helps advance our knowledge of effective marketing strategies in computer mediated communications that allow humans and brands to better communicate in digital contexts.

Finally, existing research on emoji marketing has explored the impact of emojis on brand engagement (Pancer et al. 2017), service encounter satisfaction (Li et al. 2019), positive affect and purchase intentions (Das, Weiner and Kareklas 2019; Smith and Rose 2019). However, none had considered the effects of emojis on consumer-brand connections as an indicator of consumer-brand relationship strength. This work advances 
theoretical knowledge of emoji marketing by establishing the effects of emojis on consumption consequences through a mediation process of anthropomorphism and selfbrand connections. These findings provide a theoretical foundation for future research to explore emoji marketing in other business contexts with managerially relevant contributions as the ones highlighted in the next section.

\subsection{Key Practical Implications}

Overall, findings from the present study of the influence of emojis in online brand communications will allow marketing decision makers to strategically devise digital marketing campaigns that optimize the use of emojis to benefit their brand and the relationship with their consumers. For instance, using emojis in brand's responses to consumers' comments as well as in social media posts will clarify information while adding emotions and sentiments that can improve the consumer-brand dynamic with favorable consumption consequences, such as increased willingness to pay, attitudes, word of mouth and purchase behaviors.

The positive influence of emojis on click through rates provide a valuable contribution to marketing managers that seek to improve their brands' performance in an already cluttered digital space. According to leading marketing firm, Hubspot, the average click through rate for a search ad is $1.91 \%$, and $0.35 \%$ for a display ad - this is across industries. Findings from this research reveal that emojis can significantly increase these rates, meaning that with little to no investment, brands can experience a substantial boost in click through rates, thereby improving their digital performance. 
Similarly, findings from this research demonstrate a significant increase in word of mouth behaviors (i.e. referrals and recommendations), which according to Kozinets et al. (2010) is a powerful tool especially in digital networks given the crowded spaces (i.e. bloggers, influencers, targeted advertising). Thus, managers seeking to improve word of mouth behaviors among their customers, can use emojis to connect with their consumers and motivate them to act as brand ambassadors within their own personal networks.

Further, the self-brand connection literature has greatly emphasized the benefits of strong self-brand connections which can lead to valuable consumption outcomes for the brand (Escalas and Bettman 2014). Thus, findings from this work on the effects of emojis on self-brand connections and purchase behaviors allow managers to plan digital marketing strategies that include emojis to strengthen connections between their consumers and brands. Especially given the lack of physical interactions in digital contexts, emojis can help brands form emotional bonds and connections with consumers, with important consumption implications that can improve the brands' performance in the marketplace.

Finally, marketing decision makers can use this information to connect with their consumers in a more relatable and fun manner. The current findings provide guidance regarding building and maintaining consumer connections that affect consumers' brandrelated choices and decisions. It is now in the hands of marketers to implement the tools confirmed empirically through this work, as emojis continue to grow and permeate digital spaces at a global scale. 


\subsection{Limitations}

One limitation of this dissertation is that I do not evaluate emojis that represent negative affect (i.e. sad, angry emojis). Thus, the observed effects may differ when using these emojis.

Another limitation is that all studies presented herein use cross-sectional data, which cannot be used to observe behavior across longer periods of time. Given that emojis are a relatively new digital language, observing behavior over time can reveal whether the observed effects are consistent over time, persisting even in the presence of newer digital communication technologies.

Additionally, while Study 1d (field study) demonstrated purchase behaviors and real monetary transactions, participants did not use their own money, nor did they purchase in an actual retail setting - whether online or brick and mortar. Thus, exploring consumption behavior in actual settings would increase the robustness of these findings (Morales, Amir and Lee 2017).

Finally, I am aware of the digital divide (Hoffman, Novak and Schlosser 2000) that exists between communities in which these studies took place and other communities with more limited access to digital technologies. However, in this study I do not assess patterns of emoji use among communities with less access to digital technologies or even among cultural groups whose perceptions of emoji marketing may differ.

\subsection{Future Research Opportunities}

One research opportunity is to extend the study of the influence of emojis on the consumer-brand relationship to other dimensions, such as loyalty, brand love and 
interdependence (Fournier 1998; Batra, Ahuvia and Bagozzi 2012). Providing supporting evidence of the influence of emojis in these domains will provide marketing theory with a more comprehensive understanding of the outcomes when brands include emojis in their communications within and outside online environments.

Additionally, past research has found that products with anthropomorphic features help mitigate the negative effects of social exclusion (Mourey, Olson, and Yoon 2017). Further research has found that cute elements have strong consumption implications by increasing indulgence (Nenkov and Scott 2014). Building upon this research, the study of emojis can be expanded to other consumption contexts, such as the health and organizational domains. For example, a possible research direction is to evaluate the influence of emojis in indulgent behaviors (health domain) and risk perceptions (organizational and public policy domains), which would allow a wider and deeper comprehension of this expanding textual paralanguage.

Another future research avenue is to compare the affective nature of emojis (positive versus negative), in order to understand whether the observed effects in this research persist across happy or sad, positive or negative emojis. This provides an important future direction that can clarify the influence of emojis in other brand related domains, such as brand transgressions and brand forgiveness. It is possible that negative emojis (i.e. sad, angry, frustrated) can influence different outcomes in consumption behavior.

Finally, the use of emojis in non-digital contexts (i.e. product packaging, print advertising) is another potential direction that can provide clarity of the extent of the influence of emojis beyond digital and mobile environments. 


\subsection{Conclusion}

Through this dissertation, I sought to expand current knowledge regarding the use and implications of emojis as a textual paralanguage, by providing further understanding of the influence of emojis on consumption behavior, thereby empowering brands and marketing decision makers to capitalize on their marketing potential. Understanding the implications, effects, and contexts in which emojis can benefit brands and corporations is in the hands of marketing research. Thus, I hope my study of emoji marketing will ignite further, deeper research of the intricacies of this growing, modern digital paralanguage. 


\section{REFERENCES}




\section{REFERENCES}

Aaker, Jennifer L. (1997), "Dimensions of Brand Personality," Journal of Marketing Research, 34 (3), 347-356.

Aaker, Jennifer L., Susan Fournier, and S. Adam Brasel (2004), "When Good Brands do Bad," Journal of Consumer Research, 31 (6), 1-16.

Aggarwal, Pankaj (2004), "The effects of brand relationship norms on consumer attitudes and behavior," Journal of Consumer Research, 31 (1), 87-101.

Aggarwal, Pankaj, and Ann L. McGill (2012), "When brands seem human, do humans act like brands? Automatic behavioral priming effects of brand anthropomorphism." Journal of Consumer Research, 39 (2), 307-323.

Ahluwalia, Rohini, Robert E. Burnkrant, and H. Rao Unnava (2000), "Consumer response to negative publicity: The moderating role of commitment," Journal of Marketing Research, 37 (2), 203-214.

Alvarez, Claudio, and Susan Fournier (2016), "Consumers' relationships with brands," Current Opinion in Psychology, 10, 129-135.

Arya, Vikas, Deepa Sethi, and Hemraj Verma (2018), “Are emojis fascinating brand value more than textual language? Mediating role of brand communication to SNS and brand attachment: An insight from India," Corporate Communications: An International Journal, 23 (4), 648-670.

Barcelos, Renato Hübner, Danilo C. Dantas, and Sylvain Sénécal (2018), "Watch your tone: How a brand's tone of voice on social media influences consumer responses," Journal of Interactive Marketing, 41, 60-80.

Batra, Rajeev, Aaron Ahuvia, and Richard P. Bagozzi (2012), "Brand Love," Journal of Marketing, 76 (2), 1-16.

Beer, Jeff (2015), “There's a very good reason Domino's is obsessed with Pizza Emoji right now," Retrieved November 18, 2018, from:

https://www.fastcompany.com/3046278/theres-a-very-good-reason-dominos-isobsessed-with-pizza-emoji-right-now

Beese, Jennifer (2015), “Emoji Marketing: Are We Speaking the Same Language?" Retrieved March 01, 2019, from: https://sproutsocial.com/insights/emoji-marketing/

Boman, Laura, Ganga Urumutta Hewage, and Jonathan Hasford (working paper), "The Effect of Racially Incongruent Cues in Persuasive Appeals for Conservative Brands." 
Breazeal, Cynthia, and Lijin Aryananda (2002), "Recognition of affective communicative intent in robot-directed speech," Autonomous Robots, 12 (1), 83-104.

Burge, Jeremy (2017) “5 Billion Emojis Sent Daily on Messenger," Retrieved November 18, 2018, from: https://blog.emojipedia.org/5-billion-emojis-sent-daily-on-messenger/

Caramela, Sammi (2018), "Emoji Branding: From Smiley Faces to Thumbs Up," Business News Daily, Retrieved May 10, 2018, from: https://www.businessnewsdaily.com/10722-emoji-analysis.html

Carroll, Barbara, Aaron Ahuvia (2006), "Some antecedents and outcomes of brand love," Marketing Letters, 17 (2), 79-89.

Chang, Pao-Long, and Ming-Hua Chieng (2006), "Building consumer-brand relationship: A cross-cultural experiential view," Psychology \& Marketing, 23 (11), 927-959.

Chappuis, Bertil, Brendan Gaffey, and Parviz Parvizi (2011), “Are your customers becoming digital junkies?” McKinsey Quarterly, Retrieved December 21, 2018, from: https://www.mckinsey.com/business-functions/marketing-and-sales/our-insights/areyour-customers-becoming-digital-junkies

Chen, Fangyuan, Jaideep Sengupta, and Rashmi Adaval (2018), "Does Endowing a Product with Life Make One Feel More Alive? The Effect of Product Anthropomorphism on Consumer Vitality," Journal of the Association for Consumer Research 3 (4), 503-513.

Cheng, Shirley YY, Tiffany Barnett White, and Lan Nguyen Chaplin (2012), "The effects of self-brand connections on responses to brand failure: A new look at the consumerbrand relationship," Journal of Consumer Psychology, 22 (2), 280-288.

Childers, Terry L., and Michael J. Houston (1984), "Conditions for a picture-superiority effect on consumer memory," Journal of Consumer Research, 11 (2), 643-654.

Childers, Terry L., and Jeffrey Jass (2002), "All dressed up with something to say: Effects of typeface semantic associations on brand perceptions and consumer memory," Journal of Consumer Psychology, 12 (2), 93-106.

Churches, Owen, Mike Nicholls, Myra Thiessen, Mark Kohler, and Hannah Keage (2014), "Emoticons in mind: An event-related potential study," Social Neuroscience, 9 (2), 196-202.

Das, Gopal, Hillary JD Wiener, and Ioannis Kareklas (2019), “To emoji or not to emoji? Examining the influence of emoji on consumer reactions to advertising," Journal of Business Research, 96, 147-156. 
Derks, Daantje, Arjan ER Bos, and Jasper von Grumbkow (2007). "Emoticons and social interaction on the Internet: the importance of social context." Computers in Human Behavior, 23(1), 842-849.

Dwivedi, Abhishek, Lester W. Johnson, and Robert E. McDonald (2015), “Celebrity endorsement, self-brand connection and consumer-based brand equity," Journal of Product \& Brand Management, 24 (5), 449-461.

Edwards, Steven M., Hairong Li, and Joo-Hyun Lee (2002), "Forced Exposure and Psychological Reactance: Antecedents and Consequences of the Perceived Intrusiveness of Pop-Up Ads," Journal of Advertising, 29 (3), 83-95.

Ellison, Nicole B., Charles Steinfield, and Cliff Lampe (2007), "The benefits of Facebook "friends:" Social capital and college students' use of online social network sites." Journal of Computer-Mediated Communication, 12 (4), 1143-1168.

Emojipedia (2019), Available from: https://emojipedia.org

Epley, Nicholas, Adam Waytz, and John T. Cacioppo (2007), “On Seeing Human: A Three-Factor Theory of Anthropomorphism," Psychological Review, 114 (4), 86486.

Escalas, Jennifer Edson (2004), "Narrative Processing: Building Consumer Connections to Brands," Journal of Consumer Psychology, 14 (2), 168-180.

Escalas, Jennifer Edson, and James R. Bettman (2003), "You are what they eat: The influence of reference groups on consumers' connections to brands," Journal of Consumer Psychology, 13 (3), 339-348.

Escalas, Jennifer Edson, and James R. Bettman (2009), "Connecting with celebrities: Celebrity endorsement, brand meaning, and self-brand connections," Journal of Marketing Research, 13 (3), 339-348.

Faul, Franz, Edgar Erdfelder, Albert-Georg Lang, and Axel Buchner (2007), "G* Power 3: A flexible statistical power analysis program for the social, behavioral, and biomedical sciences," Behavior Research Methods, 39 (2), 175-191.

Ferraro, Rosellina, Amna Kirmani, and Ted Matherly (2013), "Look at me! Look at me! Conspicuous brand usage, self-brand connection, and dilution," Journal of Marketing Research, 50 (4), 477-488.

Fetscherin, Marc, and Daniel Heinrich. "Consumer brand relationships research: A bibliometric citation meta-analysis." Journal of Business Research 68.2 (2015): 380390. 
Filik, Ruth, Alexandra Țurcan, Dominic Thompson, Nicole Harvey, Harriet Davies, and Amelia Turner (2016), "Sarcasm and emoticons: Comprehension and emotional impact," The Quarterly Journal of Experimental Psychology, 69 (11), 2130-2146.

Forbes (2019), "Five Ways To Build A Strong Online Presence For Your Brand," Retrieved May 16, 2019, from https://www.forbes.com/sites/forbeslacouncil/2019/03/04/five-ways-to-build-astrong-online-presence-for-your-brand/\#2b714cc15418

Fournier, Susan (1998), "Consumers and their Brands: Developing Relationship Theory in Consumer Research," Journal of Consumer Research, 24 (4), 343-373.

Fournier, Susan (2009), "Lessons Learned about Consumers' Relationships with Their Brands," in Handbook of Brand Relationships, eds. Deborah MacInnis, C. Whan Park, and Joseph R. Priester, New York: Society for Consumer Psychology and M.E. Sharp, 5-23.

Fournier, Susan, and Jill Avery (2011), “The Uninvited Brand.” Business Horizons, 54 (3), 193-207.

Gn, Joel (2018), “Emoji as a language of cuteness," First Monday, 23 (9).

Grewal, Dhruv and Michael Levy (2010), “M: Marketing, 6th Edition,” Boston: McGraw-Hill Irwin.

Guido, Gianluigi, and Alessandro M. Peluso (2015), "Brand anthropomorphism: Conceptualization, measurement, and impact on brand personality and loyalty," Journal of Brand Management, 22 (1), 1-19.

Hayes, Andrew F. (2017), Introduction to mediation, moderation, and conditional process analysis: A regression-based approach. Guilford publications.

Highfield, Tim, and Tama Leaver (2016), "Instagrammatics and digital methods: studying visual social media, from selfies and GIFs to memes and emoji," Communication Research and Practice, 2 (1), 47-62.

Hoffman, Donna L., Thomas P. Novak, and Ann Schlosser (2000), "The evolution of the digital divide: How gaps in Internet access may impact electronic commerce," Journal of Computer-Mediated Communication, 5 (3).

Hudson, Simon, Martin S. Roth, Thomas J. Madden, and Rupert Hudson (2015), “The effects of social media on emotions, brand relationship quality, and word of mouth: An empirical study of music festival attendees," Tourism Management, 47, 68-76. 
Kaye, Linda K., Stephanie A. Malone, and Helen J. Wall (2017), "Emojis: Insights, Affordances, and Possibilities for Psychological Science," Trends in Cognitive Sciences, 21 (2), 66-68.

Kelleher, Tom (2009), “Conversational voice, communicated commitment, and public relations outcomes in interactive online communication," Journal of Communication, 59 (1), 172- 188.

Kemp, Elyria, Carla Y. Childers, and Kim H. Williams (2012), "Place branding: creating self-brand connections and brand advocacy," Journal of Product \& Brand Management, 21 (7), 508-515.

Kervyn, Nicolas, Susan T. Fiske, and Chris Malone (2012), "Brands as intentional agents framework: How perceived intentions and ability can map brand perception," Journal of Consumer Psychology, 22 (2), 166-176.

Kim, Hyeongmin Christian, and Thomas Kramer (2015), "Do materialists prefer the "brand-as-servant"? The interactive effect of anthropomorphized brand roles and materialism on consumer responses," Journal of Consumer Research 42 (2), 284-299.

Kotler, Philip, Gary Armstrong, and Margaret H. Cunningham (2005), "Principles of Marketing," Toronto: Pearson Prentice Hall.

Kozinets, Robert V., Kristine De Valck, Andrea C. Wojnicki, and Sarah JS Wilner (2010), "Networked narratives: Understanding word-of-mouth marketing in online communities." Journal of Marketing, 74 (2), 71-89.

Kralj, P. Novak, Jasmina Smailović, Borut Sluban, and Igor Mozetič (2015), "Sentiment of Emojis," PLoS ONE, 10 (12).

Kressmann, Frank, M. Joseph Sirgy, Andreas Herrmann, Frank Huber, Stephanie Huber, and Dong-Jin Lee (2006), "Direct and indirect effects of self-image congruence on brand loyalty,” Journal of Business Research, 59 (9), 955-964.

Krishna R, R. Maithreyi, and Surapaneni Krishna Mohan (2010), "Research Bias: A Review for Medical Students," Journal of Clinical and Diagnostic Research, 4, 23202324.

Kwon, Eunjin, and Anna S. Mattila (2015), "The Effect of Self-Brand Connection and Self-Construal on Brand Lovers' Word of Mouth (WOM)," Cornell Hospitality Quarterly, 56 (4), 427-435.

Landwehr, Jan R., Ann L. McGill, and Andreas Herrmann (2011) "It's got the look: The effect of friendly and aggressive "facial" expressions on product liking and sales," Journal of Marketing, 75 (3), 132-146. 
Leanplum (2018), "Unlocking Engagement \& Growth With Emojis," Retrieved February 3, 2019, from http://go.leanplum.com/rs/959-TQV-

890/images/Unlocking_Engagement_and_Growth_With_Emojis.pdf?_ga=2.9104809 $\underline{0.1080688732 .1556040714-2015512195.1556040 \overline{7} 14}$

Li, Xueni, Kimmy Wa Chan, and Sara Kim (2018), "Service with emoticons: How customers interpret employee use of emoticons in online service encounters," Journal of Consumer Research, 45 (5), 973-987.

Lu, Fang-Chi and Jayati Sinha (2017), "Speaking to the Heart: Social Exclusion and Reliance on Feelings Versus Reasons in Persuasion," Journal of Consumer Psychology, 27 (4), 409-421.

Luangrath, Andrea Webb, Joann Peck, and Victor A. Barger (2017), "Textual paralanguage and its Implications for Marketing Communications," Journal of Consumer Psychology, 27 (1), 98-107.

Lufkin, Bryan (2018), "Why there are so many Japanese emoji," Retrieved August 2, 2018, from http://www.bbc.com/capital/story/20180716-why-there-are-so-manyjapanese-emoji

MacInnis, Deborah J. (2012), "“Brands as intentional agents": Questions and extensions," Journal of Consumer Psychology, 22 (2), 195-198.

MacInnis, Deborah J., and Valerie S. Folkes (2017), "Humanizing brands: When brands seem to be like me, part of me, and in a relationship with me," Journal of Consumer Psychology, 27 (3), 355-374.

Mark, M., \& Pearson, C. (2001), "The hero and the outlaw: Building extraordinary brands through the power of archetypes," New York, NY: McGraw Hill.

Marr, Bernard (2016), "Big Data-Driven Decision-Making At Domino's Pizza," Retrieved December 9, 2018, from https://www.forbes.com/sites/bernardmarr/2016/04/06/big-data-driven-decisionmaking-at-dominos-pizza/\#66ac0ab72b8e

Miller, Daniel (2001), "Disciplinary Approaches to Consumption,” In D. Miller (Ed.), "Consumption and Critical Concepts in the Social Sciences," (p. 180). London: Routledge

Miller, Hannah Jean, Jacob Thebault-Spieker, Shuo Chang, Isaac Johnson, Loren Terveen, and Brent Hecht (2016), "Blissfully happy" or "ready to fight": Varying Interpretations of Emoji," Proceedings of ICWSM, 259-268. 
Miniard, Paul W., Sunil Bhatla, Kenneth R. Lord, Peter R. Dickson, and H. Rao Unnava (1991), "Picture-based persuasion processes and the moderating role of involvement," Journal of Consumer Research, 18 (1), 92-107.

Moore, David J., and Pamela Miles Homer (2008), "Self-brand connections: The role of attitude strength and autobiographical memory primes," Journal of Business Research, 61 (7), 707-714.

Morales, Andrea C., On Amir, and Leonard Lee (2017), "Keeping it real in experimental research-Understanding when, where, and how to enhance realism and measure consumer behavior," Journal of Consumer Research 44 (2), 465-476.

Mourey, James A., Jenny G. Olson, and Carolyn Yoon (2017), "Products as Pals: engaging with anthropomorphic products mitigates the effects of social exclusion," Journal of Consumer Research, 44 (2), 414-431.

Nenkov, Gergana Y., and Maura L. Scott (2014), "So cute I could eat it up": priming effects of cute products on indulgent consumption, Journal of Consumer Research, 41 (2), 326-341.

Pancer, Ethan, Lindsay McShane, and Maxwell Poole (2017), "Emoji and Brand Engagement on Social Media," NA - Advances in Consumer Research, Volume 45, eds. Ayelet Gneezy, Vladas Griskevicius, Patti Williams, Duluth, MN: Association for Consumer Research, 1076.

Park, C. Whan, Deborah J. MacInnis, and Joseph Priester (2006), "Brand attachment: Constructs, consequences, and causes," Foundations and Trends ${ }^{\circledR}$ in Marketing, 1 (3), 191-230.

Park, C. Whan, Deborah J. MacInnis, Joseph Priester, Andreas B. Eisingerich, and Dawn Iacobucci (2010), "Brand attachment and brand attitude strength: Conceptual and empirical differentiation of two critical brand equity drivers, Journal of Marketing, 74 (6), 1-17.

Phelps, Elizabeth A. (2006), "Emotion and cognition: insights from studies of the human amygdala," Annual Review of Psychology, 57, 27-53.

Phipps, Emma (2017), "The Emoji Fundamentals: 5 keys to using Emojis in marketing communications," Association of National Advertisers. Available from: https://www.ana.net/magazines/show/id/46136.

Pinto, Luisa, Sandra Maria Correia Loureiro, Paulo Rita, and Eduardo Moraes Sarmento (2018), "Fostering online relationships with brands through websites and social media brand pages," Journal of Promotion Management, 379-393. 
Puzakova, Marina and Hyokjin Kwak (2017), "Should Anthropomorphized Brands Engage Customers? The Impact of Social Crowding on Brand Preferences," Journal of Marketing, 81 (6), 99-115.

Rauschnabel, Philipp A., and Aaron C. Ahuvia (2014), "You're so lovable: Anthropomorphism and brand love," Journal of Brand Management, 21 (5), 372-395.

Rezabek, Landra, and John Cochenour (1998), "Visual cues in computer-mediated communication: Supplementing text with emoticons," Journal of Visual Literacy, 18 (2), 201-215.

Richardson, Matthew, Ewa Dominowska, and Robert Ragno (2007), "Predicting Clicks: Estimating the Click-Through Rate for New Ads," Proceedings of the 16th international Conference on World Wide Web, 521-529.

Riordan, Monica A. (2017), "Emojis as Tools for Emotion Work: Communicating Affect in Text Messages," Journal of Language and Social Psychology, 36 (5), 549-567.

Robles, Patricio (2015), "Taco Bell is making great use of the Taco Emoji it lobbied for," Econsultancy. Available from: https://econsultancy.com/taco-bell-is-making-greatuse-of-the-taco-emoji-it-lobbied-for/.

Roehm, Harper A. Jr. and Michelle L. Roehm (2005), "Revisiting the Effect of Positive Mood on Variety Seeking," Journal of Consumer Research, 32 (2), 330-336.

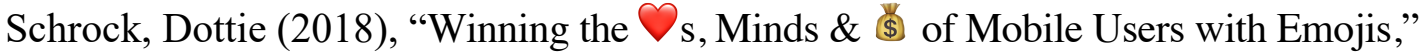
Retrieved September 13, 2018, from: https://www.leanplum.com/blog/poweringengagement-with-emojis/

Shorty Awards (2019), “2018 MTV Video Music Awards - Emoji Teases,” Retrieved February 1, 2019, from https://shortyawards.com/11th/2018-mtv-video-musicawards-emoji-teases

Simonin, Bernard L., and Julie A. Ruth (1998), "Is a Company Known by the Company It Keeps? Assessing the Spillover Effects of Brand Alliances on Consumer Brand Attitudes," Journal of Marketing Research, 35 (1), 30-42.

Smith, Leah Warfield, and Randall L. Rose (2019), "Service with a smiley face: Emojional contagion in digitally mediated relationships," International Journal of Research in Marketing, 1-19.

Sprout Social (2019), "\#BrandsGetReal: What consumers want from brands in a divided society," Retrieved May 15, 2019, from: https://sproutsocial.com/insights/data/socialmedia-connection/\#introduction 
Steinmetz, Katy (2018), “A Major Dictionary Has Officially Added Emoji,” Retrieved November 15, 2018, from http://time.com/5186512/emoji-dictionary/

Thomson, Matthew, Deborah J. MacInnis, and C. Whan Park (2005), "The Ties That Bind: Measuring the Strength of Consumers' Emotional Attachments to Brands," Journal of Consumer Psychology, 15 (1), 77-91.

Unicode Consortium, Allen JD, et al. The Unicode Standard, Version 12.0. Mountain View, CA; 2019. Available from: https://www.unicode.org/emoji/.

Urumutta Hewage, Ganga, Yue Liu and Ze Wang (working paper). Facial Cues in Anthropomorphizing Products.

van Doorn, Jenny, Martin Mende, Stephanie M. Noble, John Hulland, Amy L. Ostrom, Dhruv Grewal, and J. Andrew Petersen (2017), "Domo arigato Mr. Roboto:

Emergence of automated social presence in organizational frontlines and customers' service experiences," Journal of Service Research, 20 (1), 43-58.

Volovich, Kristina (2020), "What's a Good Clickthrough Rate? New Benchmark Data for Google AdWords," HubSpot. Available from:

https://blog.hubspot.com/agency/google-adwords-benchmark-data

Wade, Jessica (2017), "How brands have used emoji marketing successfully," Smart Insights. Available from: https://www.smartinsights.com/social-mediamarketing/social-media-strategy/brands-used-emoji-marketing-successfully/.

Walther, Joseph B. (1992), "Interpersonal effects in computer-mediated interaction: A relational Perspective," Communication Research, 19 (1), 52-90.

Waytz, Adam, John Cacioppo, and Nicholas Epley (2010), "Who sees human? The stability and importance of individual differences in anthropomorphism." Perspectives on Psychological Science, 5 (3), 219-232.

Yu-Buck, Fang, Grace, Mishra, Arul and Mishra, Himanshu (working paper), "Smiling vs. A Smiley Face: The Effect of Emojis on Recall of Online Consumer Reviews." 
APPENDICES 
APPENDIX A: Emoji Marketing Campaigns

MTV 2018 Video Music Awards Twitter Teaser Promo

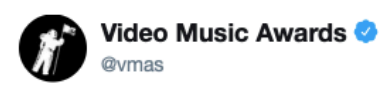

\#VMAs Best New Artist voting is still open! Here's a hint of who's in the lead:
1. $\stackrel{\square}{\underline{y}}$
2.
3.
4. บ\&

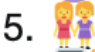
6. ${ }^{-1}$

Visit votebna.mtv.com or DM @MTV to keep voting - the top two will battle it out on Monday $8 / 20$ ! Presented by

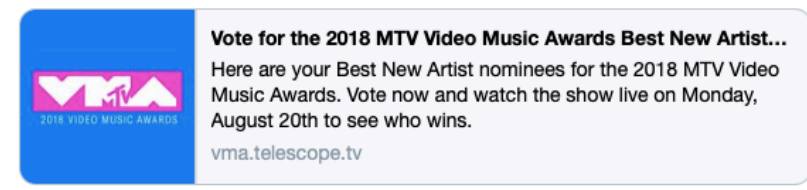

3:30 PM - 10 Aug 2018

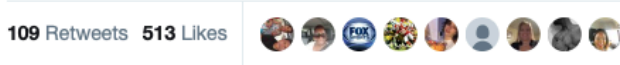

Q $63 \quad$ $\quad$ ¿ $109 \quad \bigcirc 513$

Domino's Pizza “Anyware Ordering” Campaign

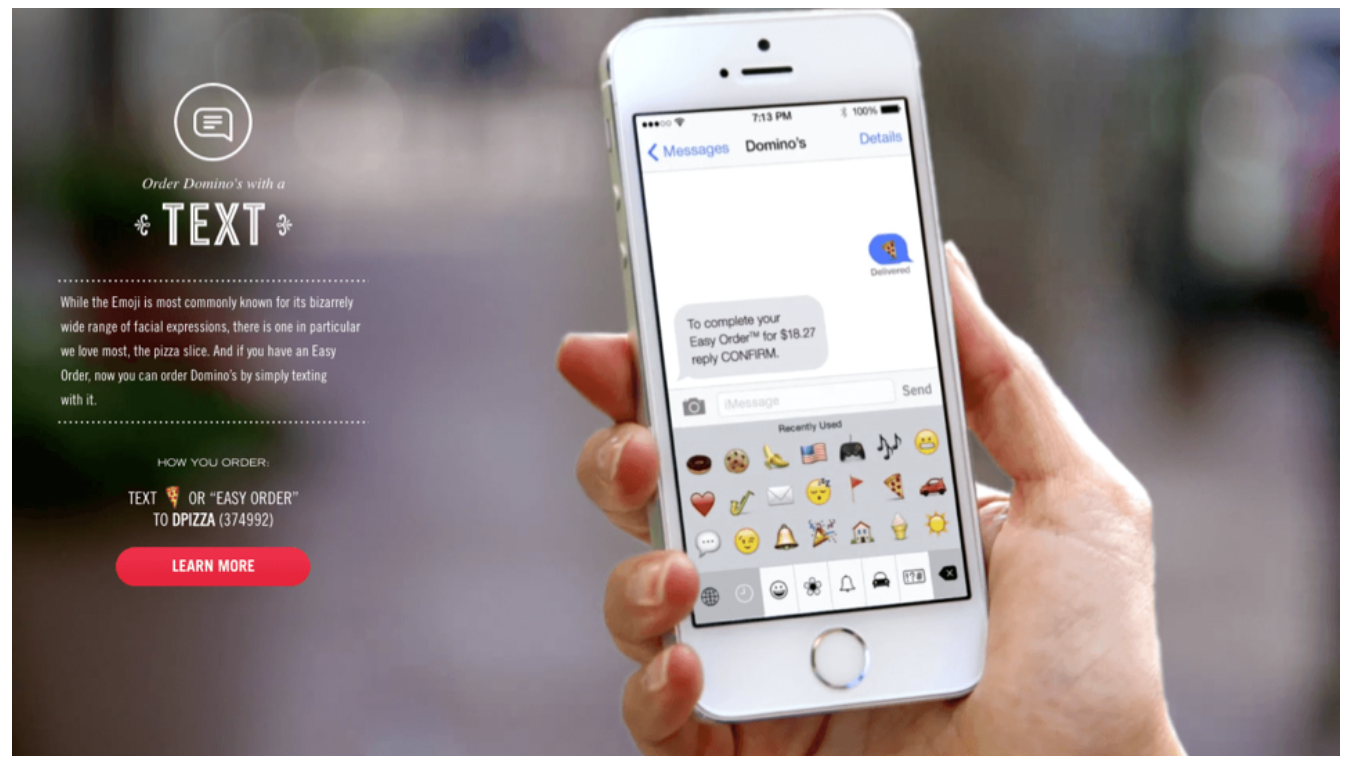




\section{APPENDIX B: Details, Study 1a}

\section{Measures and Scales:}

Attitude toward the product

7-pt bipolar scales

1. Bad-Good

2. Unfavorable - Favorable

3. Dislike - Like

4. Unpleasant - Pleasant

5. Distasteful - Tasteful

6. Negative - Positive

7. Low quality - Good Quality

Please select your gender: Male ( ) Female ( )

Age:

\section{Instructions:}

"Welcome to this Taste Test! Please leave this survey on your desk and come upfront to sample a cupcake."

"You may now proceed to sampling the cupcake and complete the questions below."

\section{Stimuli:}

Emoji Condition

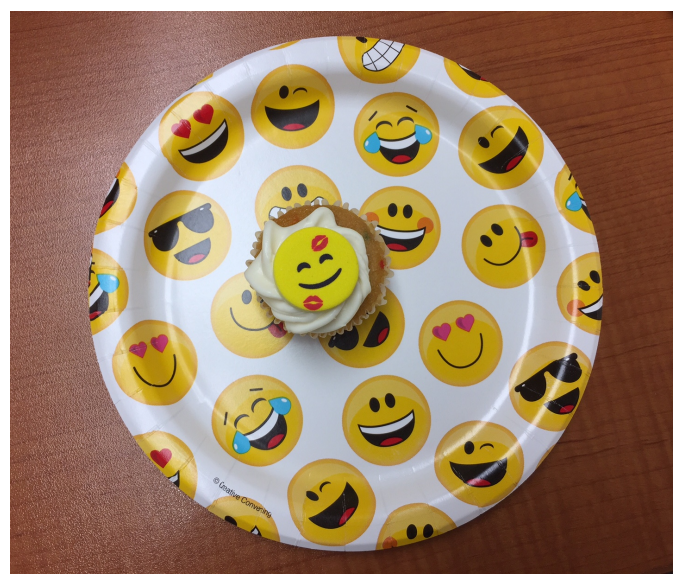

No Emoji Condition

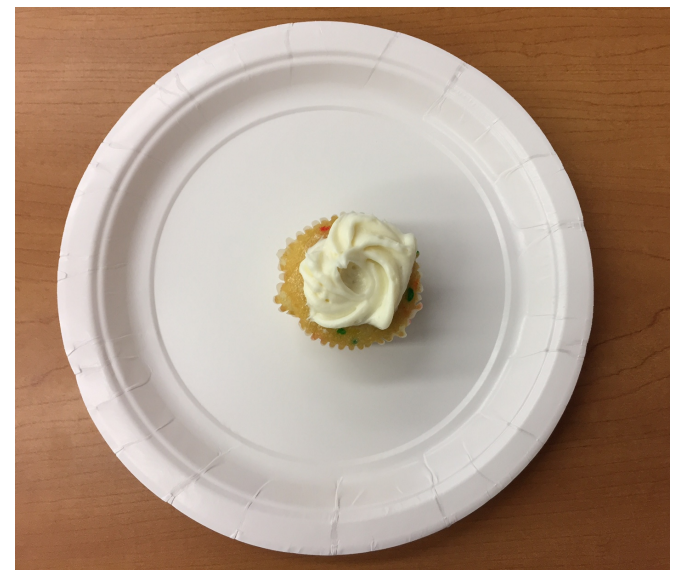




\section{APPENDIX C: Details, Study 1b}

Measures and Scales:

Purchase Intentions

7-pt Bipolar scale

1. Not at all likely - Very Likely

2. Highly improbable - Highly Probable

3. No chance at all - Very Good Chance

Brand Familiarity (Simonin and Ruth 1998)

Please indicate how familiar you are with the Starbucks brand:

1. Not familiar at all

2. Slightly unfamiliar

3. Somewhat familiar

4. Slightly familiar

5. Extremely familiar

Purchase Frequency

7-pt bipolar scale

How often do you buy Starbucks branded coffee / food products?

1. Not at all - Very often

Mood (Roehm and Roehm 2005)

7-point bipolar scale

At this moment I am feeling:

1. Bad-Good

2. Unpleasant - Pleasant

3. Negative - Positive

4. Sad - Happy

Cuteness (Nenkov and Scott 2014)

7-pt Likert scale, with anchors: 1 = Strongly Disagree, 7 = Strongly Agree

Based on the message you just saw, please indicate the extent to which you agree with the following statements about the social media post you just saw:

1. Cute

2. Adorable

3. Endearing

Mood (Roehm and Roehm 2005)

7-point bipolar scale

At this moment I am feeling:

1. Bad-Good

2. Unpleasant - Pleasant

3. Negative - Positive

4. Sad - Happy

Please select your gender: Male ( ) Female ( )

Age: 


\section{Instructions:}

"We are a marketing firm looking for your opinion to evaluate brands' social media posts. Today we are asking you to evaluate a preliminary post for the Starbucks brand, as they communicate a new promotion via social media."

\section{Stimuli:}

Emoji Condition

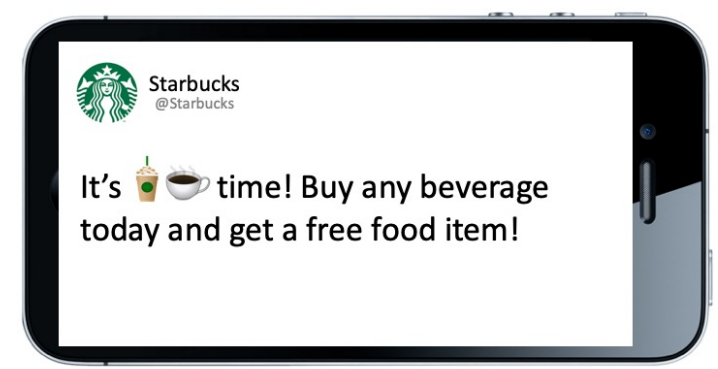

No Emoji Condition

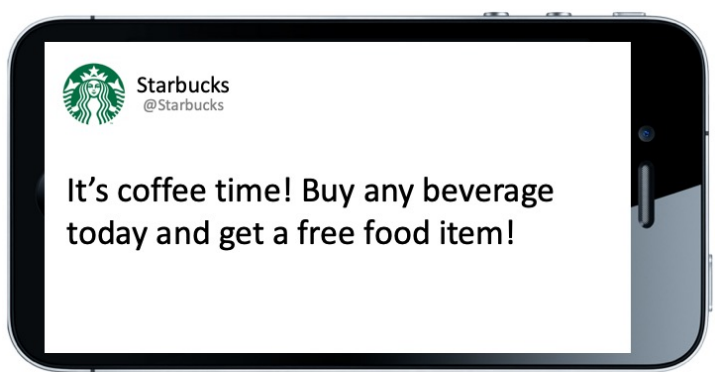




\section{APPENDIX D: Details, Study 1c}

Measures and Scales:

Click Through Rates

7-pt Bipolar scale

After reading this post, how likely would you be to click it to find out more information about

Nike's new collection:

1. Not at all likely - Very Likely

2. Not at all - Very Much So

Brand Familiarity (Simonin and Ruth 1998)

Please indicate how familiar you are with the Starbucks brand:

1. Not familiar at all

2. Slightly unfamiliar

3. Somewhat familiar

4. Slightly familiar

5. Extremely familiar

Purchase Frequency

7-pt bipolar scale

How often do you buy Nike branded products / apparel?

1. Not at all - Very often

Mood (Roehm and Roehm 2005)

7-point bipolar scale

At this moment I am feeling:

1. Bad-Good

2. Unpleasant - Pleasant

3. Negative - Positive

4. Sad - Happy

Please select your gender: Male ( ) Female ( )

Age:

\section{Instructions:}

"We are a marketing firm looking for your opinion to evaluate brands' social media posts. Today we are asking you to evaluate a preliminary post for the Nike brand, as it launches a new product collection through their online networks." 
Stimuli:

Emoji Condition

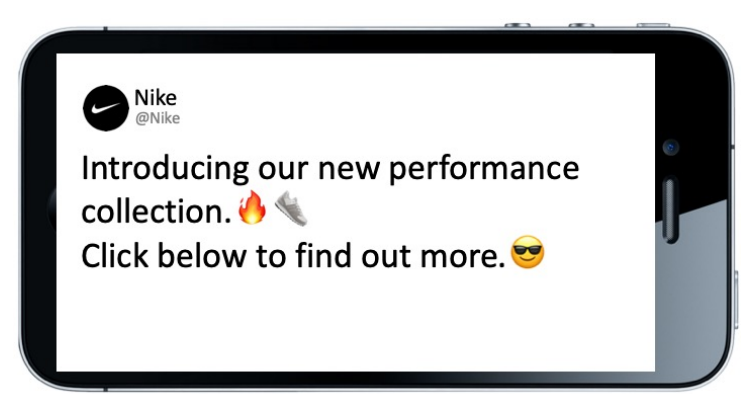

No Emoji Condition

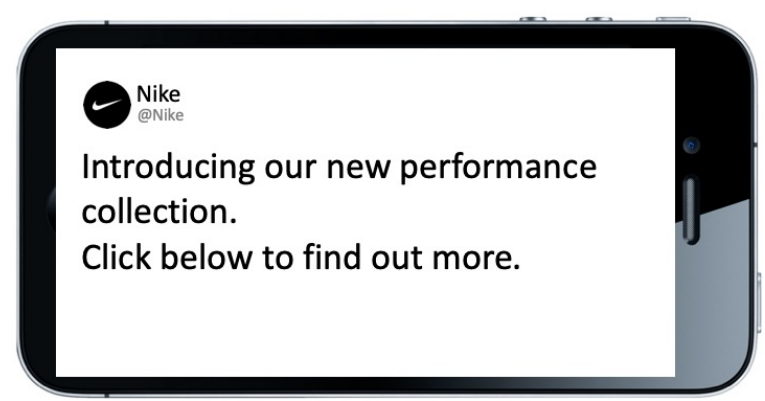


APPENDIX E: Details, Study 1d

\section{Measures and Scales:}

Attitude toward the product

7-pt bipolar scales

Please give us your opinion about the above CarePlus social media post:

1. Bad-Good

2. Unfavorable - Favorable

3. Don't like it at all - Like it very much

4. Not at all enjoyable - Very enjoyable

5. Very low quality - Very high quality

Product Quality Expectation

7-pt Likert scale, with anchors: 1 = Strongly Disagree, $7=$ Strongly Agree

To what extent do you agree that CarePlus dental kit will be a high-quality product?

Mood (Roehm and Roehm 2005)

7-point bipolar scale

At this moment I am feeling:

1. Bad-Good

2. Unpleasant - Pleasant

3. Negative - Positive

4. Sad - Happy

Please select your gender: Male ( ) Female ( )

Age:

\section{Instructions:}

Thank you for participating in this study!

As a token of our appreciation you will receive $\$ 1.00$ when you finish taking this survey.

"We are evaluating social media messages for a new brand of personal care and hygiene products CarePlus, which will be sold in our community. This brand is preparing a social media campaign that includes multiple posts like the one below to promote their newest product, a dental kit (toothbrush and toothpaste) ideal for on the go.

We would like you to evaluate one of the brand's social media posts to promote their new dental kit. Please read the following message the way you normally read social media posts and answer the questions that follow:" 


\section{Stimuli:}

Emoji Condition

Make your smile your best and freshest accessory instantly. (in) $\mathrm{W}$
No Emoji Condition

CarePlus

Make your smile your best and freshest accessory instantly.

OPTIONAL: We have samples of the new CarePlus dental kit. If you would like to purchase a CarePlus toothbrush and toothpaste set, please approach the research assistant at the table and purchase for $\underline{\mathbf{\$ 0 . 5 0} \text { each kit. }}$

How many would you like?

NOTE: If you do not want to make a purchase, tell the research assistant now. You will still get $\$ 1.00$ for the study. When you are ready, please approach the research assistant, and let them know whether you are finished with this survey or if you'd like to purchase one or more CarePlus dental kit(s). 
APPENDIX F: Dental Kit, Study 1d
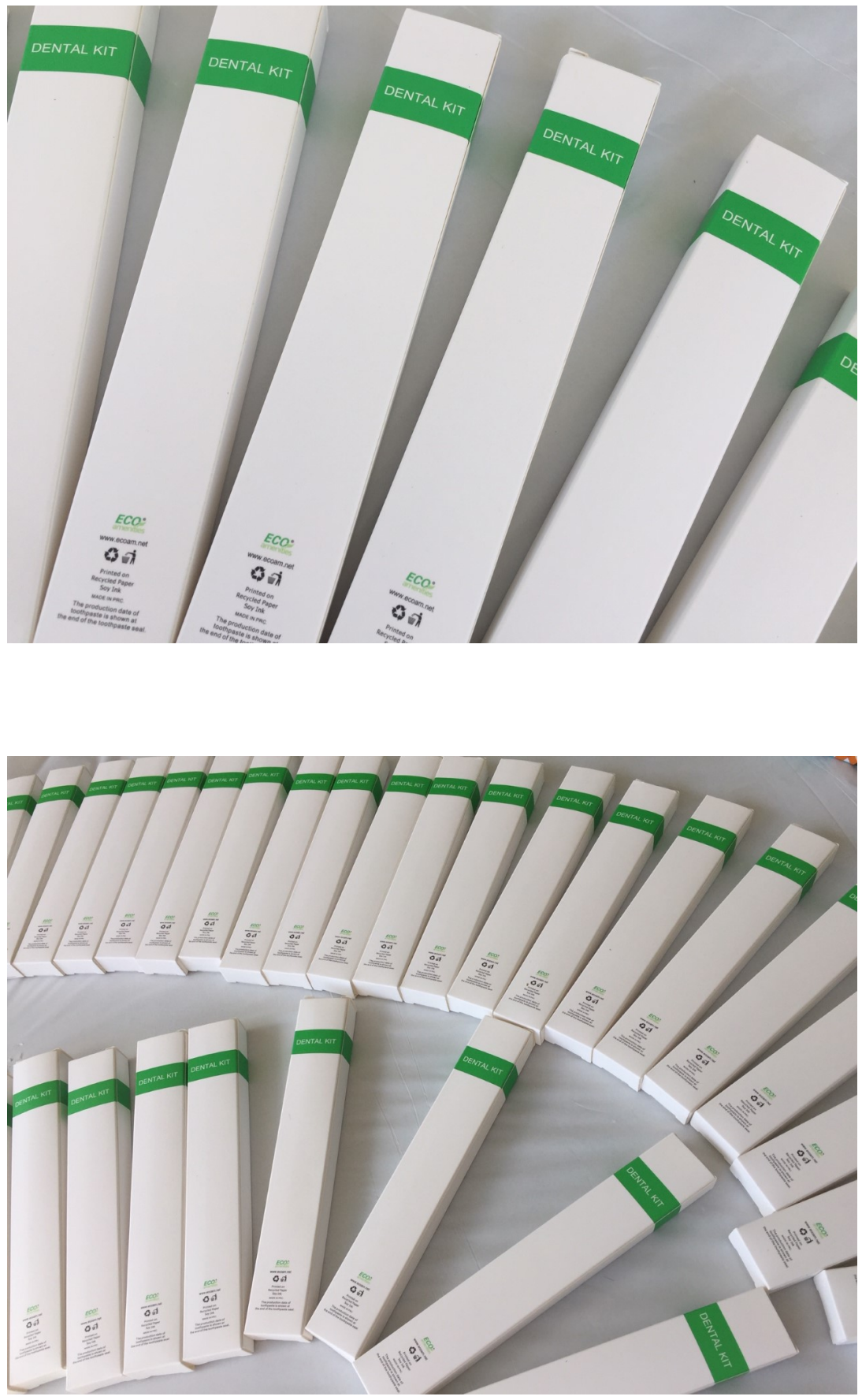
APPENDIX G: Details, Study 2a

\section{Measures and Scales:}

Self-Brand Connection (Adapted from Escalas and Bettman 2003)

7-pt Likert scale, with anchors: 1 = Strongly Disagree, 7 = Strongly Agree

3. I feel Adidas can help reflect who I am

4. This post helps me identify with the Adidas brand

5. This post helps me connect with the Adidas brand

6. This post helps me feel that I can create an emotional bond with Adidas

7. I feel I can use this brand to communicate who I am

8. This post helps me feel that I can use Adidas to communicate the type of person I want to be

Perceived Message Comprehension

7-pt bipolar scale

The message in the advertisement you just saw was:

1. Not easy to understand - Very easy to understand

2. Not clear - Very clear

Please select your gender: Male ( ) Female ( )

Age:

\section{Instructions:}

"We are looking for your opinion to evaluate brands' social media posts. Today we are asking you to evaluate a preliminary social media post for the Adidas brand, which is one of the sponsor brands for the FIFA World Cup 2018."

\section{Stimuli:}

Emoji Condition

ấldas Adidas 0

Compete for something bigger.

Be part of the solution.

\#WorldCup2018 \&
No Emoji Condition acldads @adidas

Compete for something bigger.

Be part of the solution.

\#WorldCup2018 


\section{APPENDIX H: Details, Study 2b}

\section{Measures and Scales:}

Self-Brand Connection (Adapted from Escalas and Bettman 2003)

7-pt Likert scale, with anchors: 1 = Strongly Disagree, 7 = Strongly Agree

1. I feel Starbucks can help reflect who I am

2. This post helps me identify with the Starbucks brand

3. This post helps me connect with the Starbucks brand

4. This post helps me feel that I can create an emotional bond with Starbucks

5. I feel I can use this brand to communicate who I am

6. This post helps me feel that I can use Starbucks to communicate the type of person I want to be

Brand Anthropomorphism (Epley et al. 2007; Aggarwal and McGill, 2012)

7-pt Likert scale, with anchors: 1 = Strongly Disagree, 7 = Strongly Agree

1. This post makes me feel Starbucks is has positive intentions

2. This post makes me feel Starbucks is human like

3. This post makes me feel Starbucks is like a person

Perceived Message Comprehension

7-pt bipolar scale

The message in the advertisement you just saw was:

1. Not easy to understand - Very easy to understand

2. Not clear - Very clear

Brand Familiarity (Simonin and Ruth 1998)

Please indicate how familiar you are with the Starbucks brand:

1. Not familiar at all

2. Slightly unfamiliar

3. Somewhat familiar

4. Slightly familiar

5. Extremely familiar

Purchase Frequency

7-pt bipolar scale

How often do you buy Starbucks branded coffee / food products?

1. Not at all - Very often

Mood (Roehm and Roehm 2005)

7-point bipolar scale

At this moment I am feeling:

1. Bad-Good

2. Unpleasant - Pleasant

3. Negative-Positive

4. Sad - Happy 
Time spent in Social Media (Ellison et al., 2007)

How much time per day do you spend on your Social Media networks?

1. Less than 10 minutes

2. 10-30 minutes

3. 31-60 minutes

4. 1-3 hours

5. More than 3 hours

Please select your gender: Male ( ) Female ( )

Age:

\section{Instructions:}

"We are looking for your opinion to evaluate brands' social media posts. Today we are asking you to evaluate a preliminary post for the Starbucks brand, as they communicate a new promotion via social media."

\section{Stimuli:}

\section{Emoji Condition}

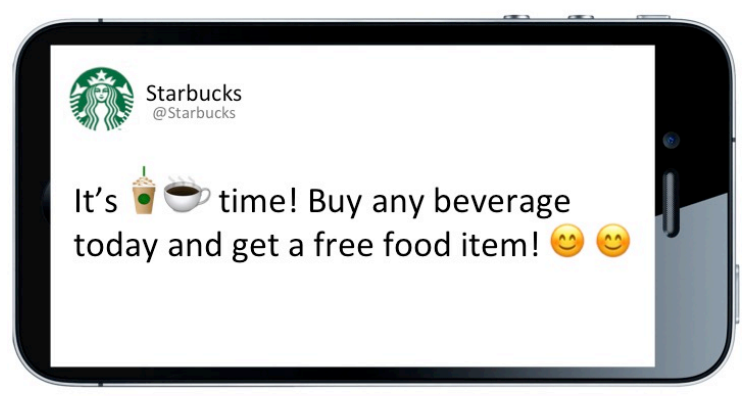

No Emoji Condition

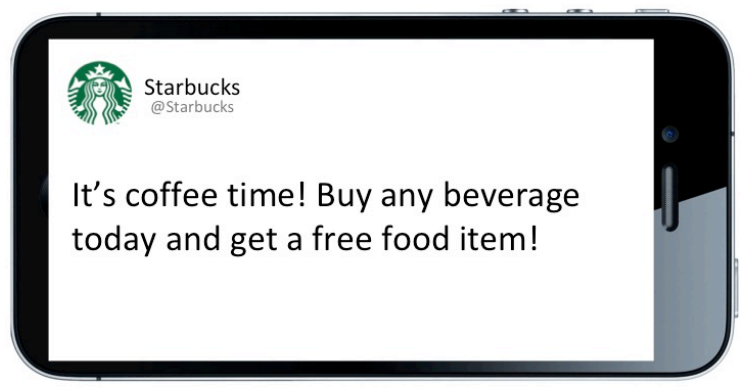


APPENDIX I: Allie Sunscreen Lotion, Study 2c

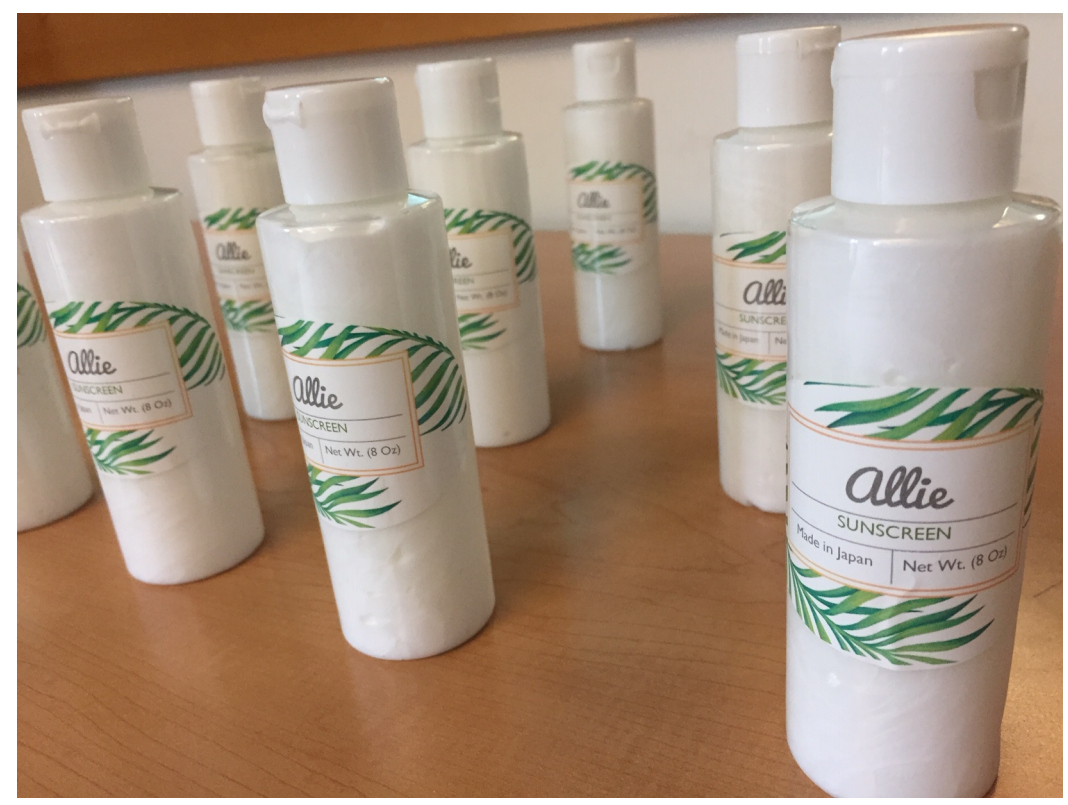

Image indicates lotion presentation in behavioral lab 


\section{APPENDIX J: Details, Study 2c}

\section{Measures and Scales:}

Self-Brand Connection (Adapted from Escalas and Bettman 2003)

7-pt Likert scale, with anchors: 1 = Strongly Disagree, 7 = Strongly Agree

1. I feel Allie can help reflect who I am

2. This post helps me identify with the Allie brand

3. This post helps me connect with the Allie brand

4. This post helps me feel that I can create an emotional bond with Allie

5. I feel I can use this brand to communicate who I am

6. This post helps me feel that I can use Allie to communicate the type of person I want to be

Brand Anthropomorphism (Epley et al. 2007; Aggarwal and McGill, 2012)

7-pt Likert scale, with anchors: 1 = Strongly Disagree, 7 = Strongly Agree

1. This post makes me feel Allie is has positive intentions

2. This post makes me feel Allie is human like

3. This post makes me feel Allie is like a person

Emotional Attachment (Thomson, MacInnis and Whan Park 2005)

7-pt Likert scale, with anchors: 1 = Strongly Disagree, 7 = Strongly Agree

Please indicate the extent to which you agree that the following words describe your feelings toward the Allie brand:

1. Affectionate

2. Friendly

3. Lovable

4. Peaceful

5. Passionate

6. Delighted

7. Captivated

8. Connected

9. Bonded

10. Attached

Purchase Intentions

7-pt bipolar scale

How likely would you be to purchase the Allie sunscreen lotion?

Not at all likely - Very Likely

Willingness to Pay

7-pt bipolar scale

Sunscreen lotions in the US typically range from a minimal price point of $\$ 10$ to the most expensive ones at $\$ 30$. What is the most you would pay for a full size (8 oz) ALLIE sunscreen lotion? \$

Word of Mouth (Carroll and Ahuvia 2006)

7-pt Likert scale, with anchors: 1 = Strongly Disagree, 7 = Strongly Agree

Please indicate the extent to which you agree with the following statements:

1. I would recommend the Allie sunscreen lotion to my friends and family. 
2. If someone was looking for a new sunscreen lotion, I would recommend they try Allie.

3. I would recommend the Allie brand to lots of people.

4. I would "talk up" the Allie brand to my friends

5. I would try to spread the good word about this brand

6 . I would give this brand tons of positive word-of-mouth advertising.

Cuteness (Nenkov and Scott 2014)

7-pt Likert scale, with anchors: 1 = Strongly Disagree, 7 = Strongly Agree

Please indicate the extent to which you agree that the following words describe the Allie brand:

1. Cute

2. Adorable

3. Endearing

Mood (Roehm and Roehm 2005)

7-point bipolar scale

At this moment I am feeling:

1. Bad-Good

2. Unpleasant - Pleasant

3. Negative - Positive

4. Sad - Happy

Time spent in Social Media (Ellison et al., 2007)

How much time per day do you spend on your Social Media networks?

1. Less than 10 minutes

2. 10-30 minutes

3. $31-60$ minutes

4. 1-3 hours

5. More than 3 hours

In general, about how many days do you use sunscreen lotion in a typical month?

In general, how often do you buy skin care products?

7-point bipolar scale

Not at all - Very often

Please select your gender: Male ( ) Female ( )

Age:

\section{Instructions:}

"Today, we are evaluating the Allie Sunscreen brand. Allie is a Japanese brand that specializes in skin care that protects from outdoor sun exposure. They are a preferred brand for their use of kind ingredients and zero chemicals. They also pride themselves in supporting initiatives that help people spend more time with nature. Now, they are expanding their brand globally and are preparing a social media campaign that includes multiple posts like the one below. We would like you to evaluate some of the brand's messages used in their social media as they promote their brand and products globally. Please read the following message the way you normally view social media messages and answer the questions that follow." 
Stimuli:

Emoji Condition

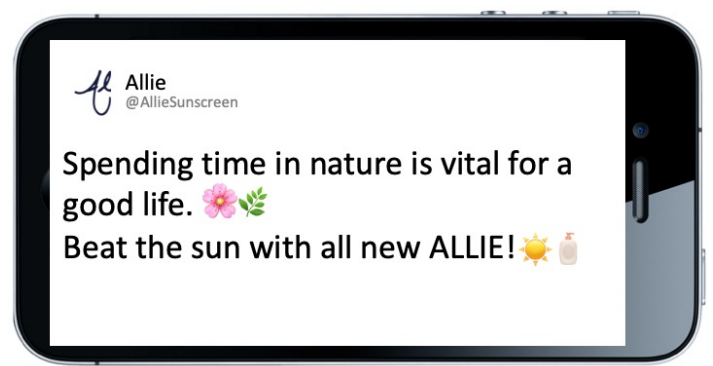

No Emoji Condition

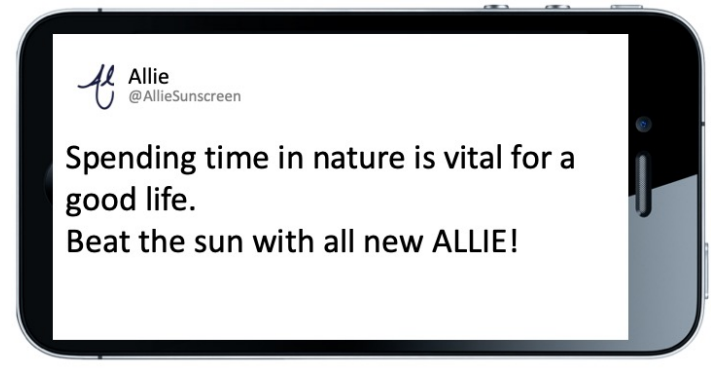




\section{APPENDIX K: Details, Study 3}

Measures:

Brand Role (Adapted from Aggarwal and McGill 2012; Kim and Kramer 2015)

7-pt Likert scale, with anchors: 1 = Strongly Disagree, 7 = Strongly Agree

Please indicate the extent to which you agree with the following statements:

1. SmartWrist is like a partner to the consumer

2. SmartWrist co-creates value with the consumer

3. SmartWrist $\mathrm{s}$ like a colleague

4. SmartWrist is like a servant to the consumer

5. SmartWrist works for the consumer

6. SmartWrist is like an assistant

Willingness to Pay

Slider Bar (\$0 - \$500)

Word of Mouth (Carroll and Ahuvia 2006)

7-pt Likert scale, with anchors: 1 = Strongly Disagree, 7 = Strongly Agree

Please indicate the extent to which you agree with the following statements:

1. I would recommend Brand $X$ to my friends and family.

2. I would recommend Brand $X$ to lots of people.

3. I would "talk up" Brand $X$ brand to my friends

4. I would try to spread the good word about this brand

5. I would give this brand tons of positive word-of-mouth advertising.

Mood (Roehm and Roehm 2005)

7-point bipolar scale

At this moment I am feeling:

1. Bad-Good

2. Unpleasant - Pleasant

3. Negative - Positive

4. Sad - Happy

Time spent in Social Media (Ellison et al., 2007)

How much time per day do you spend on your Social Media networks?

1. Less than 10 minutes

2. 10-30 minutes

3. 31-60 minutes

4. 1-3 hours

5. More than 3 hours

Please select your gender: Male ( ) Female ( )

Age:

Attention Check (Lu and Sinha 2017)

Should we exclude your data from this study for any reason? For instance, were you distracted, or did you circle answers randomly?

Yes ( ) No ( ) 


\section{Instructions:}

Brand as Partner condition:

\section{SmartWrist Series 1: \\ your new partner}

SmartWrist is a new brand of wearable technology equipped with top of the line technology that co-creates value with the consumer, just like a friend.

SmartWrist partners with the consumer to accomplish their individuals goals. A partner brand is one that creates value with the consumer (i.e. like a colleague, coworker or friend). This means that the "partner brand" is a co-producer of benefits with the consumer, and therefore, works together with the consumer.

As part of this "partner brand" positioning strategy, the SmartWrist marketing team has prepared a social media campaign that includes multiple posts like the one below.

Today, we would like you to evaluate the following social media brand message to be used to promote SmartWrist.

Brand as Servant condition:

\section{SmartWrist Series 1: \\ your new assistant}

SmartWrist is a new brand of wearable technology equipped with top of the line technology that creates value for the consumer, just like an assistant.

SmartWrist works for the consumer to accomplish their individuals goals. A servant brand is one that creates value for the consumer (i.e. like an assistant or outsourced provider). This means that the "servant brand" is an outsourced provider of benefits for the consumer, and therefore, works for the consumer.

As part of this "servant brand" positioning strategy, the SmartWrist marketing team has prepared a social media campaign that includes multiple posts like the one below.

Today, we would like you to evaluate the following social media brand message to be used to promote SmartWrist 


\section{Stimuli:}

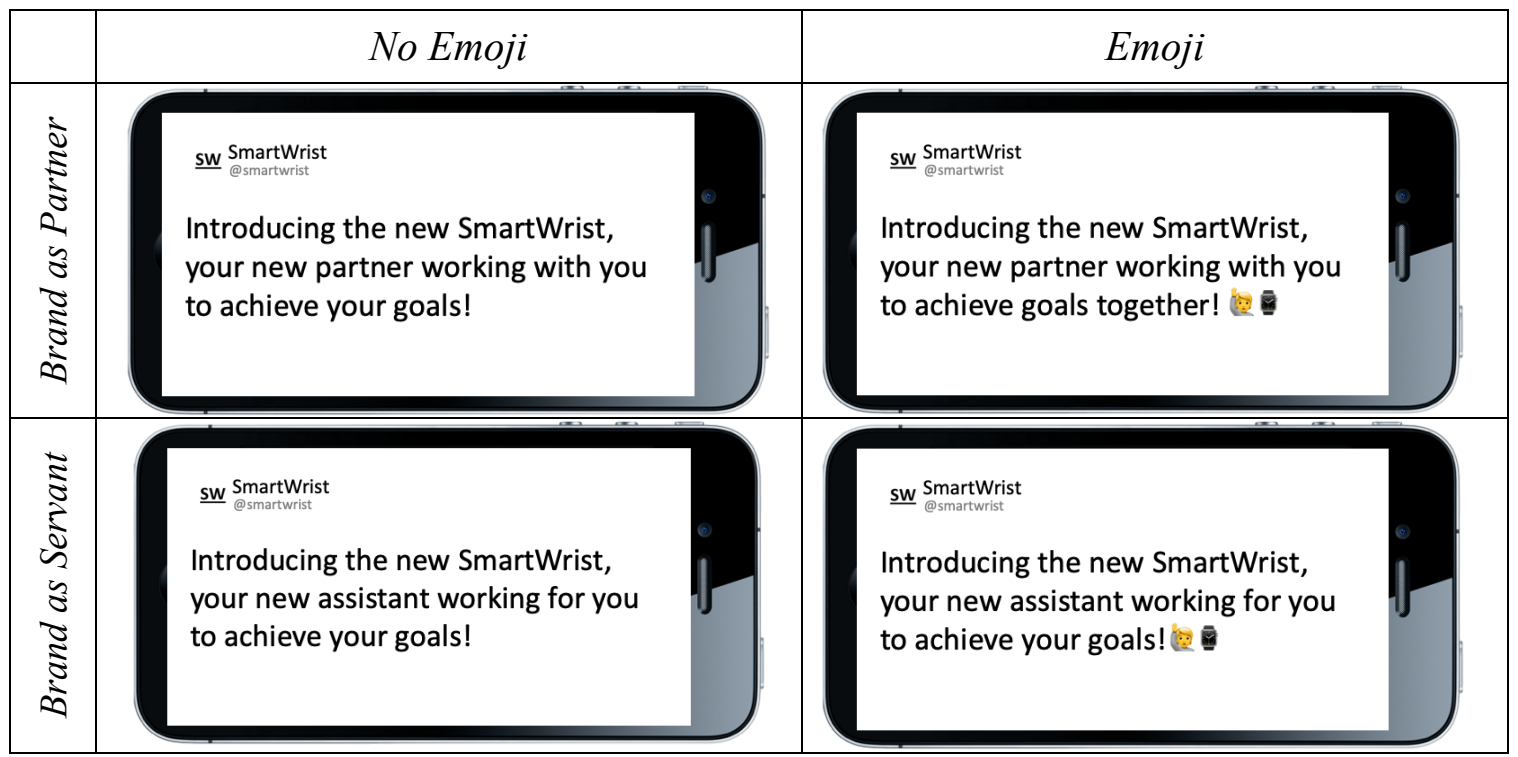




\section{VITA}


VITA

TESSA GARCIA-COLLART

2020

Ph.D., Marketing

Florida International University

2007

MBA, Global Business Administration

Thunderbird School of Global Management

2004

B.A. Marketing and International Business Administration Universidad Tecnológica Centroamericana

2020

UGS Provost Award for Outstanding Paper or Manuscript

2019

The Harold and Muriel Berkman Foundation Research Scholarship

2019

International Consumer-Brand Relationships Scholarship

2018

Marketing Science Institute Research Grant

2018

AMA-Sheth Doctoral Consortium Fellow

2018

Society of Consumer Psychology Ethnic Minority Scholarship

2017

The Russell V. Ewald Award for Academic Excellence

2017

American Marketing Association Valuing Diversity Scholarship

2016

The Melvin and Patricia Stith Transition Grant

\section{PUBLICATIONS AND CONFERENCE PRESENTATIONS}

Garcia-Collart, Tessa, Nuket Serin, and Jayati Sinha (2019), "Healthy (In)Congruence: When Hispanic Identity and Self-Framed Messages Increase Healthier Choices," Journal of Advertising.

Garcia-Collart, Tessa and Jessica Rixom (Forthcoming), "Self-Effacing versus SelfEnhancing Brand Appeals: The Influence of Impression Management Styles on Consumption Behavior," Marketing Science Working Paper Series.

- Research Project funded partially by the Marketing Science Institute

Garcia-Collart, Tessa, Nuket Serin*, and Jayati Sinha, "Healthy (In)Congruence: When Hispanic Identity and Self-Framed Messages Increase Healthier Choices" 
- Winter American Marketing Association Conference (Forthcoming, February 2020, San Diego, CA)

Garcia-Collart, Tessa* and Jessica Rixom, "The Power of Self-Effacing Advertising Messages: Building Trust and Increasing Attitudes Toward the Brand"

- Association for Consumer Research Conference (October 2019, Atlanta, GA)

Garcia-Collart, Tessa, Nuket Serin*, and Jayati Sinha, "The Role of Culture and Message Framing: Hispanic Consumers' Response to Healthy Eating Appeals"

- Association for Consumer Research Conference (October 2019, Atlanta, GA)

Garcia-Collart, Tessa* and Jayati Sinha, "Emoji Marketing: Strengthening the ConsumerBrand Relationship and its Downstream Effects"

- Olin Business School, Washington University St. Louis (June 2019, St. Louis, MO)

Garcia-Collart, Tessa* and Jayati Sinha, "Emoji Marketing: Strengthening the ConsumerBrand Relationship and its Downstream Effects"

- International Consumer-Brand Relationships Conference (May 2019, Cancun, Mexico)

Garcia-Collart, Tessa*, Nuket Serin, and Jayati Sinha, "The Role of Culture and Message Framing: Hispanic Consumers' Response to Healthy Eating Appeals"

- International Consumer-Brand Relationships Conference (May 2019, Cancun, Mexico)

Garcia-Collart, Tessa* and Jayati Sinha, "Emoji Marketing: Strengthening the ConsumerBrand Relationship and its Downstream Effects"

- FIU Business Doctoral Students Association Symposium (April 2019, Miami, FL)

Garcia-Collart, Tessa* and Jayati Sinha, "Emoji Marketing: Strengthening the ConsumerBrand Relationship and its Downstream Effects"

- American Marketing Association Conference (February 2019, Austin, TX)

Garcia-Collart, Tessa* and Jessica Rixom, "The Power of Self-Effacing Advertising Messages: Building Trust and Increasing Attitudes Toward the Brand"

-Working Paper, Association for Consumer Research (October 2018, Dallas, TX)

Garcia-Collart, Tessa*, Nuket Serin, and Jayati Sinha, "The Role of Culture and Message Framing: Hispanic Consumers' Response to Healthy Eating Appeals"

- Future Faculty Program, University of Tennessee (September 2017, Knoxville, TN)

Garcia-Collart, Tessa*, Nuket Serin, and Jayati Sinha, "The Role of Culture and Message Framing: Hispanic Consumers' Response to Healthy Eating Appeals"

- Working Paper, American Marketing Association (February 2017, Orlando, FL) 